\title{
LITERATURNACHWEIS
}

1 Dufour-Verses, L.: Origine et développement des Hauts-Geneveys et Genereys-sur-Coffrane. Genève 1884. - 2 Junod, D.: Boudevilliers, Musée neuchâtelois 1896 S. 221, 1897 S. 29 uff. 3 LcEw, F.: Les Verrières. La vie rurale d'une communauté du Haut-Jura au Moyen age. Neuchâtel 1954. - 4 Perris, L.: La commune de Savagnier. Musée neuchâtelois 1900/1901, S.312. 5 Quartier-La-Tente, Ed.: Le Canton de Neuchâtel, IVme série: Le district du Val-de-Ruz. Neuchâtel 1916. - 6 Geographisches Lexikon der Schweiz, Neuenburg 1906.

\section{VAL DE RUZ}

Le Val de Ruz est un large synclinal en forme de fuseau du Jura neuchâtelois. A part les quelques habitations isolées des époques préhistorique et romaine, la colonisation commença au VIIe siècle au milieu de la vallée puis s'étendit sur les versants. Au XIIIe siècle, des colons genevois défrichèrent la forêt sur le versant nord. Plus tard, les côtes et les croupes de la montagne furent occupées par les pâturages d'été et par des exploitations agricoles montagnardes et les proprićtés s'étendirent au-delà de la limite de partage des eaux dans les bassins de la Vallée des Ponts et du Vallon de Saint-Imier. L'industrialisation du XIXe siècle s'établit là, où le chemin de fer et le tram créèrent de bonnes communications, c'est-à-dire dans les villages du versant nord.

\section{DAS LÄNGSPROFIL DER ALPENTÄLER Ed. Gerber}

Mit 42 Figuren und 1 Tafel

\section{VORWORT}

Die vorliegende Arbeit ist der erste Teil einer Reihe von Untersuchungen, die den Alpentälern gewidmet sind. Es werden hier die Formen von Längsprofilen untersucht, von zwar abstrakten Linien, die aber auf sehr prägnante Art wichtige Aussagen über ein Tal erlauben. In einem zweiten Teil sollen die Formen der Talböden studiert werden, eine Bețrachtungsart, die besonders die Umrisse von Flächen ins Auge faßt. Der dritte Teil wird dem Gehänge gewidmet sein, mit dem erst sich das Tal zum Raum schließt. In allen drei Teilen wird vom Einzelfall her das Grundsätzliche, auch der Betrachtungsart, erörtert.

Das Hauptgewicht liegt bei diesem ersten Teil auf der kritischen Sichtung bisheriger Ansichten und Ergebnisse, der Systematik der Steilenformen und den Vorgängen der Steilenbildung und des Steilenausgleichs.

Es ist mir heute, da endlich die neben der Berufsarbeit nur langsam gewachsene Arbeit veröffentlicht werden kann, ein Anliegen, all den Vielen zu danken, die mir Anregungen gaben und mich förderten. So wußte ich es sehr zu schätzen, daß Dank der Großzügigkeit und dem steten Interesse von Herrn Prof. Dr. H. Gutersohn mir das Geographische Institut der ETH, aus dem ich hervorgegangen bin, mit seiner Bibliothek jederzeit offen stand.

Mein ganz besonderer Dank gilt Herrn Bauingenieur G. Gysel und Herrn Prof. Dr. E. WinkLER, die mir durch ihre stete Bereitschaft, durch Diskussion, Kritik und Aufmunterung einen unschätzbaren Freundesdienst erwiesen. 4 Clichés verdanke ich Herrn Dr. W. EgGenberger und der Red. der ECLOGAE GEOL. HELV., die Reinzeichnungen Herrn R. Zimmermann.

\section{DER STUFENBAU DER ALPENTÄLER}

Gehen wir von der möglichst unbefangenen Betrachtung alpiner Täler aus und betreten wir eines der großen Täler vom Vorland her, so sehen wir den Fluß vorerst in seinen eigenen Aufschüttungen inmitten eines breiten Talbodens.

Dieser bildet eine Ebene, bei nicht wenigen oberhalb eines Sees, der Rheinebene oberhalb des Bodensees, der Plaine du Rhône oberhalb des Genfersees, der Piano di Magadino oberhalb des Langensees. Gehen wir weiter talaufwärts, so wird der Talboden schmäler, so daß mit einigem Vorbehalt von einem Trichter gesprochen werden kann. Plötzlich, ganz unvermittelt, verengt sich der Talboden. Der Fluß strömt rascher, das Gefälle nimmt zu. Wir sind an einer Steile oder Stufe angelangt. In einer engen Talstrecke, wo die Straße in Kehren am Hang hinzieht, geht es rasch in die Höhe. 
Mit einemmal weitet sich das Tal, der Fluß, noch eben in schwer zugänglichem Bett, fließt ruhig. Der Talboden ist breit aufgeschüttet. Doch bald verengert er sich erneut, das Wasser fließt lebhafter. Diesmal ist es aber vielleicht nur eine kurze Engstelle und schon stehen wir ein zweites Mal auf höhere Stufe. Und dieser Wechsel von Engstrecke mit erhöhtem Gefälle und Erweiterung mit flachem Talboden wiederholt sich nun ein drittes und viertes Mal. Vielleicht folgt nach mehrmaliger Stufung ein sehr langes Talstück mit ruhig fließendem Gewässer, wie im Oberengadin oder im Goms im Rhonetal. Und nun endet das Tal, vielleicht schon so hoch, daß ein Gletscher in ihm liegt. In diesem Talschluß nimmt das Gefälle der kleinen Zufüsse oder Gletscherarme, die sich zum Hauptfluß vereinigen, noch mehrmals sehr stark zu.

Durch den Wechsel von Engen und Weiten erscheint ein Alpental mehrfach gekammert, durch die Gefällsbrüche getreppt. Steigen wir andererseits im Gehänge aufwärts, so folgen auch dort über einem Steilanstieg eine Verflachung, dann wieder ein Steilanstieg und wieder eine Verflachung in mehrmaligem Wechsel. So tritt zur Stufung des Flußlaufes der Stufenbau des Gehänges, und beides sind eindrucksvolle Merkmale der Alpenlandschaft.

Dieser Eindruck wird treffend durch den Begriff des stockwerkartigen Aufbaues der Alpen wiedergegeben. Für den Morphologen stellt sich nun die Frage: Kann die 'Talbodenstufung mit der Gehängestufung genetisch verknüpft werden? Um diese Frage zu beantworten, müssen wir vorerst die typischen Formen eines Längsprofiles erfassen und diese deuten können.

Lenken wir unsere Gedanken wieder zurück auf den unausgeglichenen Talbodenverlauf, richten wir unsern Blick vorerst vor allem auf das unregelmäßige Längsprofil des Flusses. Was uns daran besonders auffällt, haben wir soeben gesagt. Wir sprechen von unregelmäßig, unausgeglichen und nicht normal. Woher nehmen wir die Maßstäbe zu diesem Urteil ? Sicher nicht aus den Alpen. Denn wer den Bau und die Entstehungsgeschichte der Alpen kennt, der wird nicht einfach-ausgeglichene Gefällskurven erwarten. Dem komplexen Bau, dem ungleichen Material, dem Wechsel verschiedenster Gesteine und im verschiedensten Erhaltungszustand, frisch oder tektonisch zerrüttet, der Jugendlichkeit des Gebirges mit seinen Steilhängen, aus denen immer wieder Schwemm-, Gleit- und Sturzmaterial stammt, muß eine ebenso wechselvolle Gefällslinie entsprechen. Das Unregelmäßige, Unausgeglichene entspricht dem Charakter des Gebirges.

Die Vorstellung eines Normallängsprofiles im Sinne einer einfachen, glatten und ausgeglichenen Kurve entstand also sicher nicht aus der Formbetrachtung der Alpentäler, sondern ist vielmehr eine abstrakte Gedankenkonstruktion, die auf Idealvoraussetzungen beruht, die in der Natur kaum, am wenigsten in den Alpen verwirklicht sind. Trotzdem bleibt der Wert solcher Idealvorstellungen unbestritten. Am schönsten zeigt sich dies wohl bei den Idealkristallformen, die in der Natur ja auch nie restlos verwirklicht sind, aber doch immer angestrebt werden. Idealvorstellungen geben uns Normen, nach denen wir die Naturformen beurteilen und einordnen. Das Normallängsprofil entspringt der Idee, daß in der Gestaltung des Profiles durch das Gewässer ein bestimmter Zustand angestrebt werde. Unausgeglichene Täler, wie die der Alpen, müssen sich nach dieser. Vorstellung in eindeutiger Entwicklung auf diesen Zustand befinden, auch wenn diese Entwicklung immer wieder gestört und unterbrochen oder durch besondere Umstände verhindert wird. Es wird eine der Aufgaben dieser Arbeit sein, die Brauchbarkeit der Vorstellung eines gut definierten Normalprofiles zu zeigen und auf die physikalische Begründung dieser Vorstellung hinzuweisen.

\section{Endogene und exogene Vorgänge}

Die Entwicklung zum Normalprofil setzt allerdings voraus, daß die Vorgänge, die dazu führen, nicht gestört werden. 
Offensichtlich sind bei der Formentwicklung entgegengesetzt wirkende Kräfte am Werk. Der Versuch, aus den Formen den Einfluß der beiden Kräftegruppen gegeneinander abzugrenzen, scheint zuerst recht einfach durchführbar. Ordnen wir die unerschöpfliche Formenfülle, die uns die Erdoberfläche darbietet, in ganz großen Zügen, so scheint eine erste Gruppierung in horizontale Flächen und geneigte Flächen sinnvoll. Die horizontalen Flächen oder physikalisch ausgedrückt, die Niveauflächen des Erdschwerefeldes, sind Flächen der Ruhelage, weder Wasser noch loses Oberflächenmaterial kommt darauf durch die Schwerkraft in Bewegung. Alle andern Flächen sind Flächen mit Höhenunterschieden, mit Potentialgefälle. Wasser und loses Material wird auf ihnen durch Schwerkraft bewegt, und der Materialtransport findet solange statt, bis sie auch zu Niveauflächen geworden sind.

Wir nennen nun alle Vorgänge, die auf der Erdoberfläche neue Höhenunterschiede schaffen, die Niveauflächen aufbiegen, schiefstellen und zerstückeln, oder schon vorhandene schiefe Flächen neu verbiegen und verändern, endogene Vorgänge, jene, die sie wieder ausgleichen und geneigte Flächen in Niveauflächen überführen, exogene Vorgänge.

Die endogenen Kräfte sind die primären. Sie schaffen die Bedingungen dafür, daß exogene Vorgänge sich abspielen können. Die exogenen Vorgänge sind die sekundären.

Das Studium der Veränderung der Erdkruste, die durch endogene Kräfte hervorgerufen worden sind, ist vor allem die Aufgabe der Geologie; R. STAub 62 hat denn auch in der Einleitung zu seinen «Grundzügen der alpinen Morphologie» in prägnanten Sätzen auf diesen Sachverhalt hingewiesen: « Daß Krustenbewegungen bei der morphologischen Entwicklung eines Gebirges eine bedeutsame und ausschlaggebende Rolle spielen, ist seit langem bekannt. Ohne Krustenbewegungen keine Niveaudifferenzen, ohne Niveaudifferenzen kein Abtrag, ohne sukzessives Aufsteigen des Gebirges keine fortgesetzte Durchtalung desselben, ohne starkes Emporsteigen desselben innert kurzer Zeit keine kräftige Erosion, die allein zu Gebirgscharakter führt. Ohne ruckweises Aufsteigen des Gebirges keine Terrassen der Täler, keine Schärfung und Verjüngung der Bodenformen. Wie die Differenzierung der Sedimentationsräume und die Gliederung der Faciesfolgen, so ist auch die Ausgestaltung der morphologischen Geschichte eines Gebirges in erster Linic cin Werk der Bewegungen in der festen Kruste des Planeten. Ohne diese Bewegungen in der Erdrinde gibt es keine Gliederung der Fazies der Sedimente, keine Gebirgsbildung, keine Metamorphose, keinen Vulkanismus, und es scheint somit nur selbstverständlich, $d a ß$ es ohne Krustenbewegungen auch keine morphologische Differenzierung geben kann.»

Wenn auch die endogenen Vorgänge in jedem Fall die primären sein müssen und die exogenen erst die Folgeerscheinung sind, so ist doch die Trennung nicht einfach.

Denn schon der erste Augenschein, wie wir ihn weiter oben schilderten, zeigt, daß mehr oder weniger horizontale Flächen durch steilere getrennt in vcrschicdencn Höhenlagen stockwerkartig übereinander vorkommen. Wir folgern daraus, daß endogene Vorgänge mehrmals, auch in der neuesten Erdgeschichte, die Erdoberfläche veränderten, wir müssen auch annehmen, $\mathrm{da} \beta$ endogene und exogene Vorgänge glcichzeitig stattfanden, daß endlich durch exogene Vorgänge zwar neues Gefälle nicht geschaffen, wohl aber verlagert werden kann und anders verteilt wird. Und so schen wir uns plötzlich einem Wirrwarr, ciner gegenscitigen Verzahnung von zwei Kräftegruppen gegenüber. Damit führt die begrifflich so klare Scheidung in exogene und endogene Vorgänge mitten in die Problematik der genetischen Formdeutung. Das heißt, daß es sehr schwer, wenn nicht meist unmöglich ist, aus dem Stufenbau der Täler bestimmte Hebungsphasen (also endogene Vorgänge) abzuleiten, bevor alle exogenen Formumgestaltungen bekannt sind, die Stufen verlagern und an andern Stellen neu entstehen lassen und Stufen aufteilen oder sammeln. Daß diese Abklärung der endogenen Deutung vorauszugehen hat, wurde schon mehrmals betont, so von Vater und Sohn PENCK. W. PENCK 52 spricht vom «morphologischen Grundgesetz» und formuliert: «Für die Gestaltung der Erdoberfläche ist das Intensitätsverhältnis der endogenen $\mathrm{zu}$ den exogenen Massenverlagerungen maßgeblich». Dabei schwebte ihm vor, in der Gleichung mit drei Größen, den bekannten «Formen des Landes» und «zwei Unbekannten», die eine Unbekannte durch systematische Erforschung der Abtragungsvorgänge, also der exogenen Vorgänge, zu eliminieren und dadurch auch die endogenen Vorgänge, die zweite Unbekannte, zu erkennen.

Die Eliminierung der einen Unbekannten ist aber bis heute noch nicht gelungen, denn wir haben die Umgestaltung der Formen durch exogene Vorgänge noch lange nicht restlos erfaßt. Fassen wir zusammen, so zeigen die theoretischen Überlegungen, daß zwei Kräftegruppen formbildend wirken, die endogenen und die exogenen. Da sich aber diese Vorgänge zeitlich durchdringen, sind sie praktisch sehr schwer auseinanderzuhalten. 
An Versuchen allerdings, diese Verzahnung zu lösen, fehlt es, wie die unübersehbare Lite. ratur zeigt, nicht. DAvis 13 hat sich hauptsächlich mit der Umwandlung der Erdoberfläche durch exogene Kräfte beschäftigt. Um zu klaren Ergebnissen zu kommen, mußte er in seinen schematischen Entwicklungsreihen von endogenen «Störungen» absehen. Er ging dabei von irgend einem bestimmten Ausgangspunkt aus, von Uroberflächen, die tektonisch vorgeformt aus dem Meer aufgestiegen sind und nun abgetragen werden, aber auch beispielsweise von einem bestimmten fluviatilen Entwicklungszustand der Täler, der glazial umgewandelt und nachher wieder dem fluviatilen Regime zugeführt wird. Die Annahme tektonischer Ruhe während so langer Zeiträume, wie sie eine seiner schematischen Reihen beansprucht, ist natürlich unwahrscheinlich und diese ist ihm auch zum Vorwurf gemacht worden, zu Unrecht. Denn wenn wir zu klaren Vorstellungen kommen wollen, müssen wir analytisch vorgehen. Dadurch, daß Davis seine klassischen Zyklen in tektonischer Ruhe von der Jugend bis zum Greisenalter sich entwickeln läßt, gewinnt seine Lehre an Klarheit, und er kann wohl umschriebene Typen vorführen. Daß Davis sich der vielen Störungen durch endogene Vorgänge genügend bewußt war, geht aus seinen Ansätzen über Erosion während der Hebung und der Unterbrechung von Zyklen usw. hervor.

Erst durch die gesicherte Kenntnis der exogenen Vorgänge werden wir in den Stand gesetzt, auf die endogenen Vorgänge zu schließen, d.h. also, alle Formen, die sich aus einem ungestörten Ablauf nicht erklären lassen, müssen dann als durch endogene Kräfte bedingt, erklärt werden. Trotzdem wir noch lange nicht so weit sind, wird doch von den meisten Alpenmorphologen angenommen, daß vor allem ruckweise Hebungen den ungestörten Ablauf rein exogener Veränderungen unterbrochen haben. O. AMPFERER 1a meint dazu: «Es steht somit der unausgesetzten Abtragung und Entlastung der Gebirgskörper keine ebenso ununterbrochene Heraushebung, sondern nur eine in langen Pausen ruckweise wirkende gegenüber.»

«Dabei ist unter ruckweiser Hebung auch nicht mehr als eine relativ raschere Hebung gemeint. Über diese Schwierigkeit kommt man wahrscheinlich hinweg, wenn man den in der modernen Physik wichtigen Begriff eines «Wirkungsquantums» in die Betrachtung einführt.»

«Die Vorgänge der Belastung und Entlastung der Erdoberfläche vermögen nicht sofort einen entgegengesetzten Massenausgleichsstrom im Erdinnern zu erregen, sondern es ist dazu die Erreichung einer ziemlich hohen Spannung nötig. Ist diese Spannung einmal überschritten, so geht die Entladung der Ausgleichsströmung dann vergleichsweise rasch vonstatten.»

Dieser Bewegungsmechanismus der ruckweisen Hebungen und dazwischengeschalteten Ruhepausen läßt sich nach der Auffassung der herrschenden Lehre der Alpenmorphologie aus den Oberflächenformen mehr oder weniger sicher ablesen. Jeder endogenen Ruhepause entspricht die Ausbildung eines breiten Talbodens, der in der folgenden Hebungsphase zerschnitten wird. Die Reste dieser alten zerschnittenen Talböden sind die Terrassen oder Verflachungen im Gehänge. Die Zerschneidung der alten Talböden ist aber nach dieser Ansicht noch nicht bis in die Talenden vorgedrungen, so daß dort noch unzerschnittene Talböden aus jeder Ruhephase erhalten sind, die durch Steilen, Zeugen von Hebungsphasen, voneinander getrennt sind (Fig. 39-42).

Schenkt man dieser etwas schematischen und in ihrer Einfachheit leicht erfaßbaren Lehre restlos Glauben, so ist es die Aufgabe der Alpenmorphologie, auf Grund bestimmter Auswahlkriterien die echten Hebungssteilen im Talboden aus den vielen Steilen und die echten Systemreste im Gehänge aus den vielgestaltigen Verflachungen des Gehänges auszuwählen und sinnvoll zu verknüpfen, endlich daraus die verschiedenen Hebungsphasen abzuleiten und chronologisch zu ordnen.

Die vorliegende Arbeit kann sich diesem vorbehaltlosen Glauben, der überall gesicherte Terrassen mit Talsteilen sieht, nicht anschließen. Eine Spekulation kann als Arbeitshypothese ihre Berechtigung haben, so lange sie aber Hypothese bleibt, muß sie im Interesse des wissenschaftlichen Fortschrittes immer wieder auf ihre Berechtigung geprüft werden. Denn nur zu leicht werden Hypothesen, durch gewichtige Autoritäten verkündet, zu Lehrmeinungen, an denen nicht mehr gezweifelt wird.

Daß von Rütimeyer und Heim an (um irgendwo zu beginnen) über Bodmer, Gogarten, Hess, Machatscheck und Sölch bis in die neueste Zeit über die Beobachtung hinausgegangen wurde und auf Grund ungenügender physikalischer Vorstellungen, aber kräftig vorgetragener Lehrmeinungen konstruiert und spekuliert wurde, ist offenkundig. Und wenn ANNAHEIM 4, (S. 133) - um hier nur ein Beispiel zu nennen — über die Mündungsstufen schreibt: «... so liegen hier doch höchst eigenartige Verhältnisse vor, welche unverkennbar zu den Gesctzcn der fluviatilen Talbildung in schroffstem Widerspruch stehen, was gerade Davis für die Leventina dargetan hat», so zeigt das von uns gesperrte Wort Gesetz nur, wie oft Gesetz mit Ansicht, Erfahrung und Lehrmeinung verwechselt wird und die vorgetragene Ansicht durch Hinweis auf eine Autorität — hier DAvis - gestützt und bekräftigt wird. 
Zitieren wir zur Charakterisierung der heute noch weitgehend gültigen Sachlage aus dem Aufsatz von Mortensen 42: Sechzig Jahre moderne geographische Morphologie: «Auch A. PENCK stellt in seiner Morphologie der Erdoberfläche die exogenen Kräfte zwar noch sehr ausführlich dar. Doch betont er, daß 〈Ursache und Wirkung verständlich〉 seien, man sei <daher sowohl über den Umfang als auch über die geographische Verbreitung der meisten einschlägigen Erscheinungen gut unterrichtet $\gg$. Es kommt also nur noch darauf an, dieses Bekannte bei morphologischen Untersuchungen anzuwenden. Diese Ansicht trifft nicht einmal heute zu, geschweige denn vor 5o Jahren. Sie hat jedoch eine ganze Morphologenschule fast ganz auf die rein genetische Morphologie und zwar mit stark geologisch orientierter Arbeitsrichtung verwiesen. In steigendem Maße wurde dabei die Hauptaufgabe darin gesehen, nur den zeitlichen Ablauf in der geologischen Vergangenheit, wenn auch bis zum heutigen Endzustand zu untersuchen. Das heutige Landschaftsbild trat als zentrales Forschungsobjekt recht zurück. Schließlich wurde nur noch das gesehen, was Aufschluß über irgend welche Vorgänge der Vergangenheit zu geben vermochte, etwa über Hebungen, Senkungen, Verschiebungen, vielleicht auch über Klimaänderungen, ganz gleich, ob der heutige Formenschatz dadurch stark oder schwach beeinflußt war. Die Vergangenheit war damit zum Selbstzweck, das heutige Landschaftsbild eigentlich nur noch Mittel zum Zweck geworden.»

Dieser Sackgasse der rein genetischen Betrachtungsweise, z. B. der Rekonstruktion alter Talböden aus fragwürdigen Resten, entrinnen wir nur, wenn wir die allzusehr vereinfachten schematischen Vorstellungen über die Phasenlehre einer gründlichen Untersuchung unterziehen, wieder einmal in Frage stellen, unter anderm nicht nur auf die Höhenlage der Verflachungen achten und aus dem unerschöpflichen Formreichtum nur das auswählen, was uns ins Schema paßt, sondern indem wir alle Formen möglichst ohne Ausnahme systematisch zu erfassen versuchen. Hier, beim Studium des Längenprofiles heißt das, daß wir alle Steilen, seien es nun Steilen, die in ein Rekonstruktionsschema passen oder nicht, zu erfassen und zu deuten suchen. Dann werden wir auch nicht in der Vergangenheit stecken bleiben, sondern alle Formen der Gegenwart zu betrachten haben.

\section{Das Normalprofil}

Wie wir schon gesagt haben, können die gestuften Längsprofile der Alpen nicht als Normalprofile angesprochen werden. Die Grundvorstellung für diesen Begriff muß also aus andersartigen Beobachtungen stammen.

In seiner Arbeit «Die Täler der Schweizeralpen» hat F. Nussbaum 47 als Beispiele ausgeglichener Längsprofile diejenigen der Emme und ihrer Zuflüsse herangezogen. Die Kurven, die sie bilden, können mit Parabeln verglichen werden. Sie haben eine stetige, einseitige Krümmung, mit einem verhältnismäßig steilen Oberlauf im Quellgebiet und einem asymptotisch einer wenig geneigten Geraden sich nähernden Unterlauf. Ganz allgemein wird eine solche ausgeglichene Kurve als Folge langdauernder ungestörter Entwicklung gedeutet. DE MARTONNE 39 bringt in seiner Géographie physique die Profile der Loire, Seine und Garonne und nennt sie profils d'équilibre. Holmes 29 und LOBECK 35 sprechen bei solchen Profilen von profile of equilibrium oder profile at grade (graded profile), was etwa mit geordnetem Profil übersetzt werden könnte. Im französischen und englischen Ausdruck wird das Profil dynamisch aufgefaßt und DE MARTONNE exemplifiziert denn auch mit einem Wildbach, der zahm wird, wenn er das Gleichgewichtsprofil erreicht hat.

In der deutschen Literatur finden wir den neutralen Ausdruck Normalgefällskurve 51. Aber schon Richthofen 55 spricht von einem Endprofil: «Ist sie (die Kurve) hergestellt, so findet weder Erosion noch Ablagerung statt.》 PHILIPPSON 53 spricht von Erosionsterminante. Mortensen 42 wirbt für den Ausdruck «Ausgleichsgefälle». 1938 schrieb Maull 40 in seiner Geomorphologie zusammenfassend: «Über die Lage und Form der Erosionsterminante gehen die Meinungen auseinander. Daß die Erosion wirklich zum Stillstand kommt, hat PHILIPPSON bejaht... Hettrer und Penck haben es verneint.» Wir bringen dieses Zitat, um zu belegen, daß in einem großen Lehrbuch der Morphologie über einen Grundvorgang der Talbildung noch Unklarheit herrscht.

1951 schrieb H. v. Wissmann 69 in seiner Arbeit: «Über seitliche Erosion»: «Ein enges Zusammenarbeiten mit dem Physiker wäre nötig.» Das Bestreben zu einer fruchtbaren Verwertung physikalischer Methoden ist offensichtlich seit langem und bis heute vorhanden, aber es fehlt an der Durchführung. Sehr schön zeigt dies die Behandlung der Normalgefällskurve: PENCK 51 bringt eine ganze Reihe von mathematischen Ansätzen. Die Kurve ist nach dem Einen parabolisch, nach einem Andern eine Zykloide, nach dem Dritten eine logarithmische 
Kurve. Penck kommt zum Schluß: «Die Normalgefällslinien der Flüsse können keine bestimmten geometrischen Kurven sein. Schon der Umstand, daß sie innerhalb ein und desselben Flußgebietes zwischen einer Mündung und verschiedenen in verschiedener Entfernung befindlichen Quellen verlaufen und dabei streckenweise zusammenfallen sollten, widerstreitat völlig der Möglichkeit einer geometrischen Auffassung. Aber auch eine physikalische Bedeutung ist ausgeschlossen, da die Gefällskurven überhaupt nicht bestimmte Kurven sind.» Auch Philippson 53 schreibt: «Die Kurve der Erosionsterminante ist mathematisch nicht bestimmbar, denn die Wasserzunahme im Fluß ist unregelmäßig und ist bei jedem Fluß anders.»

Das Urteil von PENCK, der doch mathematischer Behandlung eines Problems zugänglich war, überrascht einigermaßen. Die Resignation ist aber fast prophetisch, wenn wir bedenken, $\mathrm{da} \beta$ auch heute, 6o Jahre nachdem er obiges geschrieben, immer noch keine allgemein anerkannte, physikalisch begründete Formel vorliegt. Doch ist zu dieser Resignation eine kritische Bemerkung nötig. Es sei zugegeben, daß eine Formel wie die von Zollikofer, die Penck zitiert :

$$
\mathrm{h}=\frac{\mathrm{m}}{\mathrm{n}+\mathrm{l}}-\mathrm{pl}
$$

worin $h$ die Höhe eines Punktes, 1 die Entfernung von der Quelle, $m, n$ und $p$ aber Konstanten sind, rein beschreibend ist und über die physikalischen Bedingungen nichts aussagt. Wir müssen aber unterscheiden zwischen der rein beschreibenden mathematischen Behandlung des Problems und ihrer physikalischen Begründung. Und eine physikalische Begründung gibt doch schon Richthofen 55, wenn er schreibt: "Sie (die Kurve des Endprofils) bezeichnet die Grenze der mechanischen Wirkung, welche das Gewässer bei gegebenem Maß allmählicher Zunahme der Wassermasse von oben nach unten und bei gegebenem Material zu leisten vermag.» Dies heißt doch, rein physikalisch betrachtet, wenn wir das Gefälle mit J, die Wassermenge mit $Q$ bezeichnen: $J=f(Q)$, und so wäre nur noch zu entscheiden, welcher Art diese Funktion ist. Wir könnten zwar dann nicht für jedes Tal, wohl aber für idealisierte Fälle das Normalprofil berechnen. Die Frage ist nun, ob Richthofen - und später z. B. Philippson 53 mit der Annahme, die Wasserzunahme begründe das Gefälle hinreichend, eine befriedigende physikalische Beschreibung geben. Diese Frage, die sich ja jeder Forscher auch stellen mußte, kann allein durch die Beobachtung von Flußläufen nicht oder nur schwer entschieden werden.

Physikalisch-mathematisch kommen wir nur weiter, wenn wir Meßresultate vorweisen können - und die fehlen dem Morphologen. Denn im allgemeinen wird er zwar die Formen genau betrachten, Profile mißt er aber meist nicht selbst aus, und was die Bestimmung der Wassermengen anbelangt, ist er erst recht auf fremde Messungen angewiesen. Die Physik hat seit ihrem Aufschwung ihre Meßresultate meist nicht der freien Natur entnommen, sondern das Experiment entwickelt.

$\mathrm{Daß}$ das Experiment auch in der Geologie und Geographie sinnvoll wäre, hat schon 1791 HutTon 40 ausgesprochen. SAPPER 57 hat 1913 auf Grund einer Zusammenstellung den dringenden Wunsch geäußert: «Daß an unsern Universitäten und an andern Lehranstalten besondere Laboratorien für physikalische Geographie eingerichtet werden, in denen gewisse Vorgänge der Erdoberfläche, um den Mechnismus der Erscheinungen eingehend studieren zu können .... unmittelbar vorgeführt werden könnten.»

Seither ist viel Zeit verflossen und doch hört man sehr wenig von morphologischen Experimenten. Auch die Versuche von WURM 70, über die er 1935 publizierte und von OGILvIE 50 vom Jahr 1936, haben keinen großen Nachhall gefunden. Doch hat Escher (Leiden) 1955 in der Festgabe der GEP 15 sehr positiv «Über den Wert geologischer Experimente» berichtet.

Der Mißerfolg all dieser Bestrebungen liegt wohl darin, daß die Experimente zu wenig «naturnah», zu wenig «wirklichkeitsgetreu» sind. Die spärliche Literatur und die spärlichen Versuche sind auch nicht durchwegs überzeugend und anregend. Vor allem fehlt es an großangelegten Versuchen. Solche aber brauchen große Laboratorien und dementsprechend große Mittel und diese stehen dem Geographen nicht zur Verfügung. Sie stehen aber dem zur Verfügung, der nachweisen kann, daß die Ergebnisse von wirtschaftlicher Bedeutung sind. Dieser Nachweis gelingt dem Wasserbauer.

Nun ist klar, daß die Fragestellung des Wasserbauers nicht ganz die gleiche sein kann wie die des Morphologen. Der Wasserbauer verlangt als Ergebnis seiner Versuche eindeutige Formeln, die erlauben, daß ein bestimmter Fall berechnet werden kann. Sie sollen eine Planung ermöglichen, bei der der Wasserbauer oft noch weitgehend die Bedingungen stellen kann. Im weitern sind nur Vorgänge von Interesse, die mit menschlichen Zeitmaßstäben gemessen werden können. Die säkulare Erosion und Verwitterung in «solidem» Gestein ist ohne Interesse, eine Felsschwelle, die in Jahrzehnten kaum meßbar verändert wird, wird als Fixpunkt betrachtet. Umso mehr Interesse wird dem Geschiebe zugewandt. 1944 hat R. MülleR 44 einige Grundbegriffe des Wasserbaues vermittelt. Sie sind auch für den Morphologen von Interesse. Wir haben schon erwähnt, daß Richthofen für das Ausgleichsgefälle einzig die Wassermenge verantwortlich gemacht hat. Dies ist aber offensichtlich ungenügend. Eine rein qualitative Betrachtung führt zu der Funktionsgleichung $J=F(Q, G, d, P r)$. Das heißt, das Gefälle J ist 
eine Funktion der Wassermenge Q, der Geschiebemenge G, der Korngröße des Geschiebes d und der Form und Größe des Querprofiles Pr. Es spielt also nicht nur die talabwärts zunehmende Wassermenge eine Rolle, sondern auch die zunehmende Geschiebemenge, die sich flußabwärts durch Abrieb charakteristisch verändert und endlich auch noch die Form des Flußbettes. Sowohl für die Geschwindigkeit des Wassers wie auch für den Geschiebetrieb besitzt der Wasserbauer Formeln, die sich für bestimmte Verhältnisse in der Praxis vollauf bewährt haben*. Hier sei nur rein qualitativ der Geschiebetransport angeführt. Nennen wir $G$ das Geschiebetransportvermögen in einer bestimmten gleichförmigen Strecke und $\mathrm{Gz}$ die $\mathrm{Zufuhr}$ von Geschiebe in diese Strecke, so können + Fälle unterschieden werden:

Ist $\mathrm{Gz}=\mathrm{G}$, so ist die Flußstrecke im Stande, alles zugeführte Material weiterzutransportieren. Die Strecke befindet sich im Beharrungszustand oder Gleichsgewichtszustand, das Gefälle bleibt erhalten.

Ist $\mathrm{Gz}>G$, so kann die Flußstrecke den Transport nicht bewältigen. Sie muß einen Teil des zugeführten Materials liegen lassen. Das Gefälle wird dadurch solange erhöht, bis wieder ein Beharrungszustand erreicht ist. Die erhöhte Geschiebezufuhr kann z. B. eintreten, wenn ein kleiner Seitenbach mit großem Gefälle und viel Geschiebe in ein Haupttal eintritt. Der Seitenbach staut dann den Hauptfuß, bis dessen Gefälle genügt, die zusätzliche Last zu transportieren.

Ist $\mathrm{Gz}<\mathrm{G}$, so kann der Fluß mehr Geschiebe transportieren, als ihm zugeführt wird. Er wird also so lange erodieren, bis das Gefälle so stark verkleinert ist, daß Gleichgewicht herrscht.

Endlich kann $\mathrm{Gz}=\mathrm{O}$ sein, z. B. beim $A$ usfluß aus einem See. Dann wird wie im vorigen Fall Abtragung eintreten, bis ein Minimalgefälle erreicht ist, bei dem das geschieblose Wasser gerade noch abfließt.

Fassen wir die heutige Sachlage zusammen, so ergibt sich, daß die beachtenswerten mathematischen Ansätze der Wasserbauer dem Morphologen doch noch keine Formel für ein Flußlängsprofil in die Hand geben. Dies ist aber kein Grund zu der von Penck und Philippson vertretenen Ansicht, daß die Gefällskurve mathematischer Behandlung nicht zugänglich sei.

Es ist doch vielmehr so, daß einfach noch kein mathematisch genügend ausgebildeter Morphologe auf Grund der heute erkannten Faktoren eine Formel aufgestellt hat für eine Gefällskurve, wie sie in jedem Lehrbuch als «Normalkurve» intuitiv gezeichnet wird. Was aber gezeichnet werden kann, kann auch gerechnet werden.

Für die weitere Untersuchung bedienen wir uns folgender Definition: Das Normallängsprofil oder die Normalgefällskurve eines Gewässers ist eine Idealkurve, die sich rein theoretisch aus bestimmten idealen Annahmen ergibt. Die Formel für die Normalprofilkurve wird eine Reihe von Parametern enthalten: den Höhenunterschied zwischen Quelle und Mündung, die Flußlänge, die Größe der Wasserzunahme, die Größe der Geschiebezunahme im Erosionsgebiet, die Größe des Abriebes, Form und Größe des Bettes in den verschiedenen Abschnitten und anderes mehr. Jeder Veränderung dieser Parameter entspricht eine andere Kurve. Ein Fluß mit einem Normalprofil wird mit der Zeit dessen Gefälle verringern. Das Normalprofil wird zunehmend flacher, wenn auch mit abnehmender Geschwindigkeit. PeNCK 51 hat für «eine Kurve von ganz minimalem Gefälle», die man «als Endziel der Flußtätigkeit bezeichnen $m u ß »$, den Begriff Endprofil vorgeschlagen. Wir möchten auch das Fremdwort Erosionsterminante auf diese Definition beschränken.

Die Normallängsprofilkurve ist eine Idealkurve und deshalb in der Natur nie restlos verwirklicht. Wir sprechen von einem Ausgleichsprofil, wenn die Abweichungen von einem Normalprofil nur gering sind. Entspricht nur eine bestimmte Teilstrecke

* Für die Geschwindigkeit eines Gewässers wird die StrickLer'sche Formel angewendet $\mathrm{v}=\mathrm{k} . \mathrm{R} \frac{2}{3} \cdot \mathrm{J} \frac{1}{2}$, worin $\mathrm{R}$ die Form des Profils, $\mathrm{k}$ einen Rauhigkeitsfaktor und $\mathrm{J}$ den Tangens der Neigung bedeutet. Für den Geschiebetrieb hat das Wasserbaulabor der ETH die Formel entwickelt :

$$
\mathrm{g}=\left(\frac{\mathrm{q}^{\frac{2}{3}} \mathrm{I}-\mathrm{ad}}{\mathrm{b}}\right) \frac{3}{2}
$$

worin $\mathrm{g}$ die Geschiebemenge pro $\mathrm{m}$ Flußbreite in $\mathrm{kg} / \mathrm{sec}$, q die Wassermenge in $\mathrm{m} 3 / \mathrm{sec}$ und pro m Flußbreite, d der maßgebende Korndurchmesser bedeuten. a und b sind Konstanten 41. 
melır oder weniger einem Normalprofil, so sprechen wir von einer Ausgleichsprofilstrecke.

Unsere Aufgabe besteht nun darin, die vielgestaltigen Abweichungen zu beschreiben, wenn möglich zu begründen und systematisch zu ordnen. Eine weitere Aufgabe wird sein, die Weiterentwicklung, die Umwandlung der Abweichungen zu untersuchen und $\mathrm{zu}$ beschreiben.

Wir haben als bezeichnendes Merkmal der Alpentallängsprofile die Treppung oder Stufung erwähnt. Einige Begriffe, die wir verwenden werden, seien hier genannt.

Wir sprechen bei den steilern Strecken zwischen zwei Flachstrecken ganz allgemein von Steilstrecken oder kurze Steilen. Wenn diese Strecke so steil ist, daß sich keine Geschiebesohle ausbilden kann, so nennen wir sie auch etwa Stufe. Wenn das Wasser als Fall darüber hinunterstürzt, nennen wir eine solche Stufe eine Wandstufe.

\section{SYSTEMATIK DER STEILEN}

Das Bestreben bei der Aufstellung einer Systematik eines Tatsachenmaterials wird darin bestehen, dieses nicht nur nach «äußern» Merkmalen, z. B. nach der Größe und äußern Form zu ordnen, sondern vielmehr auch nach einer «innern»Verknüpfung zu suchen, sei es nach verwandten Vorgängen, die zu einer bestimmten Form führen oder nach der innern Struktur. Ein solches, von innen begründetes System nennen wir ein natürliches System. Zum Ausdruck natürlich ist aber zu bemerken, daß es wohl kein absolutes natürliches System gibt. Vielmehr ist jedes natürliche System abhängig, von den Methoden und dem Stand der wissenschaftlichen Einsicht. Es ist somit jedes System mit dem Fortschritt der Einsichten verbesserungfähig. Ja, es ist oft sogar von Vorteil, den gleichen Tatsachenkomplex nach verschiedenen Ordnungsprinzipien, die sich nicht in der gleichen Systematik verwenden lassen, zu betrachten, um zu neuen Einsichten zu gelangen. Jede Systematik verlangt die Postulierung von reinen Typen oder Idealtypen. Die Tatsache, daß diese Idealtypen in reinster Form in der Natur nicht vorkommen, ist kein Grund, sie abzulehnen. Es ist nur erforderlich, daß wir die Idealtypen so allgemein fassen, daß Abweichungen als nebensächlich vernachlässigt werden können. Die Mahnung des größten Systematikers, CARL von Linné, sich an die großen Linien zu halten, mag auch hier ihre Berechtigung haben: «Wer sich in Varietäten verliert, verkennt das Prinzip der vielschaffenden Natur ${ }^{21}$.

Wir haben als natürliche Einteilungsprinzipien erwähnt:

1. Die Verknüpfung der äußern Form mit dem Inhalt. Bei den Steilen bedeutet dies, daß zu untersuchen ist, ob irgend ein Zusammenhang der äußern Form mit dem innern Gefüge, mit dem lithologischen Befund, vorhanden ist, wie weit also das Gefüge die Eigenart der Form bedingt.

2. Die Verknüpfung der äußern Form und des innern Gefüges mit den Bildungsvorgängen. Es ist zu untersuchen, in welcher Beziehung die Form zur besondern Erosionsarbeit des Wassers oder des Eises steht, wie weit Unstetigkeiten der Wasser-oder Eisführung oder Wechsel von Eis- zu Wassererosion oder andere Vorgänge zur Steilenbildung führen.

Diese beiden Einteilungsprinzipien sollen uns eine erste Unterteilung erlauben.

Wir schicken der Einzelbeschreibung eine tabellarische Übersicht voraus.

\section{RESISTENZSTEILEN}

\section{Übersicht über die Steilen}

A. Einfacher Gesteinswechsel

1. Das resistente Gestein wird vom weniger resistenten, überlagert.

2. Das resistente Gestein überlagert das weniger resistente.

B. Doppelter Gesteinswechsel

1. Typus: Das resistente Gestein ist horizontal.

2. Typus: Das resistente Gestein fällt gleichsinnig mit dem Talgefälle ein. 
1. Art: Das resistente Gestein wird in der Steile unterschnitten und fällt flacher oder gleichsteil ein wie das Gefälle der Flachstrecke.

2. Art: Das resistente Gestein wird überschnitten.

1. Form: Die Steile folgt Schichtflächen (Plattenschußteile).

2. Form: Die Steile überschneidet das resistente Gestein.

3. Typus: Das resistente Gestein fällt senkrecht ein.

4. Typus: Das resistente Gestein fällt bergwärts ein.

II. AKKUMULATIONSSTEILEN

1. Steilen durch anhaltende oder periodische Einschüttung.
a) Schwemmkegelsteilen;
b) Schuttkegel- oder Schutthaldensteilen.;
c) Steilen durch anhaltende Gehängerutschungen;
d) Steilen durch Stau durch den Seitentalgletscher;
e) Endmoränensteilen (z. T.).

2. Steilen durch einmalige oder sehr seltene Einschüttungen.

a) Bergsturzsteilen.

\section{KONFLUENZ- UND DIFFLUENZSTEILEN}

1. Steilen an der Konfluenz gleichgroßer Täler.

a) Fluviatile b) Glaziale.

2. Steilen an Seitentalmündungen.
a) Fluviatile b) Glaziale.

3. Talschlußsteilen.

a) Fluviatile b) Glaziale.

4. Diffluenzsteilen.

IV. STEILEN ALS NORMALERSCHEINUNG DES GLETSCHERBETTES ? UND STEILEN BEI REGIMEWECHSEL

\section{KRÜMMUNGS-, ANZAPFUNGS- UND VERSICKERUNGSSTEILEN}

Wir nehmen die Steilen voraus, die sich irgendwie aus dem lithologischen Befund deuten lassen, z. B. durch einen Gesteinswechsel oder einen Wechsel im Gefüge, einer besonders starken Klüftung oder aber der Einlagerung eines andersartigen Gesteins durch einen Akkumulationsvorgang.

Es sind darin zwei Gruppen zu unterscheiden. Die erste umfaßt die Steilen, die durch selektive Erosion herausmodelliert wurden, bei denen also der Erosionsvorgang nicht durch unstete Zunahme der Wasser- oder Eisführung, sondern allein durch Ungleichheiten im Erosionsbett verändert wird. Zur zweiten Gruppe gehören die Steilen, bei denen von der Seite her Material eingelagert wird. Die erste umfaßt die $R e$ sistenzsteilen, die zweite die Aufschüttungs-oder Akkumulationssteilen.

\section{Resistenzsteilen}

Von den Formen selektiver Erosion betrachten wir hier nur diejenigen, die sich im Längsprofil geltend machen. Voraussetzung ist inhomogenes Gestein. Herauspräpariert wird das widerstandsfähigere, das resistentere Gestein, das weniger resistente wird entfernt. Wir vermeiden den Ausdruck Härte, denn es ist nicht unbedingt die physikalische Härte des Gesteins - etwa die Einpreßhärte, die Schleif- und Ritzhärte die maßgebend ist. Denn ein Gestein, das im Handstück beim Anschlagen mit dem Hammer sehr hart ist, muß im Anstehenden der Erosion gegenüber nicht unbedingt besonders resistent sein, da die Erosion ja nicht nur im Abschleifen und Ritzen besteht, sondern ganze Stücke ausbrechen kann. Kluftsysteme, tektonische Zermürbung des Gefüges, Mylonite und Kakirite, auch die oberflächliche Verwitterung spielen eine wichtige Rolle. Nicht zu wergessen ist die Erosionsrichtung, da offensichtlich viele Gesteine sich der Erosion gegenüber anisotrop verhalten.

In den einfachen Fällen liegt bei den Resistenzsteilen ein offensichtlicher Gesteinswechsel vor. Es können aber ebensogut innerhalb des petrographisch gleichen Gesteins 
Fig. 1 Allgemeines Steilenschema.

$F_{1}, F_{2}$ Flachstrecken, $S_{1}, S_{2}$ Steilen, $S F_{1}, S F_{2}$ Steilenfüße, $S S_{1}, S S_{2}$ Steilenscheitel, $\quad \iota_{l} F_{1}, \quad \iota F_{2}$ Gefälle der Flachstrecken, $\iota_{S_{1}}$, $\iota_{S_{2}}$ Gefälle der Steilen, $\beta$ Fallwinkel des Gesteins.

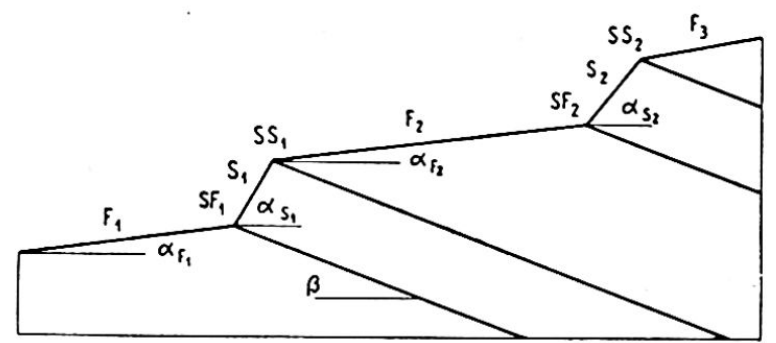

z. B. tektonisch bedingte Schwächezonen sein. Auch eine vorzügliche und zuverlässige geologische oder petrographische Karte genügt für sich allein oft nicht, eine Resistenzsteile zu erkennen oder gar auszuschließen, da geologische und petrographische Karten keine Erosionsresistenzkarten sind. Zudem kann das weniger resistente Gestein restlos ausgeräumt sein und am Steilenfuß durch Aufschüttung verdeckt sein, so da $\beta$ aus dem nur noch vorhandenen resistenteren Gestein nicht mehr auf die Entstehung geschlossen werden kann. Eine Steile, die im gleichen Gestein liegt, kann also trotzdem als Resistenzsteile entstanden sein.

In den Alpen ist immer zweier Erosionsarten zu gedenken, der fluviatilen und der glazialen. Wir haben demnach auch fluviatil und glazial entstandene Resistenzsteilen, aber auch fluviatil umgewandelte glaziale Resistenzsteilen zu unterscheiden. Bei glazialen Erosionsformen ist immer der weit größere Maßstab gegenüber den fluviatilen zu berücksichtigen. Wenn in Flußbetten von im Durchschnitt wenig Meter Wassertiefe durch selektive Erosion Kolke und Wannen entstehen und daneben Buckel mit geringen Höhenunterschieden stehen bleiben, so werden diese Bettunregelmäßigkeiten in einem ausgetrockneten Flußlauf landschaftlich kaum beachtet. Vergrößern wir aber diese Unregelmäßigkeiten in die Größenordnung glazialer Formen, so kommen wir $\mathrm{zu}$ beachtlichen Kolken, Wannen und Buckeln mit Höhenunterschieden von $100 \mathrm{~m}$ und mehr.

Wir beschränken uns in unserer Systematik auf Typen, bei denen der Gesteinswechsel senkrecht zur Talachse stattfindet und die Gesteinsbänke ebenflächig sind. Zum Einordnen verwenden wir den Fallwinkel des Gesteins in Bezug auf das Tal nach dem Schema der Fig. 1. $F_{1}, F_{2}$ sind sich folgende Flachstrecken, $S_{1}$ und $S_{2}$ Steilen, $a_{\mathrm{F}_{1}}, a_{\mathrm{F}_{2}}, a_{\mathrm{S}_{1}}, a_{\mathrm{S}_{2}}$, sind die entsprechenden Gefällswinkel. Den Fallwinkel des Gesteins bezeichnen wir mit $\beta$. SF $F_{1}$ ist der Steilenfuß, SS der Steilenscheitel.

A. Der einfache Gesteinswechsel. Da im resistenten Gestein die Erosion langsamer fortschreitet als im weniger resistenten, geht auch der Gefällsausgleich, die Abflachung des Gefälles, im resistenteren Gestein langsamer vor sich. Folgt talaufwärts auf das resistentere Gestein das weniger resistente, so ist das Gefälle im resistenteren größer als oberhalb. Der Gesteinswechsel ist für das leichter erodierbare Gestein ein relativer Fixpunkt, eine relative Erosionsbasis, wenn dieser etwas vieldeutige Ausdruck hier angewandt werden darf. Die Flachstrecke spielt sich also auf diesen Punkt ein. Bei mit dem Gefälle gleichsinnigem Gesteinseinfallen muß $\iota_{F}$ größer sein als $\beta$ (Fig. 2).

Folgt auf weniger resistentes Gestein talaufwärts resistenteres, so befindet sich die Flachstrecke unten. Geometrische Voraussetzung ist, daß bei gleichsinnigem Gesteinseinfallen $\alpha_{\mathrm{F}}$ kleiner ist als $\beta$ (Fig. 3).

Ein steileres Gefälle im resistenteren Leventinagneis unter einer Flachstrecke in weniger resistenten mesozoischen Gesteinen ist in der Dazio Grande des Tessintales vorhanden. Am Steilenfuß ist das Tal aufgeschüttet, so daß wir den Felsverlauf in der untern Flachstrecke nicht kennen.

An dieser Aufschüttung von unten her ist der Bergsturz von Chironico (die Biaschina) mitbeteiligt. Wenn Annaheim 4 schreibt: «Beim Monte Piottino ist die Sachlage geradezu paradox» (in Bezug auf die Steile), so können wir dem nicht zustimmen. 


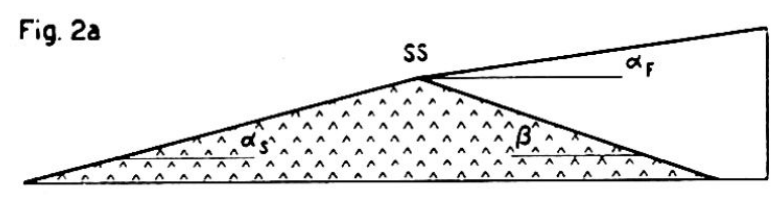

Fig. 3a

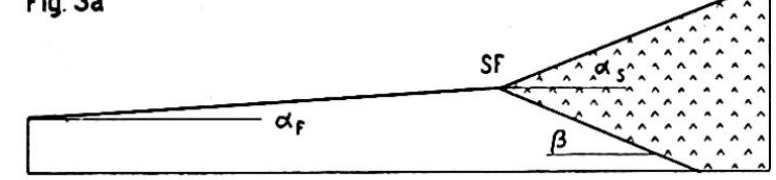

Fig. $2 b$

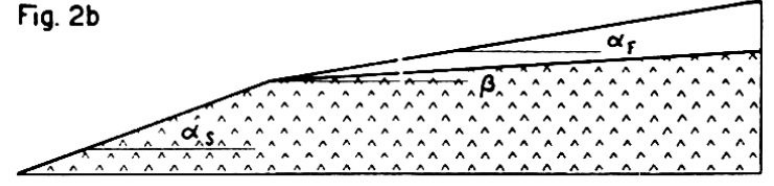

Fig. 3b

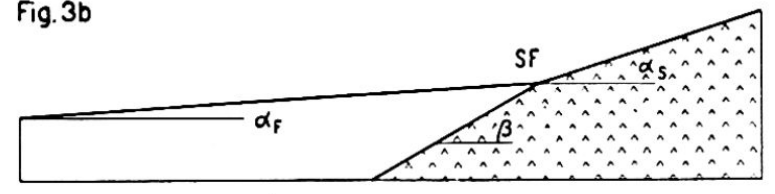

Figur 2 und 3 Einfacher Gesteinswechsel

a Das Gestein fällt bergwärts ein. b Das Gestein fällt talıärts ein.

Figur 2 Das resistentere Gestein bildet eine Steile unter einer Flachstrecke.

Figur 3 Das resistentere Gestein bildet eine Steile über einer Flachstrecke.

B. Der doppelte Gesteinswechsel. Beim doppelten Gesteinswechsel liegt eine Resistenzsteile zwischen zwei Flachstrecken in weniger resistenten Gesteinen oder eine Flachstrecke in weniger resistentem Gestein zwischen zwei Resistenzsteilen. Beim Übergang von der Flach- in die Steilstrecke ändert sich im allgemeinen nicht nur das Gefälle, sondern der ganze Talcharakter. In der Flachstrecke im weniger resistenten Gestein ist das Tal breit, ausgeweitet, in der Steilstrecke oft schluchtartig. Häufig sind auch Richtungsänderungen des Tales mit dem Gesteinswechsel verknüpft.

Im Hinterrheintal durchschneidet der Rhein zwischen Andeer und Sufers den Rofnagneißstock in der Rofnaschlucht. Ober- und unterhalb der Schlucht liegt das Tal in Schiefern. Bei Andeer beträgt das Gefälle $17 \%$, steigt dann in der Schlucht bis auf $162 \%$ und sinkt oben bei Sufers wieder auf $12 \%$ ab. Der Höhenunterschied beträgt rund $340 \mathrm{~m} 68,65$.

Bei gutgeschichtetem oder gebanktem Gestein kann beim doppelten Gesteinswechsel die Systematik verfeinert werden. Diese Verfeinerung stützt sich auf das Einfallen des Gesteins in Bezug auf die Talrichtung. Sie dient weniger der Einordnung ausgedehnter Steilen, bei denen die Größe und Richtung des Fallwinkels oft wechselt, als vielmehr der Erfassung von Kleinstufungen, die einzeln auftreten oder als. Treppungen eine größere Steile unterteilen.

Wir beginnen mit einem rein geometrischen Schema ${ }^{31}$.

\section{Die rein geometrisch-systematische Einordnung}

1. Typus: Das Gestein ist horizontal gelagert $\beta=0 \circ$ (Fig. 4).

2. Typus: Das Gestein fällt gleichsinnig mit dem Talgefälle ein.

1. Art: Das resistente Gestein wird in der Steile unterschnitten und fällt flacher oder gleichsteil ein wie das Gefälle der Flachstrecke. $a_{\mathrm{F}_{2}} \geq \beta<a_{\mathrm{s}}$ (Fig. 5).

2. Art: Das resistente Gestein wird überschnitten $\iota_{\mathrm{F}}<\beta$

1. Form: Die Steile folgt Schichtflächen $a_{\mathrm{F}}<\beta=a_{\mathrm{S}}$ (Fig. 6).

2. Form: Die Steile überschneidet das resistente Gestein. $a_{\mathrm{F}}\langle\beta\rangle$ as (Fig. 7).

3. Typus: Das Gestein fällt senkrecht ein $\beta=90^{\circ}$ (Fig. 8).

4. Typus: Das Gestein fällt bergwärts ein (Fig. 9).

Dieses rein geometrische Schema ist morphologisch zu verfeinern, wobei sowohl die Verhältnisse in der Steile zwischen zwei Flachstrecken als auch diejenigen der Flachstrecke zwischen zwei Steilen zu betrachten sind. 


\section{Typus: Das resistente Gestein ist horizontal $\beta=0^{\circ}$}

Wir können bei allen Typen je nach dem Verhalten des Gesteins in der Steile mehrere Formen unterscheiden. Die erste Form bei Typus 1 ist die Wandsteile oder Wandstufe (Fig. 10). Das Wasser stürzt frei über die Wand, in der es folglich auch nicht erodiert. Die Entstehung dieser Form ist oft an die Bildung eines Kolkes im weniger resistenten Gestein am Fuß der Wandstufe geknüpft. Dadurch wird die Wand unterspült und das resistente Gestein bricht als ganzer Komplex nach. (Das bekannteste Beispiel ist der Niagara, auf den wir S. 195, wie wohl er sich außerhalb der Alpen befindet, noch zu sprechen kommen.)

Die zweite Form ist die Treppensteile (Fig. 11). Sie entsteht in gut geschichteten oder geschieferten Gesteinen mit Wechsellagerung mit weniger resistenten $Z_{\text {wischen- }}$ schichten, so daß im ganzen Komplex die resistenteren Glieder treppenartig herauspräpariert werden.

Die dritte Form ist die Steile mit unregelmäßigem schiefem Schnitt (Fig. 12), die sich in massigem, unregelmäßig resistenten Gestein herausbildet.

Eine Flachstrecke zwischen zwei Steilen ist umso länger, je mächtiger die weniger resistente Gesteinsbank und je geringer das Gefälle ist. Wir nennen die Länge einer Flachstrecke auch den Steilenabstand.

\section{Typus: Das resistente Gestein fällt gleichsinnig mit dem Talgefälle ein}

1. Art: Das resistente Gestein wird in der Steile unterschnitten und fällt flacher oder gleichsteil ein wie das Gefälle der Flachstrecke (Fig. 13-15).

Es läßt sich leicht einsehen, daß in Talstrecken mit geringem Gefälle die resistente Gesteinsbank nur wenig geneigt sein kann. In flachen Gefällsstrecken unterscheiden sich diese Formen nur wenig von denjenigen mit horizontalgelagertem Gestein. Bei größerem Gefälle und gut gebanktem oder geklüftetem Gestein besteht natürlich durch das Unterschneiden die Möglichkeit, daß ganze Schichtpakete abrutschen.

Wir können auch hier die drei Formen Wandstufe, Treppensteile und Steile mit un regelmäßigem Schnitt unterscheiden.

\section{Art: Das resistente Gestein wird überschnitten $\alpha_{\mathrm{F}}<\beta$}

1. Form: Die Steile folgt Schichtflächen $\beta=\omega_{s}$, Plattenschußsteile (Fig. 16).

Bei gut geschichtetem oder geklüftetem Gestein kann die ganze Steile von einer einheitlichen Schicht- oder Kluftfläche gebildet werden. Die Schichtköpfe oberhalb der Steile bilden dann eine Felsschwelle, in die das Gewässer unter Umständen nur eng eingeschnitten ist. Oberhalb dieser Schwelle erweitert sich das Flußbett wieder.

Der Steilenabstand ist bei gegebenen Gesteinsmächtigkeiten umso größer, je größer das Gefälle und je flacher das Gesteinsfallen ist.

2. Form: Die Steile überschneidet das resistente Gestein. $\beta<a_{\mathrm{s}}$ (Fig. 17 u. 18.)

Je nach dem Gestein kann die Steile aus einem Wechsel von Plattenschüssen und Schichtköpfen bestehen, also treppenförmig sein, die Steile kann aber auch ein unregelmäßiger schiefer Schnitt durch die resistente Gesteinsbank sein.

3. Typus: Das resistente Gestein fält senkrecht ein. $\beta=90^{\circ}$ (Fig. 19-20.)

Wie beim horizontalgelagerten Gestein können wir drei Formen unterscheiden, so aber, daß Schichtflächen und Schichtköpfe ihre Rolle vertauschen. Bei der Wandstufe wird die ganze Stufe von einer Schichtfläche gebildet. Bei der Treppensteile wechseln Schichtflächen als Abstürze mit Schichtköpfen als Treppenstufen. In massigem Gestein entstehen Steilen mit unregelmäßigem Schnitt.

Der Steilenabstand ist unabhängig vom Talgefälle. 
4. Typus: Das resistente Gestein fällt bergwärts ein (Fig. 21-23)

Auch hier können wir die drei Formen Wandstufe, Treppensteile und Steile mit unregelmäßigem Schnitt unterscheiden.

Der Steilenabstand ist umso größer, je kleiner das Talgefälle ist.

Auf typische Formen, die mit Steilen verknüpft sind, sei hier nur kurz hingewiesen, da wir sie in den Skizzen teilweise angedeutet haben. Bei fluviatiler Erosion bilden sich am Steilenfuß oft Kolke. Beim Rückschreiten der Steile wird der Kolk talabwärts wieder zugeschüttet. In der Flachstrecke fließt das Gewässer dann in seinen eigenen Aufschüttungen. Bei glazialer Erosion sind die Flachstrecken oft tief wannenförmig ausgekolkt, wurden aber seit dem Gletscherrückgang meist wieder völlig gefüllt (Fig. 19-21).

\section{Akkumulationssteilen}

Zur Unterteilung dieser formreichen Steilen eignet sich am besten die Art der Akkumulation.

Zeitlich kann die Akkumulation anhaltend oder periodisch stattfinden, der Vorgang kann aber auch ein einmaliges oder ein sehr seltenes Ereignis sein.

Die Akkumulation kann als Massentransport durch Wasser oder Eis vor sich gehen. Die Massen können aber auch ohne Transportmittel, rein nur durch die Schwerkraft sich verlagern, wobei das Wasser nur die Rolle eines Schmiermittels spielt. Wir sprechen dann von Massenbewegung.

\section{Anhaltende oder periodisch wiederkehrende seitliche Einschüttung}

a) Die Schwemmkegelsteilen (Massentransport).

Damit ein geschiebeführendes Gewässer einen Schwemmkegel bildet, ist es in erster Linie notwendig, daß eine plötzliche Gefällsvermiñderung eintritt, die so groß sein muß, daß das Gewässer nicht mehr all sein Geschiebe transportieren kann. Dies ist aber meist nicht die alleinige Ursache. Die Gefällsstrecke, in der das Gewässer aufschüttet, bietet oft so viel Raum, daß das aufschüttende Gewässer fächerförmig

Figur 4-9 Schema der Resistenzsteilen mit doppeltem Gesteinswechsel

Fig. 4 Das resistente Gestein ist horizontal. Die Schichtköpfe bilden die Steile.

Fig. 5 Das resistente Gestein fällt talwärts ein, aber flacher als die Flachstrecke. Die Schichtköpfe bilden die Steile.

Fig. 6 Das resistente Gestein fällt talwärts ein. Die Schichtflächen bilden die Steile (Plattenschußsteile).

Fig. 7 Das talwärts einfallende resistente Gestein wird von der Steile schief geschnitten. Die schief geschnittenen Schichtköpfe bilden die Steile.

Fig. 8 Das Gestein fällt senkrecht ein. Die Stufe wird durch Schichtflächen gebildet.

Fig. 9 Das Gestein fällt bergwärts ein. Die Steile wird durch Schichtköpfe gebildet.

Fig. 10 Wandstufe in horizontal gelagertem Gestein mit Kolk am Wandfuß und fortlaufender Kolkaufschüttung beim Rückwärtswandern.

Fig. 11 Treppensteile in horizontal gelagertem Gestein mit höherwachsender Aufschüttung am untersten Steilenfuß.

Fig. 12 Unregelmäßige Steile in horizontalem Gestein mit zugeschüttetem untersten Steilenfuß.

Fig. 13 Wandstufe in leicht talwärts einfallendem Gestein und Kolk am Wandfuß und Aufschüttung des Kolkes beim Rückwärtswandern.

Fig. 14 Treppensteile in leicht talwärts einfallendem Gestein.

Fig. 15 Unregelmäßige Steile in leicht talwärts einfallendem Gestein.

Fig. 16 Plattenschußsteile. Wenn der Plattenschuß sehr steil ist, mit Kolk am Steilenfuß.

Fig. 17 Treppensteile im steil talwärts einfallendem Gestein. Die einzelnen Steilen oder Stufen sind Plattenschüße.

Fig. 18 Unregelmäßige Steile in steil talwärts einfallendem Gestein.

Fig. 19 Wandstufe in senkrecht einfallendem Gestein.

Fig. 20 Treppenstufe in senkrecht einfallendem Gestein.

Fig. 21 Unregelmäßige Steile in senkrecht einfallendem Gestein.

Die gestrichelte Linie soll zugeschüttete glaziale Kolke andeuten.

Fig. 22 Wandstufe bei bergwärts einfallendem Gestein.

Fig. 23 Treppensteile bei bergwärts einfallendem Gestein.

Fig. 24 Unregelmäßige Steile bei bergwärts einfallendem Gestein. 
Fig. 4

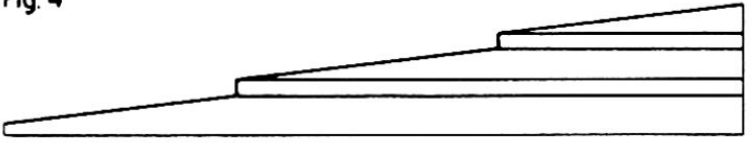

Fig. 5
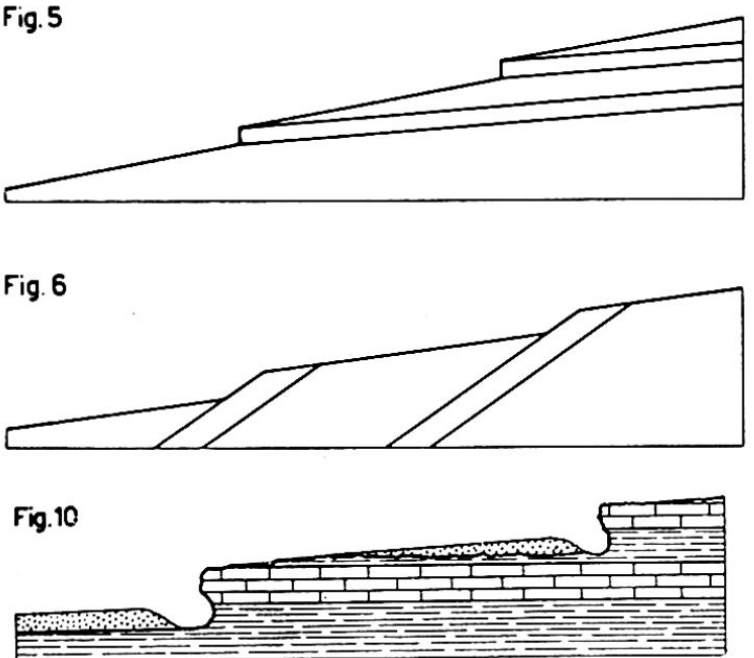

Fig. 11

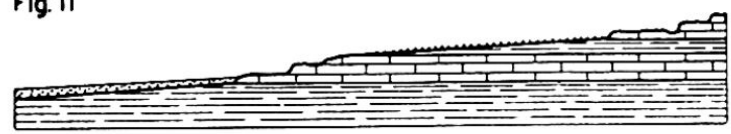

Fig. 12

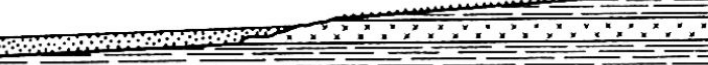
-

Fig. 13
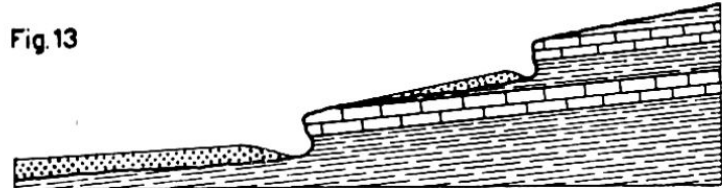

Fig. 14
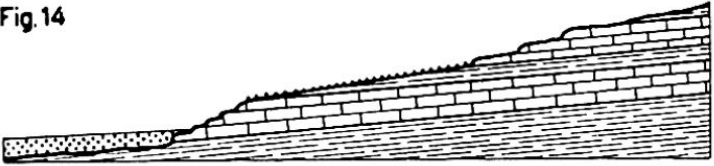

\section{Fig. 15}

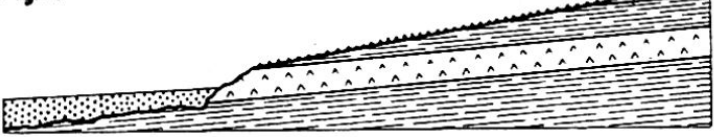

Fig. 22

(n)
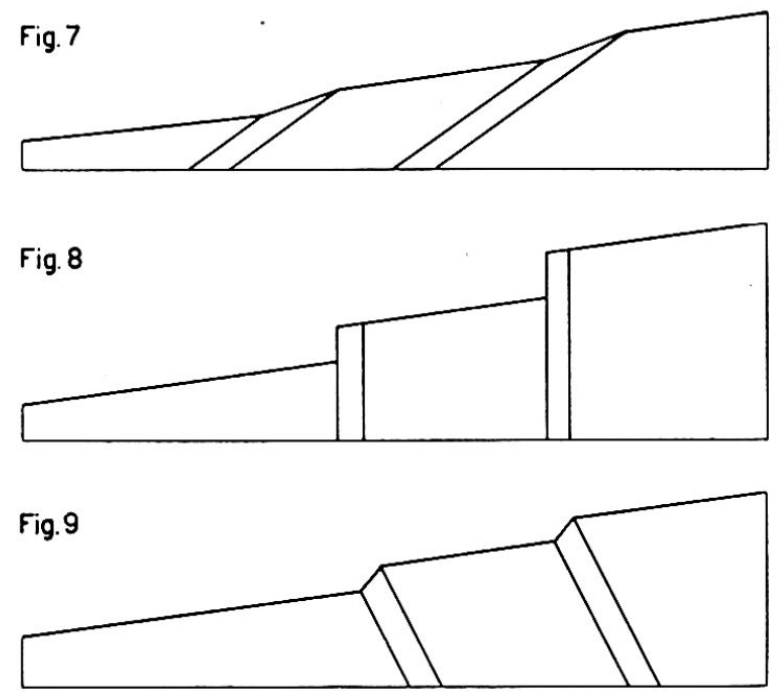

Fig. 16

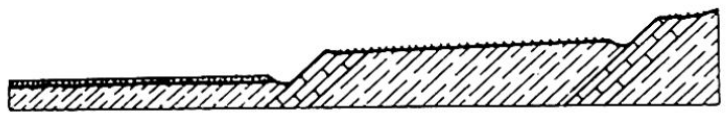

Fig. 17

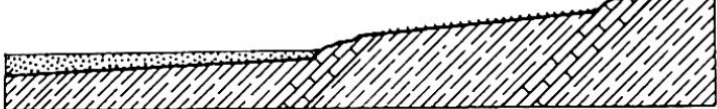

Fig. 18

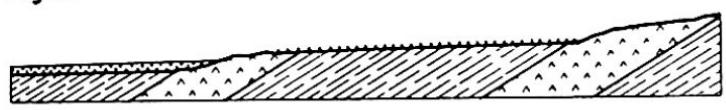

Fig. 19

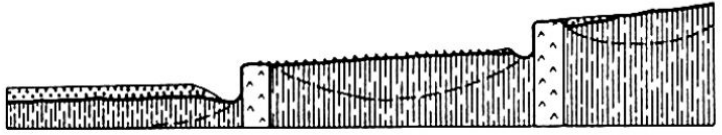

Fig. 20

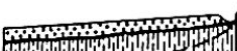

Fig. 21

-

Fig. 23

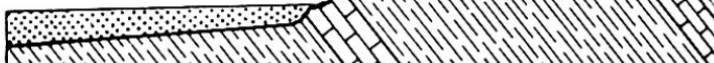

Fig. 24

(1) 
ausufern kann. Durch das Ausufern wird das Gewässerbett verbreitert, das Verhältnis von Umfang zu Querschnitt des Bettquerprofiles vergrößert und damit die Schleppkraft zusätzlich herabgesetzt.

Ein Gewässer, dessen Längsprofil wir untersuchen, kann in seinem eigenen Tal einen Schwemmkegel aufschütten, so unterhalb einer Steile, beim Übergang von einer Engtalstrecke in einen erweiterten Talboden. Durch diesen Vorgang wird aber keine Steile gebildet, sondern im Gegenteil eine schon vorhandene verflacht. Damit eine Schwemmkegelsteile entsteht, muß das Material von einem seitlichen Gewässer aufgeschüttet werden, wenn dieses aus einem Seitental oder aus einer Gehängerinne in den Haupttalboden gelangt. Größe und Form dieser seitlichen Schwemmkegel haben wir in Beziehung zu bringen mit der Breite des Haupttales. Mündet das aufschüttende Gewässer in eine Engtalstrecke, so gelangt der Schutt aus dem Seitengewässer direkt ins Haupttalgewässer. Es sind nun verschiedene Fälle zu unterscheiden. Ist der seitliche Schuttanfall so gering, daß das Haupttalgewässer ihn fortlaufend bewältigen kann, so kann sich nur ein kleiner, unbedeutender Schwemmkegel bilden, der an der Stirne fortlaufend unterschnitten wird. Im Längenprofil des Haupttales wird sich dann keine oder nur eine unbedeutende Treppung ausbilden. Vermag das Haupttalgewässer die Schuttzufuhr nicht zu bewältigen, so wird anfänglich der Schwemmkegel in die Höhe wachsen und das Haupttalgewässer stauen, das dadurch auch zum Akkumulieren gezwungen wird. Der Vorgang strebt einem Gleichgewichtszustand zu. Durch die Stauung wird das Gefälle vom Schwemmkegel an talabwärts vergrößert, so daß in diesem Teil des Kegels die Erosionskraft zunimmt. Der Gleichgewichtszustand ist erreicht, wenn das Gefälle auf dem Schwemmkegel talabwärts so groß wird, daß der Haupttalfluß alles Geschiebe des Seitentales weiterbefördern kann. Dabei ist noch die Größe des seitlich zugeführten Materials zu berücksichtigen. Dieses kann so grobblockig sein (besonders aus steilen Gehängerinnen), daß das Haupttalgewässer sie nicht zu schleppen vermag. Talabwärts wird in diesem Fall das Gefälle bestimmt vom Böschungswinkel des Blockschuttes. Gleichgewichszustände der eben geschilderten Art sind immer sehr labil. Wechsel von Hochwasser und Niederwasser, ja völliger Austrocknung von kleinen Zuflüssen, wobei die Phasen im Haupttal und Zufluß zudem noch verschoben sein können, stören das Gleichgewicht, so daß Höherwachsen, Ruhelage und Erniedrigung solcher Stufen abwechseln.

Im Saasertal stürzt der Schweibbach, der Abfluß des Balfringletschers, über eine Felswand in die Haupttalsohle. Am Fuß der Felswand befindet sich ein steiler Sturzkegel, durchsetzt von Blöcken von einigen Metern Durchmesser. Über diesen fließt das Wasser in kleinen Stürzen und stark verwirbelt auf den eigentlichen Schwemmkegel, der dem Sturzkegel vorgelagert ist. Dieser Schwemmkegel hat die Visp ans rechte Gehänge gedrängt und aufgestaut. Auch im stauenden Schwemmkegel sind sehr große Felsblöcke eingebettet, die wohl von Hochwassern und Muren aus dem Seitental ins Haupttal gelangten und die von der Visp bei gewöhnlichem Wasserstand nicht transportiert werden können. Es handelt sich also hier um eine typische gemischte Akkumulationssteile mit Block- und Schwemmkegelschutt.

Besitzt das Haupttal einen breiten aufgeschütteten Boden, so können sich naturgemäß auch flächenmäßig viel größere Schwemmkegel aufbauen. Mündet ein größeres Seitental, das einen Schwemmkegel bildet, so kann sich ein relativ flacher, aber weitausgedehnter Kegel aufbauen, der den Haupttalfluß, ohne ihn stark zu stauen, ganz ans Gegengehänge drängt.

Im Rhonetal hat bei Sitten die Borgne einen sehr flachen, aber großen Schwemmkegel aufgebaut, der die Rhone zu einer großen Schleife zwingt, aber ohne bemerkenswerte Stauwirkung.

Unbedeutende, wenig schuttführende Seitengewässer bauen am Gehängefuß kleine Schwemmkegel auf, die den breiten Talboden nicht zu sperren vermögen, die also ohne Einfluß auf das Längsprofil bleiben. Wenn aber kleine, meist steilangelegte Sei- 
tentäler viel Schutt führen, vermögen sie, besonders bei Hochwasser, einen so großen Schwemmkegel aufzubauen, daß sie sehr wohl auch einen breiten Talboden sperren können.

So hat oberhalb St-Maurice der Torrent de St-Barthélemy im 1,5 km breiten Rhonequertal das Gefälle der Rhone von 2\%o oberhalb auf 18,2\%o im Bereich der Schwemmkegelsteile gesteigert. Gleich unterhalb daran sinkt das Gefälle wieder auf $4,7 \%$. Die Stufenhöhe beträgt etwas über $20 \mathrm{~m}$ und wird von einem Elektrizitätswerk genutzt.

Wir haben schon angedeutet, daß das Höherwachstum der Schwemmkegel kein stetiges sei und daß daran katastrophenartige Hochwasser maßgebend beteiligt seien. Ein Wildbach wird dann gern zur Mure und kann Blöcke schleppen, die sonst weit über sein Transportvermögen gehen.

L. Collet 12 berichtet von einem Wildbach im Bavonatal (Tessin), der bei einem Hochwasser im Jahr 1903 die Bavona bei Roseto um 2,5 m aufstaute.

Kommt aus irgend einem Grund der Schwemmkegel zur Ruhe (abgestorbener Schwemmkegel), z. B. wenn das Gefälle im Seitental ausgeglichen wird und der Schuttransport klein wird, oder die viel Geschiebe liefernde Gesteinszone ausgeräumt wird, so wird vom Haupttalfluß die Stelle wieder zerschnitten und das Gefälle ausgeglichen, ohne, um das vorwegzunehmen, Aufwärtswandern der Steile.

Beispiele solcher «erloschener» Schwemmkegel, die vom Haupttalfluß angeschnitten wurden, liefert das Goms im obern Rhone- und das Tavetsch im obersten Vorderrheintal.

Fassen wir zusammen: Schwemmkegelsteilen sind an die Mündungen von Seitentälern und Gehängerinnen geknüpft, also örtlich fixiert und von meist unbedeutender Höhe. Wenn sie durch Wildbäche aufgebaut werden, so ist ihr Wachstum unstet, besonders rasch und sprunghaft im Zusammenhang mit katastrophenartigen Ausbrüchen. Der murartige Charakter solcher Bildungen leitet zur nächsten Steilenart, derjenigen aus Massenbewegungen, über. Sie sind im säkulären Talbildungsprozeß mehr oder weniger unbeständige und vorübergehende Hindernisse.

Über die Form und Größe der Schwemmkegel soll bei den Talbodenformen näher berichtet werden.

\section{b) Schuttkegel- und Schutthaldensteilen (Massenbewegung).}

Damit aus einem Gehänge loser Schutt allein durch die Schwerkraft, ohne Hilfe des Wassers, abstürzt oder abrollt, muß es steiler sein als die Böschung von aufgeschüttetem Schutt. Die Maximalböschung trockener Schutthalden hängt von der Materialbeschaffenheit und der Form und Rauhigkeit der Trümmer ab. Sie schwankt nach PIwowaR ${ }^{54}$ von ca. $28^{\circ}$ bei glattbrüchigen und schiefrigen Trümmern bis zu $43^{\circ}$ bei körnigem und massigem Material. Schutthalden setzen also sehr steiles Gehänge voraus. Sie springen wenig vor, bei $28^{\circ}$ Neigung, der kleinsten von PIwowar gemessenen, ist die Horizontaldistanz zwischen dem obern Rand und dem Fuß bei einer $100 \mathrm{~m}$ hohen Halde $180 \mathrm{~m}$, bei $43^{\circ} 104 \mathrm{~m}$. Schuttkegel und Schutthalden sind also eng ans Gehänge gebunden. Ist ein breiter Talboden vorhanden, so beeinflussen sie das Längsprofil des Talflusses nicht. In einer engen Talstrecke kann aber der Schutt bis zum Talgewässer abrollen und wird dieses stauen, also eine Schuttsteile bilden, wenn das Talgewässer den anfallenden Schutt nicht bewältigen kann.

Hier einzuordnen sind der Vollständigkeit halber die Lawinenkegel. Diese an der gleichen Stelle meist periodisch auftretenden Schneerutsche vermögen wohl vorübergehend ein Gewässer zu stauen, können aber leicht durchschnitten werden. Anhaltender wirkt das mitgeschleppte feste Material.

c) Steilen durch anhaltende Gehängerutschungen.

Unter bestimmten Bedingungen können ganze Gehängepartien in anhaltendes Gleiten kommen. Es kann sich dabei um das ganz oberflächliche Gekrieche der Verwit- 
terungsschicht bis zu tiefgreifenden Rutschungen und Sackungen handeln. All diese Rutschungen werden zwar durch ein steiles Gehänge erleichtert, bei starker Durchnässung können aber auch noch weit unter den Maximalböschungen von losem trokkenem Material Rutschungen auftreten. Erreicht die abrutschende Masse das Gewässer im Tal, so kann es zu einer Stauwirkung und einer Steilenbildung kommen.

A. Buxtorf ${ }^{11}, 23, \mathrm{II}_{2} \mathrm{~S} .959$ und 65 , berichtet von zahlreichen Gehängerutschungen im Bündnerschiefergebiet des Safientales, wo vom Westhang mit gleichsinnig einfallendem Schichten ganze Gehängepartien absackten. Durch die tiefgründige Sackung wurde der Talgrund nach Buxtorfs Skizzen weit über $100 \mathrm{~m}$ hoch aufgeschüttet und die Rabiusa nach rechts gedrängt, so daß epigenetische Flußstrecken entstanden. Oberhalb der Sackung wurde durch den Fluß der wohl zuerst entstandene See aufgefüllt, so daß eine Talstufe mit wenig geneigter oberer Flachstrecke entstand.

H. JÄCKLI ${ }^{30,65}$ beschreibt aus dem Hinterrheintal die Casanwaldrutschung, die den Rhein auf eine Länge von $2 \mathrm{~km}$ gegen die südliche Böschung drängt und staut, so daß flußaufwärts junge Aufschüttungen entstanden. Das Gefälle der untern Flachstrecke beträgt 13,3\%o, in der Steile 18,1\%o und in der obern Flachstrecke 13,7\%o.

\section{d) Steilen durch stauende Wirkung des Seitentalgletschers.}

Dringt ein Seitengletscher ins gletscherfreie Haupttal, so wird der Haupttalfluß gestaut, einmal durch das Eis des Seitengletschers, dann aber auch durch dessen Moränenmaterial. Hinter dem stauenden Gletscher bildet sich ein See, der bei langwirkendem Stau mit Schotter, Sand und Schlamm gefüllt werden kann. Solche Steilen können sehr eindrücklich werden, wenn das stauende Hindernis plötzlich durchbrochen wird, der Stausee sich plötzlich entleert und viel Schutt und Schlamm talabwärts bringt.

Das bestbekannte Beispiel in der Schweiz ist wohl die Mattmark im hintern Saasertal im Wallis. Hier staute früher der Allalingletscher das Saasertal, wodurch der Mattmarksee entstand. Mehrmals kam es zu verheerenden Durchbrüchen, bei denen das Haupttal auf über $8 \mathrm{~km}$ mit Schlamm und Gestein überschüttet wurde. Zur Bannung der Gefahr wurde ein Umgehungsstollen gebaut. Heute ist die ehemalige Seefläche völlig verlandet. Die Stufe ist über $100 \mathrm{~m}$ hoch.

e) Endmoränensteilen (Endmoränen des Haupttales).

Bleibt ein Gletscher längere Zeit stationär, so vermag er einen Endmoränenwall aufzuschütten, der das Tal sperrt. Wenn der Gletscherbach diese Endmoräne nicht fortlaufend durchschneidet, so ergibt sich, wenn der Gletscher sich zurückzieht, eine Steile im Längsprofil.

Die systematische Einordnung solcher Gletscherendsteilen bereitet einige Schwierigkeiten. Denn offensichtlich sind an solchen Steilen nicht nur die Endmoräne, sondern auch der Regimewechsel von Glazial- zu fluviatiler Erosion beteiligt. Es sind also wohl immer mehrdeutige Steilen, die nicht durch den lithologischen Befund allein zu erklären sind.

\section{Einmalige oder sehr seltene seitliche Einschüttungen}

\section{a) Bergsturzsteilen.}

Die größten Steilen durch seitliche Einschüttung entstehen durch Bergstürze. Damit wirklich große Massen abstürzen, ist zwar ein hohes Gehänge Voraussetzung. Dieses braucht aber durchaus nicht besonders steil $\mathrm{zu}$ sein. Viel wichtiger sind die Lagerungsverhältnisse des Gesteins. So beträgt bei Goldau das Gefälle im Abrißgebiet $19,5-20^{\circ} 22$.

Die Höhe der Bergsturzsteile ist abhängig einmal von der Masse des abgestürzten Materials, dann aber auch von der Form des Talquerschnittes. In engen Talstrecken vermögen kleine Felsstürze, ja, einzelne große Blöcke, Stauungen von einigen Metern Höhe zu verursachen. 
Da Bergsturzsteilen durch einen sehr kurzdauernden, einmaligen Vorgang entstehen, sind Aufbau und Erniedrigung der Steile zeitlich getrennte Vorgänge. Wie rasch die Erniedrigung erfolgt, hängt von der Erosionskraft des Talgewässers, vor allem aber auch von der Qualität des abgestürzten Materials ab. Als ein Material besonderer Art ist das Eis bei Gletscherabstürzen zu nennen, das aber, wie bei den Lawinenkegeln, nur zu vorübergehenden, wenn auch verheerenden Stauungen des Haupttalflusses führen kann.

Von den unzähligen Bergstürzen, die Steilen verursachten, seien folgende Beispiele herausgegriffen.

Der mächtigste Bergsturz der Alpen, der Bergsturz von Flims, sperrte auf $15 \mathrm{~km}$ das Vorderrheintal. HeIM ${ }^{22,}{ }^{23}$ schätzte das Volumen auf $12 \mathrm{~km}^{3}$. Beim Sturz wurde zwischen den größeren Kalkblöcken das Material zu feinen Splittern und Pulver zerrieben. Der Rhein wurde bis weit talaufwärts aufgestaut. Das bemerkenswerteste für unsere Untersuchung ist das Ergebnis, daß heute diese allergrößte Bergsturzstufe vollständig durchsägt ist. Im Durchbruchtal erheben sich beidseitig des leicht geschlängelten Flusses hohe, fast senkrechte Wände mit Kalkbrocken, alles durch weißschimmerndes Gesteinsmehl verkittet.

Vergleichen wir damit den ungefähr gleichaltrigen Bergsturz von Siders, der aus gleichem Material aufgebaut ist, aber lange nicht so mächtig ist (ca. $3 \mathrm{~km}^{3}$ ), so muß auffallen, daß er nicht auch durch eine Schlucht zerschnitten ist. Wir können diesen Unterschied nur begreifen, wenn wir die Bergsturzstufe im Zusammenhang mit dem riesigen Schwemmkegel des Illgraben betrachten. Dieser Schwemmkegel, der genau am obern Ende der gut $100 \mathrm{~m}$ hohen Steile liegt, und der die Rhone ganz an das linke Gehänge drängt, hat offenbar immer so viel Schutt geliefert, daß die Rhone wohl Material des Bergsturzes mittransportieren, sich aber doch nicht in einer Schlucht in die Bergsturzmasse eintiefen konnte.

Vergleichen wir diese beiden ähnlichen Bergstürze mit demjenigen von Chironico ${ }^{58}$. Hier, in diesem engen Tal wurde zwischen Lavorgo $(618 \mathrm{~m})$ und Giornico $(378 \mathrm{~m})$ eine Bergsturzstufe von $240 \mathrm{~m}$ aufgeschüttet. Im Gegensatz zu den vorherbesprochenen Bergstürzen wurde das Material aber lange nicht so stark zertrümmert. Zwischen dem Feinmaterial liegen mächtige Gesteinstrümmer. Diese sind z. T. so groß, daß F. Rolle auf der ersten geologischen Karte des Gebietes 1:100 000 anstehenden Gneis eintrug. Bei einem Stollenbau zur Ausnützung der Gefällsstufe wurden dann mehrmals Richtungsänderungen notwendig, weil man immer wieder auf Schutt und einbrechendes Wasser stieß, sodaß die wahre Natur der Stufe sehr eindrücklich offenbar wurde. Auch hier muß oberhalb des Bergsturzes zuerst ein See entstanden sein, der aber ganz mit Schutt erfüllt wurde.

\section{Konfluenz- und Diffluenzsteilen}

Der lithologische Befund kann lange nicht alle Steilen erklären. Es gibt offensichtlich noch eine ganze Reihe von Steilen, die mit den Eigentümlichkeiten der Erosionsarbeit verknüpft sind, also durch Unstetigkeiten im Erosionsablauf zu deuten sind.

Eine große $Z$ ahl von Steilen ist mit der Vereinigung von Tälern verknüpft. Hier ändern sich die Verhältnisse in der Wasser- oder Eisführung sprunghaft, so daß auch die Erosionsarbeit sich sprunghaft ändert.

\section{Steilen an der Konfluenz gleichgroßer Täler}

\section{a) Fluviatile Konfluenz.}

Beim Zusammenfluß gleichgroßer Gewässer muß das gemeinsame Bett entsprechend verbreitert und vertieft sein, oder die Geschwindigkeit muß sich verändern, damit die vergrößerte Abflußmenge bewältigt werden kann. Hier in diesem Zusammenhang interessiert uns nur die sprunghafte Bettvertiefung, die aber beim Zusammenfluß von Gewässern morphologisch unbedeutend ist. 


\section{b) Glaziale Konfluenz.}

Fließen zwei ungefähr gleichgroße Gletscher zusammen, so muß bei genau gleichem Verhalten beider Gletscher die Bettvertiefung am Zusammenfluß nach dem Gletscherrückzug am Eingang der zwei Täler als Steile oder Stufe sichtbar werden. $\mathrm{Da}$ aber wohl nur in den seltensten Fällen beide Täler gleichzeitig eisfrei werden, wird der sich später zurückziehende Gletscher das andere Tal sperren, so daß dessen Ausgang mit Stauschottern und Moränenmaterial verstopft wird. Unmittelbar nach dem Gletscherrückzug wird das zuletzt eisfrei werdende Tal die geringere Mündungsstufe besitzen.

Von den vielen mit Moränen verstopften Talmündungen sei das Val d'Entremont (das zum großen St. Bernhard hinaufführt) erwähnt, das bei der Vereinigung mit dem ungefähr gleichgroßen, aber stärker vergletscherten Val Ferret von dessen Gletscher gestaut wurde. Der Bach aus dem Val d'Entremont hat in diese Schuttsteile eine Kerbe geschnitten.

Beim Zusammenfluß von Rhone und Fiescherbach besitzt nur die Rhone eine Steile. Offensichtlich hat bei jedem Gletschervorstoß der viel nähere, aber bei Hochstand schwächere Fieschergletscher zuerst die Konfluenzstelle erreicht. Der später anlangende Rhonegletscher hat dann wohl seine Eismassen auf den Fieschergletscher aufgeschoben. Auch beim Gletscherrückzug war das Goms vom Fieschergletscher längere Zeit gesperrt. Heute ist die glaziale Stufe fluviatil zerschnitten.

\section{Steilen und Stufen an Seitentalmündungen}

Die auffallendsten Steilen und Stufen finden wir in den Alpen an den Mündungen von Seitentälern. Die Stufenmündungen werden geradezu als cin Charakteristikum glazial überformter Täler angesehen. Sie beschränken sich aber sicher nicht nur auf glaziale Täler.

\section{a) Fluviatile Steilen an Seitentalmündungen.}

Wenn die Tiefenerosion im Haupttal rascher vor sich geht als im Seitental, so ist das gleichbedeutend mit einer anhaltenden relativen Hebung des Seitentales inbezug auf das Seitental. Die entstehende Mündungssteile ist umso ausgeprägter, je stärker die Relativbewegung ist. Eine Mündungssteile kann sich auch durch eine kräftige Seitenerosion durch das Haupttalgewässer, durch die das Seitental im Mündungsbereich unterschnitten wird, ausbilden. Steilen und Stufen von Seitentälern können ferner lithologisch bedingt sein. Das Haupttal kann in einer weniger resistenten Gesteinszone liegen als die Seitentäler. Auch die Richtung des Haupttales und Seitentales zum Streichen kann eine Rolle spielen, wenn die Erosionsresistenz längs und quer zu einem Gestein verschieden groß ist.

\section{b) Glaziale Steilen an Seitentalmündungen.}

Bei den glazialen Mündungssteilen haben wir, wie wir schon zeigten, vor allem an Bettstufen zu denken. Ein kleiner Seitentalgletscher benötigt ein viel kleineres und dementsprechend auch weniger tiefes Bett als der Haupttalgletscher. Es ist auch zu beachten, daß ein mächtiger Haupttalgletscher den Seitentalgletscher stauen kann und ihn, je nach Gletscherstand, verschieden hoch über die talabwärtsliegende Eckkarte verschleppt. Glaziale Mündungen sind in Form und Größe, besonders aber auch in der Richtung nicht gleich wie die fluviatilen ${ }^{17}$.

\section{Talschlußsteilen}

Bei einzelnen Tälern rinnt das Wasser im Talursprung in vielen einzelnen, wenig eingetieften Rinnen steiles Gehänge hinunter und sammelt sich in einem weiten, aufgeschütteten Talzirkus, aus dem es mit wesentlich kleinerem Gefälle abfließt. Oft ist der Talzirkus hoch oben von Gletschern eingerahmt, aus denen das Wasser mehr oder weniger flächenhaft abrinnt, und sich erst allmählich in kleine Bäche sammelt. 
Diese obersten Steilen des Tales, die oben in unzerschnittene, weniger geneigte Hochflächen übergehen können, sind offensichtlich erste Sammelstellen des abfließenden Wassers. Wenn häufig das Wasser aus Gletschern (oft kleinen Hängegletschern) stammt, so ist dies ein Hinweis, daß alpine Talschlüsse aus dem Zusammenspiel glazialer und fluviatiler Erosionsvorgänge zu deuten sind.

a) Fluviatile Talschlußsteilen.

Der rein fluviatile Talschluß ist ein Erosionstrichter, in dessen Zentrum die einzelnen steilen Wasserrinnen sich sammeln.

b) Glaziale Talschlußsteilen.

Glaziale Talschlüsse, die ja immer als Folgeformen von fluviatilen Formen aufzufassen sind, sind zu Kesseln oder Zirken erweiterte Erosionstrichter.

Ein sehr eindrückliches Beispiel eines Talschlusses ist der Talzirkus von Breuil auf $2000 \mathrm{~m}$. Der höchste Gipfel des Hochgebirgsrahmens ist das $4478 \mathrm{~m}$ hohe Matterhorn, der tiefste Paßeinschnitt der $3317 \mathrm{~m}$ hohe Theodulpaß. Von den Firn- und Eisfeldern unter den Felsabstürzen fließt das Wasser in vielen einzelnen Rinnsalen über steile, in sich auch wieder gestuften Hänge in den Talkessel von Breuil, wo es in einem Strang gesammelt wird.

\section{Glaziale Diffluenzsteilen}

Wenn von einem Tal aus durch eine Lücke der Umrahmung Eismassen in ein Nachbartal überfließen, so entsteht im Anstieg zur Paßlücke eine Diffluenzsteile. $\mathrm{Ob}$ gleichzeitig auch im Haupttal eine Steile ausgebildet wird, ist denkbar, da durch den Eisverlust eine Querschnittsverkleinerung entsteht, wenn nicht einfach das Eis langsamer fließt. Da aber eine solche Querschnittsverkleinerung, wenn sie sich auch in der Sohle geltend macht, ein Gegengefälle erzeugen würde, so könnte dieses nur durch eine seismische Untersuchung nachgewiesen werden, da die auf den sich zurückziehenden Gletscher folgende glaziale und fluviatile Zuschüttung die Steile verdecken würde.

Sehr schöne Beispiele glazialer Diffluenzsteilen sind der Ceneri im Tessintal und der Brünig im Aaretal.

\section{Steilen als Normalerscheinung des Gletscherbettes? und Steilen bei Regimewechsel}

\section{Steilen im Gletscherbett}

Der vom Gletscher verlassene Talboden zeigt ein außergewöhnlich unregelmäßiges Längsprofil. Tiefe Becken im breiten Talboden wechseln mit Schwellen und Engstellen. Ein eingehendes Studium erweist vielleicht viele der Schwellen als Resistenzstellen, andere als durch Konfluenz bedingt. Und doch scheinen Becken und Schwellen übrig zu bleiben, die so nicht geklärt werden können. Diese Bettun regelmäßigkeiten, ein mehr oder weniger regelmäßiger Wechsel von Stufen und Steilen mit wannenartig übertieften Flachstrecken wird von einzelnen Autoren als die natürliche, normale Längsprofilausgestaltung angesehen. Nach DE MARTonne ${ }^{39}$ ist das profil d'équilibre glaciaire (Fig. 38, S. 207) stark gewellt, ja getreppt mit Wannen in den Treppenabsätzen. Hier sei auf diese Bildungsmöglichkeit vorderhand nur hingewiesen. Wir kommen später nochmals darauf zurück.

\section{Steilen beim Regimewechsel}

Wir haben dort den Faden wieder aufzunehmen, wo wir von Endmoränensteilen schrieben. Am Ende eines Gletschers werden nicht nur Moränen aufgeschüttet, es findet auch ein Regimewechsel statt. Dies kann nicht ohne Einfluß auf die Gefällsverhältnisse im Längsprofil sein.

Wenn der Gletscher seine abschleifende Wirkung über eine sehr große Fläche verteilt, so vermag sich das Wasser, das aus dem Gletscher abfließt, in einem verhält- 
nismäßig sehr engen Bett zu sammeln. Das Gletscherende ist dann einer Talschlußsteile $\mathrm{zu}$ vergleichen, bei der sich auch verschiedene Rinnsale zu einem geschlossenen Gewässer sammeln. Ausschlaggebend ist der Schuttanfall. Ist die Geschiebemenge kleiner, als die Transportkraft des Gewässers, so vermag das Gewässer am Gletscherende $\mathrm{zu}$ erodieren, sodaß eine Steile entsteht.

\section{Krümmungs-, Anzapfungs- und Versickerungssteilen}

\section{Krümmungssteilen}

In Krümmungen des Tales treten durch die Zentralbeschleunigung andere Erosionsbedingungen auf als in geraden Strecken. Die Seitenerosion wird zu Ungunst der Tiefenerosion erhöht.

a) Fluviatile Krümmungssteilen.

In Gerinnen mit beweglicher Sohle stellt sich durch den Einfluß der Krümmung eine Erhöhung des Gefälles ein, damit der Energieverlust durch die Krümmung ausgeglichen werden kann. Diese im Wasserbau ${ }^{45}$ nachgewiesenen Gefällsschwankungen in Krümmungen sind aber morphologisch von geringer Bedeutung.

b) Glaziale Krümmungssteilen.

$\mathrm{Ob}$ auch bei Glazialerosion Krümmungen zu Gefällsveränderungen Anlaß geben, ist noch nie näher untersucht worden.

Viele Steilen der Alpentäler fallen mit Richtungsänderungen zusammen, so der Absturz des Rhonegletschers in den Gletschboden und daran anschließend die Stufe aus dem Gletschboden ins Goms hinunter. Da aber mit Richtungsänderungen oft auch lithologische Änderungen verknüpft sind, sind die reinen Krümmungseinflüsse wohl sehr schwer abzuschätzen.

\section{Anzapfungssteilen}

Wird ein Tal von einem Nachbartal angezapft, so entsteht eine Anzapfungssteile. Das frisch angezapfte Gewässer hat dann im Oberlauf ein verhältnismäßig kleines, vielleicht sogar ein ausgeglichenes Gefälle und im Bereich der Anzapfung den Gefällsbruch.

Als eine Anzapfung besonderer Art kann der Durchbruch durch eine Mäanderschlinge hier eingeordnet werden, wodurch im eigenen Flußbett eine Steile entsteht.

\section{Versickerungssteile}

Versickert in einem Gerinne Wasser, so vermag der verminderte Wasserfluß das Geschiebe nicht mehr zu bewältigen. Es wird im Versickerungsbereich so lange akkumuliert, bis unterhalb dieser Stelle das erhöhte Gefälle das Geschiebe transportieren kann.

\section{Tektonische Steilen}

Alle Steilen, die wir in unsere Steilensystematik eingeordet haben, sind durch exogene Kräfte und Vorgänge entstanden. Die exogenen Kräfte, die bei der Steilenbildung im Spiele sind, die Erosion durch Wasser und Eis und die Massenverlagerung durch die Schwerkraft setzen aber, wie wir schon in der Einleitung mit dem Zitat von R. Stau z zeigten, endogene Vorgänge voraus. Wenn wir also in unserer Steilensystematik den exogenen Steilen nicht endogene Steilen oder tektonische Steilen gegenüberstellten oder sogar einordneten, dann eben, weil tektonische Vorgänge die Grundbedingung überhaupt aller Steilenbildung sind, weil in einem weitern Sinn alle Steilen tektonisch bedingt sind.

Sowohl Resistenzsteilen wie Akkumulationssteilen sind örtlich gebunden. Resistenzsteilen sind mit ganz bestimmten lithologischen Verhältnissen verknüpft und können nur in Erosionsstrecken entstehen und sich erhalten. Akkumulationssteilen können zwar in jeder beliebigen Stelle des Längsprofiles, sowohl in Akkumulationsstrecken 
wie in Ersosionsstrecken entstehen, sie setzen aber doch genügend Gefälle der $\mathrm{Zu}$ flüsse und des Gehänges voraus, auch können örtlich umgrenzte besondere Materialverhältnisse eine rasche seitliche Aufschüttung, das Abstürzen oder Abgleiten, begünstigen.

Tektonische Vorgänge aber können in jeder beliebigen Stelle des Längsprofiles tiefgreifende Veränderungen der Form des Längsprofiles hervorrufen. Es kann eine rein exogen betrachtet endgültige Akkumulationsstrecke neu belebt und wieder in eine Erosionsstrecke verwandelt werden, es kann ein Gehänge eine neue Neigung oder ein Zufluß ein neues Gefälle erhalten. Tektonsiche Vorgänge, die an sich keine Steile hervorrufen - d. h. keinen Wechsel von Flach- und Steilstrecken erzeugen sondern z. B. durch eine großräumige Aufwölbung in einzelnen Tälern das Gefälle vergrößern, können dazu führen, daß Resistenzsteilen wieder neu belebt oder neu gebildet werden, daß Bergstürze oder Gehängerutschungen ausgelöst werden. Es kann aber auch durch relatives Rücksinken eine Erosionsstrecke in eine Akkumulationsstrecke übergeführt werden.

Wir haben also zu unterscheiden zwischen tektonischen Vorgängen, die direkte Steilen bilden, die wir dann tektonische Steilen im engern Sinn nennen können - z. B. Verwerfungen quer zum Tal und in standfestem Gestein - und tektonischen Vorgängen, die die exogenen Vorgänge so anregen, daß durch diese neue Steilen gebildet werden, die wir tektonische Steilen im weitern Sinne nennen können.

Nun ist aber nicht zu übersehen, daß in den Alpen mit den ständig Wasser und viel Geschiebe führenden Flüssen, aber auch mit der ständig fortschreitenden Verwitterung, alle tektonischen Steilen nach, meist aber wohl sogar während ihrer Entstehung exogen umgestaltet werden. Auch dort, wo tektonische Steilen im engern Sinn entstanden sind, werden wir diese in den Alpen meist nicht unverändert und an den Entstehungsort gebunden antreffen.

Tektonische Steilen werden verwandelt und verlagert. Dies ist eine alte Prämisse der Alpenmorphologie und auf ihr beruht auch die Steilenwanderungstheorie, die annimmt, Hebungen am Alpenrand seien als Steilen talaufwärts viele Kilometer weit ins Alpeninnere verlagert worden, ohne daß dabei die Steilenform grundsätzlich verändert worden sei. Daß Gefälle verlagert wird, ist eine unbestrittene und unbestreitbare Tatsache. Ob diese Verlagerung allerdings nur in der Form der Steilenwanderung vor sich geht, wird in dieser Arbeit nicht als gesichert angenommen. Den Ausgleichvorgängen an Steilen, der Gefällsverlagerung, aber auch der Neubildung von Steilen wird im folgenden unsere ganze Aufmerksamkeit gehören.

\section{DER AUSGLEICH UND DAS WANDERN VON STEILEN}

In der Systematik wurden die Steilen vor allem statisch-beschreibend aufgezählt, die ruhende Form, die Formmöglichkeiten standen im Vordergrund. Steilen sind aber, wie schon eingangs betont wurde, Unregelmäßigkeiten im Längsprofil, die im Verlauf der weitern Talentwicklung bei tektonischer Ruhe und rein fluviatilen Erosionsvorgängen unter gleichen klimatischen Bedingungen ausgeglichen werden. Diesen Ausgleichsvorgängen, der Umformung von Steilen haben wir uns nun zu widmen. Daß diese dynamische Betrachtungsweise weit schwieriger ist, ist leicht einzusehen. Zwar ist der Ausgleichsvorgang an sich eine logisch gesicherte Annahme, wie er sich aber abspielt, darüber sind wir recht wenig unterrichtet. Denn die Vorgänge spielen sich meist so langsam ab, daß der einzelne Mensch sie nicht direkt beobachten kann, ja, für die meisten dieser Vorgänge würde sogar die Zeit der ganzen Menschheitsgeschichte nicht ausreichen. Fast alle Steilen sind für den planenden Menschen örtlich fixiert. Wir können uns also den Ausgleichsvorgang nur durch Kombination aus vielen kleinen, oft recht zufälligen Beobachtungen zurechtlegen. Dieses Vorgehen hat bis jetzt noch zu keiner gesicherten Theorie geführt. Wir befinden uns immer noch 
im Stadium der Lehrmeinungen, der Hypothesen und Spekulationen, und Hypothesen und Spekulationen werden wir auch immer brauchen müssen, wenn wir über das Offensichtliche zu tiefern Zusammenhängen vorstoßen wollen. Dies muß uns für das Folgende bewußt bleiben. So machen denn auch die hier vorgetragenen Ideen, die sich auch wieder nur auf Kombinationen von vielen einzelnen Beobachtungen und einige aufschlußreiche Experimente stützen, durchaus nicht den Anspruch auf endyültige Lösung des Problems, ihr hypothetischer, ja spekulativer Charakter sei hier ausdrücklich betont. Sie haben aber ihren $Z_{\text {weck }}$ erreicht, wenn sie dazu beitragen, den Glauben an allzu einfache und schematische Lehrmeinungen zu erschüttern, und wenn sie dazu führen, den immer wieder notwendigen Weg zu beschreiten, nämlich die Grundlagen zur weitern Forschung zu verbreitern und zu vertiefen, um den Spekulationen und Hypothesen ein besseres und tragfähigeres Fundament zu geben.

\section{Die klassische Steilenwanderungstheorie}

Als Grundlage vieler morphologischer Arbeiten dient immer noch eine Lehrmeinung, die wir die Steilenwanderungstheorie nennen wollen. Wir lassen am besten die Verfechter dieser Theorie selbst sprechen.

SöLch ${ }^{60}$ schreibt in seinem «Fluß und Eiswerk in den Alpen» in einem besondern Abschnitt: Zur Theorie des Aufwärtswanderns der Gefällssteilen:

«Der für die Auffassung einfachste Fall unserer Theorie wäre wohl der, daß ein Gebirgskörper an einer lotrechten Verwerfung über das Vorland aufsteigt und zwar mit einem Ruck (dieser Ausdruck darf natürlich nicht wörtlich genommen werden).» Es entsteht dann ein Wasserfall, «der mit der Zeit von einer Kerbe abgelöst wird, deren Scheitel aufwärts wandert.» «Kerbenscheitel, Kerbe und neuer Talboden steigen hintereinander in das Gebirge hinauf.» «Erfolgen nun mehrere solche Rucke hintereinander..., so wird jedesmal zuerst das ältere Tal von unter her zerschnitten....», «andauernd bedeutet die Erosionsbasis am Gebirgsrand den Hauptregler der 'Tiefennagung, aber die jeweilige Erosion an einem bestimmten Punkt des Flusses wird bestimmt durch den nächsten unterhalb gelegenen Kerbenscheitel. Zwischen je zwei Kerbenscheitel spannt sich ein Stück Gefällskurve des Flusses zusammen.» Als Hauptergebnis faßt er zusammen:

«1. Die jüngern Taleinschnitte sind in die ältern eingeschachtelt und laufen nach oben hin spitz in diese aus.

2. Die Talböden der ältern Talgeschlechter laufen über dem Vorland «in die Luft aus».

3. Die einzelnen Einschnitte wandern hintereinander, bei genügend langer tektonischer Ruhe müssen die jüngern Kerbenscheitel die ältern im Quellgebiet nahezu einholen. Im ganzen ergibt sich so eine Folge von stockwerkartig übereinander gelegenen Flächensystemen.»

«Derartige Gedankengänge sind schon vor Jahr und Tag von RüTIMEYeR und von HerM entwickelt worden, traten dann aber ganz in den Hintergrund.»

MachatscheK schlo $B$ sich in seinem Beitrag zu Supan «Die Arbeit des fließenden Wassers 39 ganz der Ansicht von SöLch an. Es ist nicht uninteressant, in Kendes Handbuch 60 a SöLchs Beitrag von 1914 nachzulesen: "So entwickeln sich aus Wasserfällen nach und nach Kaskaden, Katarakte und Stromschnellen, bis auch sie zuletzt gänzlich verschwinden. Alle Wasserfälle sind daher vergänglich....»

Auch Mortensen 42, S. 53 schreibt: «Mit dem Begriff rückschreitende Erosion soll ausgedrückt werden, da $B$ jeder Flu $\beta$ das Bestreben hat, seine Quelle und auch z. B. irgendwelche nicht lokal gebundene Gefällsversteilungen flußaufwärts, d. h. also rückwärts, zu verlegen.» «Als Beispiel einer rückwärtswandernden Gefällsversteilung sei der Niagarafall erwähnt, der bekanntlich jedes Jahr etwa $1 \frac{1}{2}$ m zurückwandert.»

Experimentell scheint die rückschreitende Erosion direkt beobachtbar, denn MaUli 40 schreibt über Versuche im feinsandigen Strand: «Das streckenweise Tieferlegen einer solchen Rinne führt zu einer Belebung des Miniaturoberlaufes, an dem sich die rückschreitende Erosion zusehends einfrißt.» Die Vorstellung der Stufenwanderung scheint so sichergestellt, da $\beta$ sie einer der Grundpfeiler einer ganzen Reihe morphologischer Arbeiten ist. Einige willkürlich herausgegriffene Veröffentlichungen seien hier erwähnt.

1914 hat O. Lehmann 33 für das. Wandern der Stufen in der Adamellogruppe eine fluviatile Verspätungsregel aufgestellt.

1927 haben Machatschek und STAUB 37 in einer Profilzeichnung unterhalb einer Stufe einen alten Talboden eingezeichnet. $1931 \mathrm{nahm}$ O. Hess 28 die Vorstellung der Steilenwanderung in einem Aufsatz über die Normalkurve und die Erosionsterminante als gesichert an. 1935 zeichnete F. GYGAX 20 vom Verzascatal entsprechende Längsprofile (s. S. 208). 1936 führte An Naheim 3 
den Begriff Rückschneidungskœffizient (s. o. LEHMAnN, wir werden später auf diese Begriffe nochmals kritisch zu sprechen kommen) ein. 1941 versuchte A. BöGLI9 die Steilenwanderung im Goms nachzuweisen. 1945 schrieb F. Nussbaum 48: «Die rückschreitende Tiefenerosion, durch welche das erste interglaziale Tal gebildet wurde, vermochte nicht bis in die allerhöchsten Talabschnitte zu gelangen ....» 1946 veröffentlichte $H$. ANNAHEIM 4 seine Geomorphogenese der Südalpen, in welcher für das Rückschreiten der Steilen in zwei sich trennende Täler der Rückschrittsquotient eingeführt wurde.

1954 schrieb F. AHNERT 1: «Die Lehre von der rückschreitenden Erosion hat in der Morphologie vielfache Früchte getragen; das Aufwärtswandern von Gefällsbrüchen im Flußbett, der Stufenbau der Alpentäler und manches andere werden mit ihr zwangslos erklärt.»

Diese Auswahl von Arbeiten, in denen der Begriff Steilenwanderung verwendet wird, reicht von RüTIMEYER ${ }^{56}$, der 1869 publizierte, über bald 90 Jahre bis in die Jetztzeit. Es scheint doch, daß in dieser langen Zeit intensiver Talbildungsforschung die Steilenwanderungstheorie immer besser ausgebaut worden sei und durch Tatsachen in Sicherheit gewonnen habe. In Wahrheit ist dies aber in nur geringem Maß der Fall. Neues Tatsachenmaterial oder gar Versuche zur Stützung der Theorie liegen nicht vor. Das Vertrauen in die Idee scheint zu genügen. Selbstverständlich ist diese nicht aus der Luft gegriffen, Bäche, die sich einschneiden und ihr Gefälle rückwärts verlegen, kleine Gerinne im Sand, bei denen eine Steile aufwärts wandert (MAULL) und dann vor allem das Großbeispiel des Niagarafalles, der Jahr für Jahr sichtbarlich und meßbar zurückwandert, sind Stützen dieser Idee. Aber es soll gezeigt werden, $\mathrm{da} \beta$ sie nicht genügen und $d a \beta$ notwendigerweise vorerst einmal die Grundlagen gefestigt werden müssen, bevor darauf weitergebaut werden darf.

Es fehlt auch nicht an indirekten Beweisversuchen für die Steilenwanderung. Mit ihnen wollen wir uns vorerst auseinandersetzen. O. LeHMANN ${ }^{33}$ hat in seiner Arbeit über die Adamellogruppe von «Gesetzmäßigkeiten, mit denen sich eine talaufwärtsschreitende, ruckweise begonnene Tiefenerosion in den Seitentälern fortpflanzt», gesprochen. Es «entstehen, nachdem der Gefällsbruch, der im Haupttale die Vertiefung nach oben begrenzt, die Mündung der Seitentäler passiert hat, daselbst auch Gefällsbrüche». Je weiter oben im Haupttal ein Nebental mündet, umso später wandert in ihm der Gefällsbruch aufwärts. Es zeigt sich, «daß es bei der Fortpflanzung eines Gefällsbruches mit Vertiefung die Wassermasse ist, durch die vor allem die Geschwindigkeit des Emporgreifens der Erosion positiv bedingt wird». Die Geschwindigkeit ist also abhängig von der Tallänge. LeHMANN zeigt dann bei der Besprechung der Einzelfälle an Hand von 4 Tabellen, daß die Gesetzmäßigkeiten durch allerlei Einflüsse, verschiedene Gesteinsarten vor allem, gestört werden können.

1937 ist aber LeHMANN ${ }^{34}$ von der Steilenwanderungstheorie völlig abgerückt. Er legte dar, daß eine Steilenwanderung über viele Kilometer, wie sie SöLch postuliert hatte, und wie sie als spekulative Annahme von den vielen andern zur Erklärung von Steilen beigezogen worden war und bis heute wird, in dieser allgemeinen Form gar nicht stattfindet. $\mathrm{Zu}$ seinen in der Adamellogruppe festgestellten Gesetzmäßigkeiten bemerkt er: «Als ich einst in der Adamellogruppe Trogschlüsse als präglaziale emporgewanderte Stufen deutete, die durch eine tektonische Steilheit am Gebirgsrande entstanden waren, habe ich die Auffrischung dieser Stufen unterhalb an der TonalitSchiefergrenze für wichtig angesehen, damals ohne Kenntnis der hydraulischen Ergebnisse. Wo aber der Tonalitrand 6-8 $\mathrm{km}$ vom Trogschlu $\beta$ entfernt war, wollte mir dieser Abstand schon als sehr reichlich erscheinen, im Hinblck darauf, daß 300-400 m hohe Stufen in «aufgefrischter»Form noch so weit gewandert sein sollten. Niemand hat mir seither entgegengehalten, da $\beta$ diese Annahme willkürlich war. Ich hatte allerdings die Lage der Trogschlüsse bis in die kleinsten Nebentäler hinein nach einer fluviatilen Verspätungsregel mit scheinbar befriedigendem Erfolg überprüft.»

Es ist bemerkenswert und stimmt nachdenklich, da $\beta$ in all den vielen Arbeiten, die ich eingesehen habe und die nach. 1937 publiziert wurden, und die die Steilenwanderungstheorie als gesicherte Grundlage verwenden, wohl SöLch und z. T. der sehr 
fragwürdige Gogarten zitiert werden, dessen haltlose Ergebnisse vom sehr gründlichen und zuverlässigen OBERHOLZER ${ }^{49}$ * schon 1933 verurteilt wurden, die Arbeit von LEHMANN von 1937 aber fehlt, trotzdem dieser nicht an einer versteckten Stelle publiziert hatte. LeHMANN ist also nicht widerlegt worden, seine Schrift bleibt lesenswert.

Annaheim hat, in etwas veränderter Form, die Idee von Lehmann über das Wandern von Steilen in verschiedenen Tälern übernommen, zuerst in seiner Arbeit über das Luganerseegebiet 1937 unter dem Namen Rückschneidungskœffizient, 1946 in seiner Geomorphogenese der Südalpen als Rückschrittsquotient. Hier wird wohl Lehmanns Adamelloarbeit zitiert, die Arbeit von 1937 ist aber offensichtlich übersehen worden.

Nach der Vorstellung von Annaherm ${ }^{3,4}$ ist die Geschwindigkeit des Wanderns einer Steile einzig abhängig von der Tallänge. Wandert eine Steile über eine Konfluenzstelle weg, so teilt sie sich hier. In den Einzeltälern wandert sie umso schneller aufwärts, je länger das Tal ist. Er bildet deshalb den Quotienten $q=\frac{a \cdot 100}{b} \%$, wobei a der Abstand der Steile von der Konfluenzstelle, b die ganze Tallänge von der Konfluenzstelle bis zum Quellgebiet bedeutet. Je zwei konfluierende Täler bilden so ein Paar, dessen Rückschnittsquotienten gleiche Werte ergeben müssen. AnNaheisi hat für eine Reihe von Tessinertälern eine Tabelle veröffentlicht, aus welcher die sehr auffallende Übereinstimmung klar hervorgeht, und so benützt er denn auch diese Zahlen als eine Stütze für die Steilenwanderungstheorie.

$Z_{\text {wei }}$ Beispiele aus dieser Tabelle sollen das Berechnungsverfahren und das zugrundeliegende Zahlenmaterial zeigen.

1. Gaggio (Val Bavona)-Bignasco: Tallänge (b) $20 \mathrm{~km}$, Rückschnitt (a) $14 \mathrm{~km}$. Rückschnittsquotient $\mathrm{q}=\frac{14 \cdot 100}{20} \%=70 \%$.

1. Casone (Val Lavizzara)-Bignasco: b $27 \mathrm{~km}$, a $20 \mathrm{~km}, \mathrm{q} 74 \%$ Rückschnittsquotientenpaar: $70 \%$ und $74 \%$.

3. $1500 \mathrm{~m}$ in Val Redorta-Sonogno: b $6 \mathrm{~km}$, a $4 \mathrm{~km}, \mathrm{q} 67 \%$.

3. Corte di Fondo (Val Vigornesso)-Sonogno: b $9 \mathrm{~km}$, a $6 \mathrm{~km}, \mathrm{q} 67 \%$ Rückschnittsquotientenpaar $67 \%$ und $67 \%$.

Da Zahlen, wenn ihr Wert einwandfrei feststeht, von besonderer Beweiskraft sind, soll diese Tabelle einmal kritisch betrachtet werden.

Rechnen wir vorerst die Quotienten auf Grund der vorhandenen Zahlen nach, so ergibt sich, mit einer Ausnahme, wie das nicht anders zu erwarten war, deren Richtigkeit. Bei Steilenpaar 4 beträgt der Quotient für das Misox nicht 74\%, sondern $71 \%$. Dieser Wert stimmt mit dem der Leventina genau überein.

In der Tabelle sind die Zahlengrundlagen zur Berechnung der Quotienten die Tallänge und die Rückschnittslängen. Sie sind durchwegs in ganzen Kilometern angegeben. Das heißt nun nichts anderes, als daß die Meßgenauigkeit $0,5 \mathrm{~km}$ beträgt. Der Rückschnittsquotient gibt nun an, wieviel \% der Tallänge die Steile vom gemessenen Talanfang zurückgeschritten ist. $1 \%$ der Tallänge beträgt im günstigsten Fall, bei der Leventina, $690 \mathrm{~m}$, überschreitet also um einiges die Meßgenauigkeit. Im ungünstigsten Fall, beim Val Redorta (Verzasca) beträgt aber $1 \%$ nur $60 \mathrm{~m}$, trotzdem wird auch hier auf die Übereinstimmung bis auf $1 \%$ Gewicht gelegt. Es wird also aus dem Quotienten mehr herausgelesen, als auf Grund der Meßgenauigkeit zulässig ist.

Es frägt sich nun, ob nicht einfach die Meßgenauigkeit verbessert werden könnte. Eine Nachprüfung auf der Karte zeigt aber sofort, daß dies kaum möglich ist. Die

* Ich habe 1951 erneut auf Oberholzer hingewiesen: «Zum Problem der alpinen Talterrassen 》. S. $131-13518$. 
Hauptschwierigkeit besteht in der genauen Festlegung des Talanfangs. Welcher Punkt ist maßgebend? Dann frägt sich, wie weit jede Biegung des Tales zu berücksichtigen ist, denn die Tallänge ist nicht die Flußlänge. Messen wir unter mehreren Malen Tallängen, so ergeben sich Abweichungen von mindestens $0,5 \mathrm{~km}$. Die gleiche Unsicherheit gilt für die Festlegung der Steilenkante, da diese durchaus nicht immer so scharf ausgeprägt ist, wie sie es nach den idealen Vorstellungen der Steilenwanderungstheorie sein sollte. Wenn wir diese Meßunsicherheit berücksichtigen und mit verschiedenen, gleichberechtigten Meßwerten den Quotienten ausrechnen, so dürfen diese bei kurzen Tälern höchstens auf $10 \%$, bei sehr langen auf 1-2\% genau angegeben werden.

Viel größer als die Unsicherheit der Meßgenauigkeit ist aber diejenige der Auswahl der richtigen Steile. Wenn es sich doch um die fluviatil zurückverlegte Steile handelt, so darf zur Steilenlage nur eine Steile oder Stufe des Flußlängsprofiles verwendet werden. Z $Z_{\text {wei }}$ der von Annaheim herangezogenen Formen entsprechen aber nicht dieser Bedingung. Da ist einmal Stalvedro zu nennen. Hier handelt es sich um eine örtlich bedingte Talbodenverengung, ursprünglich sicher um eine Härtestufe, die aber völlig durchsägt ist. Das Flußlängsprofil weist hier keine auffallende Stufung auf. Wie J $\ddot{A C K L I}{ }^{31}$ schon gezeigt hat, handelt es sich um einen Härteriegel steilstehender Gneise der Lucomagnodecke zwischen Rauhwacke mit Gips der Trias im Norden und Bündnerschiefern im Süden. Dieser Riegel kann, nachdem er durchschnitten ist, nicht weiter wandern, als Talverengung wird er aber stehen bleiben. Ebenso besteht beim Grumascio im Bleniotal keine Stufe des Flusses. Die nächste Flußstufe finden wir erst kurz vor Olivone. Der Grumascio ist ein dem Gehänge vorgebauter Hügel, der mit einer Wanderstufe nichts zu tun hat.

Endlich ist auffallend, daß die Werte der Quotienten der «Pu-Vollformen» alle zwischen 60 und $74 \%$ liegen. D. h. nichts anderes, als daß alle Steilen dieser Form im obern Drittel der Täler liegen. Wir werden später noch zeigen, daß dieses obere Drittel das Idealgebiet der Stufungsmöglichkeit ist, d. h. daß in diesem obern Drittel überhaupt am meisten Stufen vorhanden sind. In diesem Stufenoptimum hat es genügend zur freien Auswahl, die «richtige» ist diejenige, welche den besten Quotienten ergibt.

In der Beurteilung und Auswahl von Terrassen und Steilen sind Zirkelschlüsse leicht möglich. Der eine lautet: Eine Terrasse ist eine echte Eintiefungsterrasse, wenn sie einen bestimmten Abstand von einem höhern oder tiefern System aufweist (Abstandstypik von AnNAHerm). Sehr schön ausgebildete Terrassen müssen einem System angehören, folglich ist der Abstand zweier schön ausgebildeter Terrassen für zweifelhafte Fälle maßgebend, oder entsprechende Steilen haben gut übereinstimmende Rückschnittsquotienten, folglich sind Steilen entsprechend, wenn sie gleichen Rückschnittsquotienten haben. So ausgewählte Steilen können dann wieder für die Bestimmung guter Terrassen maßgebend werden und einen Anhaltspunkt für die Abstandstypik abgeben usw.

Endlich sind für die Bildung der Rückschnittsquotienten noch grundsätzliche Bedenken anzuführen. Es ist nicht einzusehen, weshalb für den Rückschnitt einzig die Tallänge, und nicht auch die Einzugsfläche maßgebend sei. Beim Talpaar LeventinaBlenio trifft es beim Tessin auf $1 \mathrm{~km}$ Tallänge $8,2 \mathrm{~km}^{2}$ Einzugsgebiet gegen $11,2 \mathrm{~km}^{2}$ beim Brenno, beim Talpaar Calanca-Misox lauten die Zahlen $8,2 \mathrm{~km}^{2}$ und $5,3 \mathrm{~km}^{2}$, bei Leventina-Misox 14,5 $\mathrm{km}^{2}$ und $11,7 \mathrm{~km}^{2}$, beim Talpaar Bavona-Lavizzara heißen die Werte $6,1 \mathrm{~km}^{2}$ und 7,2 $\mathrm{km}^{2}$. Dies sind immerhin beachtenswerte Unterschiede.

Aus allen diesen Gründen können wir der Übereinstimmung von Rückschnittsquotientenpaaren keine große Bedeutung zulegen. Sie kann auch nicht als Beweis für die Steilenwanderung gelten. 


\section{Experimentelle Beobachtung von Ausgleichsvorgängen und rasche Vorgänge in der Natur}

Einen Einblick in die Ausgleichsvorgänge an Steilen können wir von Experimenten erwarten. Für Experimente, die sich quantitativ auswerten lassen, braucht es Laboratorien, die einem Morphologen kaum zur Verfügung stehen. Immerhin lassen sich auch mit bescheidenen Mitteln sehr instruktive Versuche machen, die qualitativ beweiskräftig sind.

Ich habe in einer $21 / 2 \mathrm{~m}$ langen Rinne aus wieder angefeuchtetem Opalinustonpulver* aus einer Tonwarenfabrik Steilen zwischen zwei Flachstrecken modelliert und darüber einige Minutenliter Wasser in einer vorgeformten Rinne fließen lassen. Das Längsprofil habe ich jeden Tag ausgemessen. Ein einzelner Versuch lief 8-10 Tage. Gleich angelegte Versuche habe ich in reinem Sand wiederholt. In diesem viel weniger kohärenten Material vollzieht sich der Ausgleich jeweils in wenigen Minuten.

Die Versuche in Ton verliefen alle übereinstimmend so, daß beim Ausgleichsvorgang die scharf modellierte Oberkante bald abgeflacht wurde und dadurch das Gefälle der obern Flachstrecke von der Steile her zunehmend und immer mehr in diese übergreifend vergrößert wurde. Bei der Steile waren zu unterscheiden wenig geneigte Steilen und Stufen. Bei den Stufen, vor allem bei den Wandstufen, bildeten sich am Fuß rasch Kolke aus, die so wirksam wurden, daß sie die Stufe selbst unterschnitten und zum Nachbrechen brachten. Dadurch blieb der untere Teil der Stufe in seiner Steilheit erhalten und wanderte auch langsam talaufwärts, aber unvergleichlich langsamer, als die Gefällsversteilung in der obern Flachstrecke an Länge zunahm. Der Kolk blieb nur am jeweiligen Fuß der Stufe erhalten und wurde weiter abwärts beim Aufwärtswandern fortlaufend wieder aufgefüllt. Die untere Flachstrecke erhält dadurch durch Akkumulation eine Deckschicht. Bei sehr flachen Steilen wanderte der Steilenfuß nicht zurück. Die ganze Steile wurde von oben her abgerundet und in die obere Flachstrecke hinein abgeflacht und in die Länge gezogen.

Bei den sehr rasch ablaufenden Ausgleichsvorgängen im Sand lief die Stufe sehr rasch aufwärts, wobei sie nur dadurch als Stufe erhalten blieb, daß sie an der Frontfläche fortwährend steil nachbrach. Gleichzeitig aber fand eine Eintiefung in der obern Flachstrecke von der Oberkante der Steile her statt, die zu einer Versteilung dieser Flachstrecke führte. Da sehr viel Sand mitgeführt wurde, kam es am Steilenfuß trotz des Steilabsturzes nicht zu einer Kolkbildung, vielmehr wurde der Sand am Steilenfuß als Schwemmkegel abgelagert.

Rein qualitativ lassen sich die Ergebnisse kurz folgendermaßen zusammenfassen:

1. Von der Steile her wird die Erosion in der darüberliegenden Flachstrecke angeregt, so da $\beta$ die Oberkante abgerundet wird und das Gefälle in der obern Flachstrecke erhöht wird. Dadurch wird die Oberkante unscharf und die Steile von oben her erniedrigt.

2. Der Steilenfuß

a) wandert aufwärts, wenn am Steilenfuß ein Kolk entsteht und die Steile unterspült wird,

b) bleibt stationär, wenn sich kein Kolk bildet, aber auch nicht aufgeschüttet wird,

c) wird nach unten verlängert, wenn so viel Material transportiert wird, da $\beta$ sich dieses am Steilenfuß ablagert und einen Schwemmkegel bildet.

Diese experimentellen Ergebnisse lassen sich durch rasch ablaufende Naturvorgänge ergänzen und erweitern.

* Auch Ogilvie 50 machte die Erfahrung, daß reines Leitungswasser fertig gequollenen Ton in nützlicher Frist nicht abzuspülen vermag. Er mischte deshalb den Ton mit Sand. Ich habe aber mit frisch angefeuchtetem Tonpulver, das gut durchknetet wurde und sehr standfest ist, gute Erfahrungen gemacht. 
Ein sehr instruktives Beispiel, eine Art Großversuch, ist die Ablenkung der Kander in den Thunersee ${ }^{7,67} .1711$ wurde von der Kander aus ein Stollen durch den Strättlighubel getrieben, um bei Hochwasser der Kander einen Teil des Flusses in den Thunersee abzulenken, da die Kander durch ihre Geschiebeführung die geschiebelose Aare unterhalb des Thunersees aufstaute. Der Stollen hatte ein Gefälle von $50 \%$. Die Höhendifferenz betrug $50 \mathrm{~m}$. Als der Stollen 1714 vollendet war, erodierte die Kander mit unvorhergesehener Geschwindigkeit in die Tiefe. Bald stürzte die Decke des Stollens ein, eine eng eingeschnittene Schlucht entstand, die im Bereich des Strättligenhubels $80 \mathrm{~m}$ tief ist. Die Kander hat sich vor allem in die stark verfestigten Deltaschotter (nach $\mathrm{P} . \mathrm{BECK}^{\top}$ Hochterrasseninterglazial) eingeschnitten. Diese plötzlich auftretende Stufe (wir könnten sie Anzapfungsstufe nennen) ist nun aber im Kandertal nicht als Stufe aufwärtsgewandert, sondern hat sich rasch abgeflacht und die Erosionstätigkeit bis ins Kandertal hinein neu angeregt. In der Simme, die knappe $2 \mathrm{~km}$ oberhalb des Durchstiches in die Kander mündet, ist der Gefällszuwachs bis in den Felsriegel zwischen Burgfluh und Simmenfluh aufwärts gewandert, wo heute die Felsschwelle als Sockel eines Stauwehres dient. Beim Kanderdurchstich handelt es sich offensichtlich um eine Steile, die sich in Akkumulationen einschnitt und ausglich. Der Steilenfuß ist nicht aufwärtsgewandert.

Als Beispiel einer starken Akkumulation am Steilenfuß ist die Steile von Oberwald nach Gletsch im obersten Rhonetal zu nennen, wo die Rhone einen Schwemmkegel vom Steilenfuß her in die untere Flachstrecke, das Goms, hineingebaut hat. $\mathrm{Da}$ ein Teil des Geschiebes aus einem Seitenbach stammt, ändert an der Tatsache nichts, daß am Steilenfuß akkumuliert wird, dieser also sicher nicht aufwärts, wohl aber als Schwemmkegelsteile abwärts verlängert wurde.

\section{Theorie des Steilenausgleichs}

Wenn wir uns nun dem einfachen Schema der aufwärtswandernden Steilen auch nicht anschließen können, so scheint es klar, daß wir es nicht einfach durch ein einziges anderes ersetzen können, daß wir vielmehr der Fülle der Erscheinungen nur beikommen, wenn wir eine Reihe von vereinfachten schematischen Ausgleichsvorgängen als Typen aufstellen. Wir werden diese Ausgleichstypen, die wir in reiner Form kaum je in der Natur antreffen, den Einsichten anpassen, die wir dem Studium der natürlichen Längsprofile, den experimentellen Untersuchungen und den eben beschriebenen Naturvorgängen verdanken.

Wir gehen am besten aus von Steilen im homogenen Gestein, die z. B. als Hebungssteilen oder Konfluenzsteilen (vor allem glaziale) entstanden sein mögen und gehen dann zu den Ausgleichsvorgängen bei lithologischen Steilen über.

\section{Ausgleich von Steilen in homogenem Gestein}

Vorerst sei an einem allgemeinen Schema eine Terminologie* für die verschiedenen Abschnitte eines Längsprofiles gegeben, wie sie im folgenden Verwendung finden soll. Wir betrachten zuerst die Verhältnisse in einem ungestuften Tal. Solange darin erodiert wird, kann sich der Fluß in drei verschiedenen Zustandsformen befinden, im Zustand der Tiefenerosion, des Gleichgewichtes oder der Akkumulation. Die Strecken mit gleichem Zustand nennen wir Zustandsstrecken.

In einem Normallängsprofil (Fig. 25) folgen sich von oben nach unten eine Erosionsstrecke E - wir verstehen unter Erosion im folgenden immer Tiefenerosion, wenn wir nichts besonderes bemerken - und eine Akkumulationsstrecke A, zwischen die eine Gleichgewichtsstrecke $\mathrm{G}$ eingeschaltet sein kann, in welcher weder in die Tiefe erodiert, noch akkumuliert wird. In der Erosionsstrecke E sind zu unterschei-

* Zur Terminologie sei auf die Arbeit von H. v. Wissmann: Über seitliche Erosion. Colloquium Geographicum Bd. 1 Bonn 1951, verwiesen, die einen guten Einblick in die vielen Synonyme gibt. Auf eine Diskussion der verschiedenen Begriffe wird hier verzichtet. 


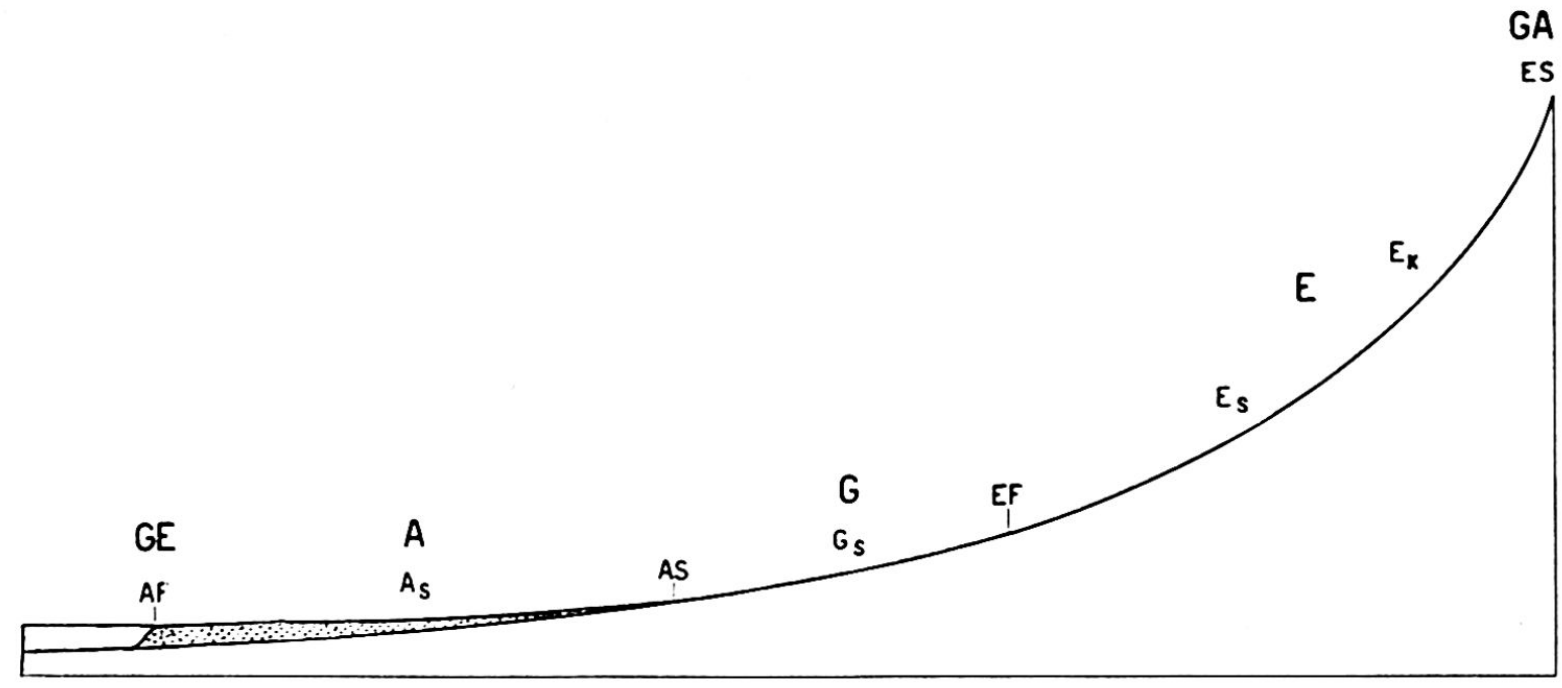

Fig. 25 Schema eines Normallängsprofiles.

A Akkumulationsstrecke, G Gleichgewichtsstrecke, E Erosionsstrecke. Übrige Buchstaben s. Text.

den Strecken, in denen die Tiefenerosion vorherrscht und die Seitenerosion unbedeutend ist, so daß eine Kerbe entsteht, und wir von Erosionsstrecke mit Kerbbildung $\mathrm{E}_{\mathrm{K}}$ sprechen können, und Strecken mit Tiefenerosion und beachtlicher Seitenerosion, so daß sich ein Talboden ausbildet, die wir Erosionsstrecke mit Seitenerosion $\mathrm{E}_{\mathrm{s}}$ nennen. Den höchsten Punkt der Erosionsstrecke nennen wir Erosionsscheitel ES, den untern Endpunkt Erosionsfu $\beta$ EF. In der Gleichgewichtsstrecke $G$ kann die Seitenerosion beträchtlich sein. Eine solche Strecke nennen wir Gleichgewichtsstrecke mit Seitenerosion $\mathrm{G}_{\mathrm{s}}$. In der Akkumulationsstrecke A mit beachtlicher Seitenerosion sprechen wir von Akkumulationsstrecke mit Seitenerosion $\mathrm{A}_{\mathrm{s}}$ und unterscheiden einen Akkumulationsscheitel AS und einen Akkumulationsfuß AF.

Den durch zu vielseitige Verwendung unklar gewordenen Begriff Erosionsbasis ersetzen wir durch den neutralen Ausdruck Gefällsende GE. Den höchsten Punkt eines Gewässers nennen wir Gefällsanfang GA. In der schematischen Normalprofilskurve (Fig. 25) folgen sich die Zeichen in der eindeutigen Anordnung GA, ES, $E_{\kappa}$, $E s, E F, G, G s, A S, A, A s, A F, G E$.

Wenn der Punkt AF sich als vorderster Deltapunkt in einem Alpenrandsee abwärts verlagert, so wird dadurch nicht nur die Gefällsstrecke verlängert, sondern auch verflacht, so daß die Akkumulation quasi durch die Akkumulation gefördert wird und unter Umständen auch der Akkumulationsscheitel $A F$ aufwärts rückt.

Liegt der Erosionsscheitel ES auf einer scharf ausgeprägten kammartigen Wasserscheide, so wird er mit fortschreitender Tiefenerosion an Höhe abnehmen. Ob dabei das Tal verlängert oder verkürzt wird oder gleich lang bleibt, hängt vom Erosionsverhältnis der beiden an der Wasserscheide opponierenden Gewässer ab. Liegt der Erosionsscheitel in einer Hochfläche, so wird der Scheitel mit fortschreitender Erosion aufwärtsrücken, das Tal verlängert werden. Der Erosionsfußpunkt EF kann je nach dem Belastungsverhältnis mit Geschiebe im Verlauf der Entwicklung sowohl aufwärts wie auch abwärts rücken. Wenn die Geschiebezufuhr bei sehr lebhafter Erosion im Oberlauf noch sehr groß ist, so rückt er talaufwärts, wenn aber im Oberlauf die Erosion abnimmt und die Geröllzufuhr geringer wird, so wird von oben her das ganze Gefälle erniedrigt. Der Fluß beginnt von oben her in seine eigenen Aufschüttungen einzuschneiden und lagert sie talabwärts flacher wieder ab.

Die verschiedenen Zustandsstrecken im Längsprofil ändern offensichtlich im Verlauf des Talbildungsprozesses ihre Lage, die Endpunkte sind äußerst labil. Schwankungen in der Wasserführung innerhalb des Jahresablaufes, wobei vor allem auch an außergewöhnliche, katastrophenartige Ereignisse, wie sie in den Alpen immer wieder vorkommen, zu denken ist, Klimaänderungen, aber auch kleinere und größere tektonische Veränderungen, Hebungen, Senkungen, Verbiegungen, verschieben sie. Es wird 


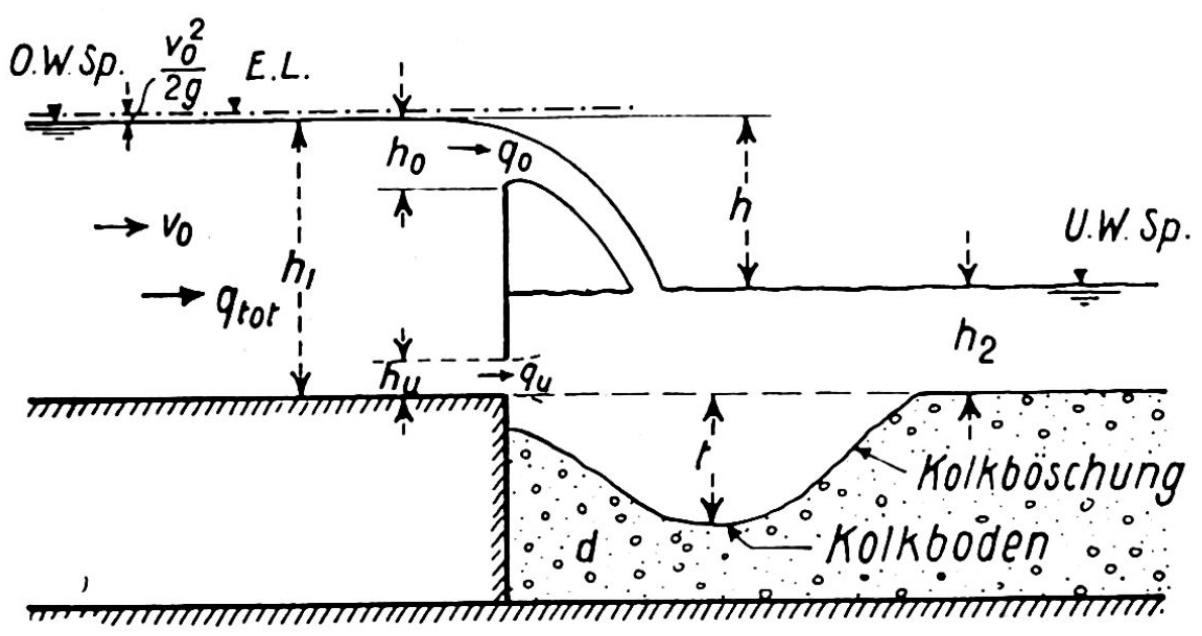

Fig. 26 (Aus W. Eggenberger ${ }^{14}$ )

$\mathrm{q}_{0}$ Überfallwassermenge in $\mathrm{m}^{3} / \mathrm{secm}$

h1 Oberwassertiefe in $\mathrm{m}$

h2 Unterwassertiefe in $\mathrm{m}$

$h$ Absturzhöhe in $m$

$t$ Kolktiefe in $\mathrm{m}$

d maßgebender Korndurchmesser des Geschiebes in $\mathrm{mm}$

Das zerflatterte Wasser vermag in der Wand nicht die geringste Erosionswirkung zu vollziehen, besonders auch, weil das Geschiebe frei abfällt. So kann man denn auch nicht die Spur eines Einschnittes in der Wand erkennen, auch dort nicht, wo der Fels im untern Drittel der Wand wulstig und intensiv gefaltet vorspringt, trotzdem hier das Wasser ständig daraufstiebt. Wenn nun auch das Geschiebe und Wasser in der Wand nicht erodiert, so doch oben, wo der Bach in «der Felsen Ritze» dahinschießt. Am Wandfuß ist zwar im Fallschuttkegel ein zirkusartiger Trichter freigelegt, ähnlich der Öffnung eines Vulkankegels, aber die Felswand wird nicht unterschnitten. Der Fall weicht nicht zurück, er wandert nicht, er wird aber, wenn wohl auch sehr langsam, durch Einschneiden und Abschrägen von oben her erniedrigt.

In der gleichen Felswandflucht stürzen noch drei Fälle zu Tal, zuerst der Spießbach, ganz dem Staubbach verwandt, wenn auch nicht so imposant. Auch er besitzt am Steilenfuß einen Doppelkegel, nämlich einen steilen Fallschuttkegel, der nach unten in einen viel flachern Schwemmkegel übergeht.

Es folgen der $̈$ gertenbach und der Mürrenbach, beide ohne Fallschuttkegel, der Mürrenbach hat sich sogar in die Schutthalde am Gehängefuß eingeschnitten.

Im Rhonequertal unterhalb Martigny stürzt der Pissevache ins Rhonetal, ohne die geringste Kerbe in der Wand, doch offensichtlich am Fallscheitel klammartig eingeschnitten.

Im Misox, dem bündnerischen Seitental zum Tessin, hat der Buffalora einen typischen Fallschuttkegel, der wie beim Staubbach durch das aufprallende Wasser ausgehöhlt ist. Der Fall stürzt frei über die unversehrte Wand.

Die eben geschilderten Wasserfälle haben sich alle nicht in die Wand, über die sie abstürzen, eingeschnitten. Es gibt aber nun doch auch Wasserfälle mit freiem Sturz, wo dies der Fall ist. Es mag sein, daß dazu eine gewisse, der Fallhöhe angepaßte minimale Wassermenge nötig ist, so daß das Wasser in mehr oder weniger geschlossenem Strahl den Fallfuß erreicht. Solche Abstürze mit geschlossenem, nicht zerflatterndem Wasserfall werden bei den Stauwehren künstlich erzeugt und sind deshalb systematisch untersucht worden.

Wir stützen uns im folgenden auf die Untersuchung von W. EgGenBERger ${ }^{14}$, die im Wasserbaulaboratorium der Eidg. Technischen Hochschule durchgeführt wurde. Die Problemstellung von Eggen berger weist auch auf morphologische Probleme hin. Er schreibt: «Wo Wasser über ein Bauwerk oder eine steile Felswand des Flußbettes abstürzt, trifft es das Flußbett mit großer Bewegungsenergie in der Regel unter einem steilen Winkel; wenn die Sohle an dieser Stelle aus beweglichem Material (Geschiebe) oder nicht sehr festem Fels besteht, so wird sie ausgekolkt. Der Überfallstrahl taucht bis auf den Boden des Kolkes und wird flußabwärts umgelenkt. Vor und hinter diesem Strahl entsteht je eine große Walze (siehe Fig. 27) ; die hinter dem Strahl, also flußaufwärts desselben liegende spült die Sohle flußaufwärts aus und bewirkt die Unter- 


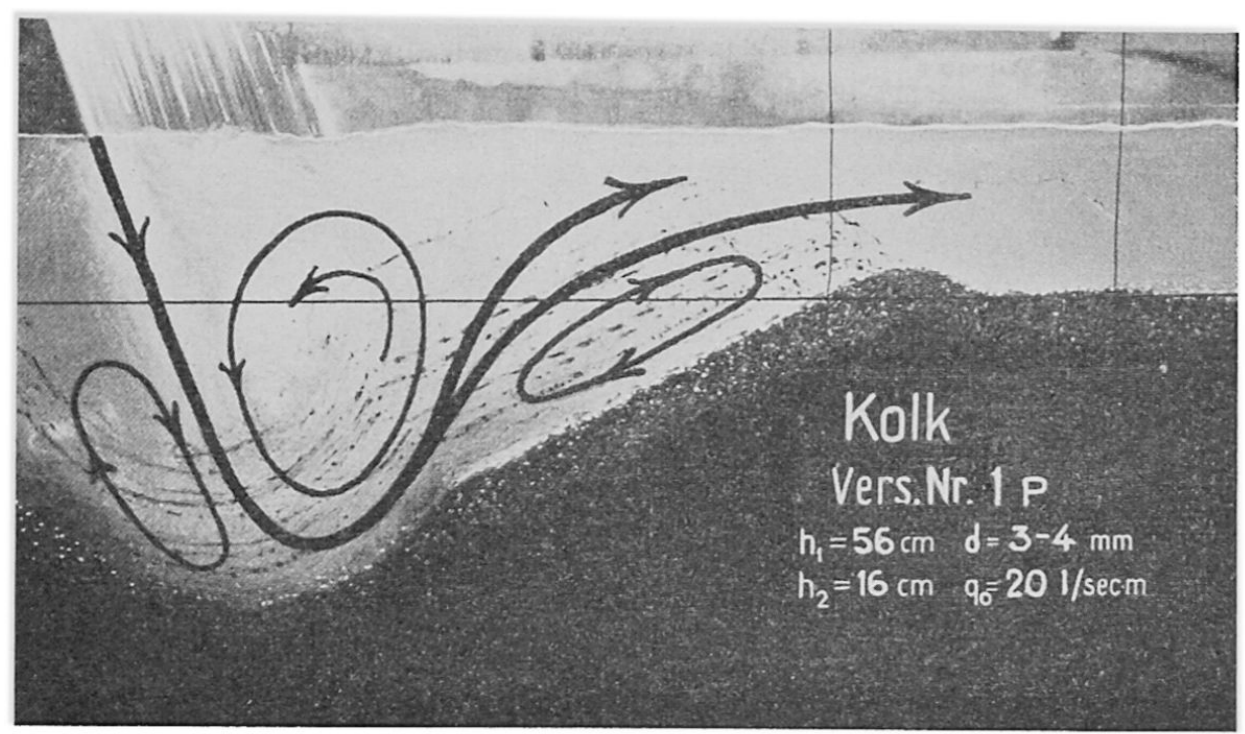

Fig. 27 Kolkversuch von W. Eggenberger nach 363 Stunden. (Aus W. Eggenberger ${ }^{14}$ )

spülung von Bauwerken bzw. der steilen Wand an Wasserfällen. Wenn diese Unterspülung weit genug fortgeschritten ist, bewirkt sie den Einsturz des Bauwerkes bzw. das Nachbrechen der Felswand an Wasserfällen, was schließlich zu dem vielfach beobachteten Flußaufwärtswandern der Wasserfälle führt.»

Natürlich ist Eggenbergers Untersuchung ganz auf den Kraftwerkbau zugeschnitten, doch ist eine kurze Zusammenfassung der gewonnenen Resultate auch für den Morphologen von Interesse.

Für seine Berechnungen bedient er sich der Größen, die aus der Figur 26 zu ersehen sind. Auf Grund seiner Messungen kommt er zu einer Formel, die auf Vorarbeiten von Schoklitsch und Veronese fußt und die aussagt, daß die größte Kolkwassertiefe $t+h_{2}$ einer Potenz der abstürzenden Wassermenge $q_{0}$ und einer Potenz des maßgebenden Geschiebedurchmessers d umgekehrt proportional sei. Sie hat die Form :

$$
\mathrm{t}+\mathrm{h}_{2}=\mathrm{w} \frac{\mathrm{h}^{a} \mathrm{q}^{\beta}}{\mathrm{d} \gamma}
$$

Mit den aus den Messungen erhaltenen Exponenten heißt die Formel:

$$
\mathrm{t}+\mathrm{h}_{2}=\mathrm{w} \frac{\mathrm{h}^{0,5} \mathrm{q}_{\mathrm{n}} 0,6}{\mathrm{~d}_{90} 0,4}
$$

$\mathrm{t}, \mathrm{h}_{2}$ und $\mathrm{h}$ sind in Metern $\mathrm{q}_{0}$ in $\mathrm{m}^{3} / \mathrm{sec}$ pro $\mathrm{m}$ Gewässerbreite einzusetzen, $\mathrm{d}_{90}$ ist der maßgebende Korndurchmesser, in $\mathrm{mm}$ gemessen, der bei einer Geschiebeanalyse der Pflästerungsschicht des Kolkbodens von 90\% der Körner (Gewichtsanteil) nicht erreicht, vom Rest überschritten wird. Die Konstante w hat den Wert 22,88. EgGenBERGER untersucht dann noch die Form des Kolkes (Fig. 28). Auf Grund seiner Messungen kommt er zu den Werten:

$$
\frac{l_{1}}{t_{\max }+h_{2}}=0,5 \pm 0,1 \text { und } \frac{l_{2}}{t_{\max }+h_{2}}=1,8 \pm 0,2
$$

Der Böschungswinkel $\varphi$ beträgt $30^{\circ} \pm 2^{\circ}$.

Wenn nun auch die Untersuchungen für die Praxis des Ingenieurs ausgeführt wurden und ein werkgerechtes, sehr einfaches Modell als Grundlage diente, so vermitteln sie doch dem Morphologen interessante Einsichten, so in die Form und die Lage der Walzen beim Tauchstrahl, die Form des Kolkes mit der flacheren

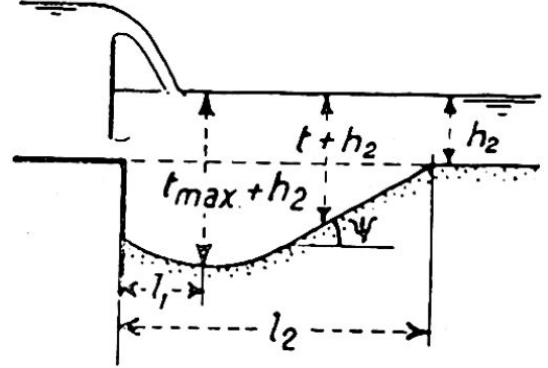

Fig. 28 Form des Kolkes. (Aus W. Eggenberger ${ }^{14}$ ) 
Kolkböschung talabwärts. $Z$ u beachten ist aber, daß Eggenberger nur Kolke in beweglichem Geschiebe untersucht hat. In der Natur sind die Kolke im anstehenden Fels ebenso wichtig. Wichtig ist die Feststellung, daß die Kolktiefe vom Geschiebedurchmesser abhängig ist. Die großen Kolktiefen beruhen auf dem Umstand, daß bei den Versuchen kein neues Geschiebe in den Kolk gelangte. Diese Voraussetzung dürfte z. B. weitgehend für den Niagara zutreffen, in den Alpen aber doch recht selten verwirklicht sein.

Morphologisch ist nun aber nicht der Kolk am Wandfuß allein ausschlaggebend, sondern Art und Form des Nachbrechens der Wand. Nur wenn diese unter günstigen lithologischen Verhältnissen parallel nachbricht, und wenn das Sturzmaterial im Kolk zerrieben werden kann, wandert der Wasserfall talaufwärts. Das wird noch zu besprechen sein.

Nun spielen aber bei gewissen Wasserfällen neben dem Unterspülen der Wand, wie verschiedene Beispiele zeigen, senkrechte Strudellöcher, Wirbel mit vertikaler Achse, eine Rolle. Es sind dies in den Alpen Wasserfälle, die in eine enge Schlucht oder Klamm abstürzen. Die Felsbeschaffenheit in der Klamm zeigt, daß die Klammwände durch Strudellöcher entstanden sind, daß in der Absturzstelle der Fels also sozusagen fortlaufend weggebohrt wurde (BRUNHES ${ }^{10}, \ddot{A N G E B Y}^{2}$ ).

Der Handeggfall im Oberhasli ist ein Sturz der Aare von ungefähr $40 \mathrm{~m}$ Höhe. Er liegt in einem Felsriegel, der als breite Rippe das Tal quert. Unterhalb und oberhalb weitet sich der Talboden wieder. Schon 1894 hat A. BALTzER ${ }^{6}$ den Fall im Livret-guide géologique folgendermaßen beschrieben:

«Der Handeckfall bildet nicht, wie der Reichenbachfall, Cascaden, sondern stürzt in einem Sprung ab. Seine Bildung wurde wohl begünstigt durch einen härteren Querriegel von Granit, dem sich nördlich etwas weichere Gneißgranite und Augengneiße vorlegen.» In diesem Querriegel ist der Fall rückwärtsgewandert. Die Schluchtwände zeigen die typischen Strudellochformen. Gleichzeitig mit dem Rückwärtswandern des Falles hat sich aber die Aare auch als enge Kerbe oberhalb des Falles in den Stufenscheitel eingetieft. Da der Handeggfall in einem Felsriegel liegt, und sich das Tal oben wieder weitet, die Felssohle des Talbodens oberhalb des Riegels vielleicht noch übertieft ist, ist die Geschichte dieser Stufe wohl mit der endgültigen Zerschneidung des Riegels abgeschlossen.

Ganz ähnliche Verhältnisse treffen wir im Reußtal beim Pfaffensprung kurz vor Wassen. Auch hier finden wir unterhalb der Fallstrecke eine kurze Schlucht, die beweist, daß der Fall rückwärts gewandert ist, offensichtlich wurde aber auch der Stufenscheitel erniedrigt. Der Pfaffensprung befindet sich wie die Handegg in einem Felsriegel, der den Talboden quert. Oberhalb folgt ein breiterer, offensichtlich aufgeschütteter Talboden. Mit dem Durchsägen des Riegels verschwindet voraussichtlich auch dieser Fall. Wenn dann das dahinterliegende Talbodenstück ausgeräumt wird, wird der Felsriegel erst recht zur Geltung kommen.

\section{Steilen mit Akkumulation am Steilenfuß.}

Wenn nun senkrechte Fälle unter bestimmten Bedingungen, wie wir eben beschrieben haben, aufwärts wandern, immerhin unter gleichzeitiger Höhenabnahme, weil der Fallscheitel durch Erosion in der obern Flachstrecke tiefergelegt wird, so scheint ein Wandern über viele Kilometer doch recht fraglich. Völlig ausgeschlossen erscheint dies bei Steilen, an deren Fuß akkumuliert wird.

Das Gefälle in den Steilen der großen Alpentäler beträgt im Durchschnitt um $10 \%$, d. h. um $5-6^{\circ}$. Wir sind im allgemeinen durch die fast stets überhöhten Längsprofile bildmäßig an viel zu große Gefälle gewöhnt. In der Natur auffallende Steilen, die sich durch verwirbeltes und schäumendes Wasser auszeichnen, lassen sich beim Herauszeichnen aus einer Karte 1:50000 kaum erkennen, wenn wir das Profil nicht stark überhöhen (Fig. 36D). Es ist zudem zu beachten, daß der Begriff «Steile» 
keine Neigungsangabe umschreibt, sondern immer als Relativbegriff aufzufassen ist, als relative Versteilung zwischen zwei Flachstrecken. Eine Steile im breitangelegten und aufgeschütteten Tal ist gleich oder sogar weniger steil als eine Flachstrecke im engen, an sich schon steilen Tal des Oberlaufes.

Wir bedienen uns des Steilenschemas Fig. 1. Wir gehen von der Annahme aus, $F_{1}$ sei eine Akkumulationsstrecke und $S_{1}$ eine Erosionsstrecke. Dann kann in der Strecke $\mathrm{F}_{2}$ wenigstens in unmittelbarer Nähe vom Steilenscheitel $\mathrm{SS}_{1}$ nicht akkumuliert werden. Das heißt, in keiner Flachstrecke über einer Steile kann in ihrer ganzen Ausdehnung akkumuliert werden.

Wird nun in der Steile kräftig erodiert; und ist die Steile lang genug, so muß die Erosion im Bereich des Steilenscheitels am kräftigsten sein und gegen den Steilenfuß zu abnehmen, da die Geschiebemenge zunimmt. Dies führt bei fortschreitender Entwicklung zu einer Gefällsverminderung gegen den Scheitel zu. Wird von der Steile her ein Schwemmkegel in die untere Flachstrecke hineingebaut, so wächst er auch in die Steilstrecke hinauf. Dadurch wird der Knick am Steilenfuß verwischt, und durch das Höherwachsen des Schwemmkegels wird die Steile von unten her ernied rigt.

$\mathrm{Zu}$ dieser Verhüllung des Steilenfußes durch einen Schwemmkegel können ganze Reihen von Beispielen aufgezählt werden. Die Steile von Gletsch mündet mit einem Schwemmkegel ins Goms. Die Steile zwischen dem Goms und Brig mündet in den hochaufgeschütteten Talboden bei Brig. Bei Amsteg mündet die unterste Steile der Reuß im aufgeschütteten Reußtal.

Am Steilenscheitel $\mathrm{SS}_{1}$ wird der Zustand der obern Flachstrecke $\mathrm{F}_{2}$ bestimmt. Wenn die Flachstrecke auf diesen Punkt eingespielt ist, so kann bei gleichbleibender Wasser- und Geschiebeführung nicht akkumuliert werden. Von diesem Steilenscheitel aus greift die Erosion aus der Steile in die Flachstrecke über. Geschiebe, das sich in der Flachstrecke gerade noch halten kann, wird hier, am vordersten Punkt, weil das Gefälle plötzlich zunimmt, mitgerissen*. Dadurch wird der Steilenscheitel und die benachbarte Flachstrecke ständig der Erosion ausgesetzt. Wenn der Scheitel durch Erosion tiefer gelegt wird, beeinflußt dies, vom Scheitel ausgehend, die ganze Flachstrecke. Dadurch wird der Scheitel, wenn er ursprünglich als scharfer Knick ausgebildet war, abgerundet, vom Steilenscheitel her wird die obere Flachstrecke zunehmend abgeschrägt ***

Mit fortschreitendem Ausgleich wird also der Fußpunkt der Steile zunehmend verschüttet und rückt mit dem Höherwachsen der Akkumulation in der untern Flachstrecke höher, aber nur soweit talaufwärts, als die Akkumulation talaufwärts rückt. Die Steile selbst wird zunehmend flacher, nach oben abgerundet und länger. Dieser Ausgleichsvorgang geht solange vor sich, bis an Ort und Stelle, ungefähr mit dem wenig sich verschiebenden Fußpunkt als Drehpunkt ein Ausgleichsgefälle ausgebildet ist.

Bei einer Steile oberhalb einer Steile wird der Ausgleichsvorgang ganz durch das Verhalten der dazwischenliegenden Flachstrecke beeinflußt. Wie wir eben zeigten, bestimmt der Steilenscheitel der untern Steile $\mathrm{SS}_{1}$ den Zustand der obern Flachstrecke $\mathrm{F}_{2}$. Bei einem noch ganz unausgeglichenem Längsprofil kann am Fuß der obern Steile $\mathrm{FS}_{2}$ noch akkumuliert werden. Mit fortschreitendem Ausgleich der untern Steile $\mathrm{S}_{1}$ wird auch die dazwischenliegende Flachstrecke $\mathrm{F}_{2}$ immer steiler, der untere Steilen-

* Der von O. LeHMANn 34 Gefällsentwicklung S. 7 ff betonte scharfe Unterschied zwischen strömendem und schießendem Wasser in bezug auf die Erosionsarbeit an der Oberkante der Steile und die Behauptung, bei schießendem Wasser könne sich die plötzliche Gefällszunahme der Steile nicht auf die obere Flachstrecke auswirken, ist ein Irrtum.

** Es ist eine bekannte Erscheinung, daß es recht schwer ist, Steilen zu begrenzen, da meist keine scharfe Obergrenze, sondern eine Abrundung vorliegt. Die Niveaukurven mit einer Äquidistanz von $20 \mathrm{~m}$ erlauben nur eine Höhenbestimmung auf $20-30 \mathrm{~m}$ genau und eine Längenbestimmung mit einer Unsicherheit von weit über $100 \mathrm{~m}$. 

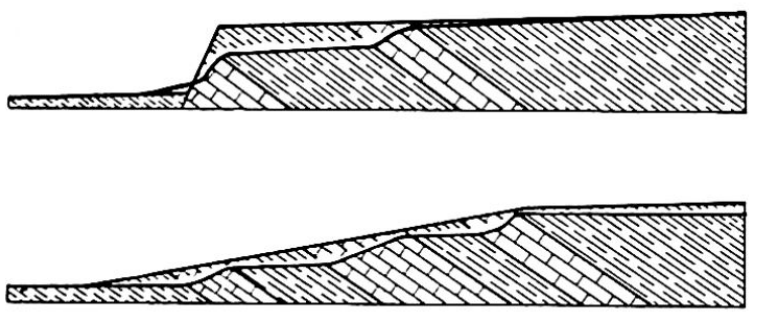

Fig. 30 Unterteilung einer Steile. Verteilung eines einheitlichen Gefälles auf drei resistente Gesteinsbänke.

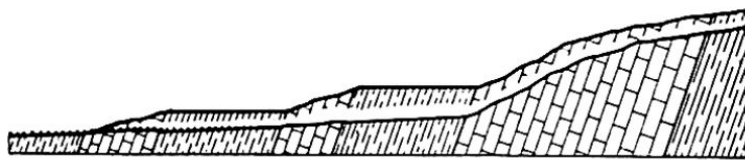

Fig. 31 Sammeln von Gefälle unterer Steilen in einer einzigen Steile und Überschüttung der untersten Steile.

scheitel $\mathrm{SS}_{1}$ rückt immer näher an die obere Steile heran, wodurch die ursprüngliche Flachstrecke $\mathrm{F}_{2}$ immer mehr verkürzt, und ihr Zustand von Akkumulation über Gleichgewicht in Erosion übergeführt wird. Erreicht der Scheitel der untern Steile den Fuß der obern, so verschmelzen die beiden Steilen zu einer einzigen, zuerst noch etwas gewellten Steile.

In Wirklichkeit gibt es in der Natur keine Steilen in vollkommen homogenem Gestein, weiterhin sind Störungen von der Seite, durch Akkumulation, vorhanden. Steilen von einiger Ausdehnung sind deshalb meist zusammengesetzt aus verschieden geneigten Stücken mit mehr oder weniger großen Flachstrecken dazwischen. Vom Ausgleich von Resistenz und Akkumulationssteilen soll im folgenden an Hand einiger Beispiele die Rede sein.

\section{Bildung und Ausgleich von Resistenzsteilen}

Resistenzsteilen können, im Gegensatz zu Akkumulationssteilen, nur in Erosionsstrecken gebildet werden und werden, falls die Erosionsstrecke sich in eine Akkumulationsstrecke verwandelt, durch die höhersteigende Akkumulation zugedeckt. Wir treffen im nicht homogenen Gestein Resistenzsteilen auch in mehr oder weniger ausgeglichenen Längsprofilen in der obern Talhälfte, die ja immer eine Erosionsstrecke bleibt.

Wir können Resistenzsteilen als Großformen zwischen zwei ausgedehnten Flachstrecken beobachten, es können aber auch innerhalb einer ausgedehnten Steile oder in der Erosionsstrecke gegen das Talende zu kleine Resistenzsteilen zwischen kleinen Flachstrecken auftreten, die die Großsteile treppenartig gliedern. Übergänge zwischen Groß- und Kleinformen sind vorhanden, so daß oft nur willkürlich entschieden werden kann, ob zwei benachbarte Steilen zu einer Großsteile zusammenzufassen seien oder nicht.

Über das Wandern von Resistenzsteilen hat in dieser Zeitschrift H. JäcKLI ${ }^{31}$ berichtet. Auch AURADA ${ }^{5}$ hat ein Jahr früher dazu Skizzen veröffentlicht. Beide sind sehr schematische Darstellungen, die nur ganz generelle Hinweise auf Wandermöglichkeiten geben.

Umreissen wir vorerst die Entstehungsmöglichkeiten. Resistenzsteilen werden durch selektive Erosion herauspräpariert. Dieser Vorgang kann sich an verschiedenen Stellen des Profiles abspielen. Gehen wir von der in der Terrassenliteratur so häufigen Annahme einer Hebung, oder wie SöLcH es noch bestimmter postuliert, einer Verwerfung am Alpenrand aus, so wird dadurch neues Gefälle geschaffen.

Dieses Gefälle wird aber nicht an Ort und Stelle erhalten bleiben, sondern durch den Ausgleichsvorgang je nach den Umständen sehr verschieden verteilt werden. Soweit das Steilgefälle in lockern wenig resistenten Gesteinen geschaffen wird, wird es sehr rasch sich verflachend in die Länge gezogen werden. Als Beispiel einer solchen rasch sich ausgleichenden Steile haben wir schon auf den Kanderdurchstich hingewiesen. Stößt dieses rasch aufwärtswandernde Gefälle aber auf resistenteres Gestein, dann wird dieses als Resistenzsteile von unten her herauspräpariert (Fig. 29). 
Sind in der ursprünglichen Hebungssteile verschieden resistente Gesteine vorhanden, so werden diese bei der neu einsetzenden Erosionstätigkeit herauspräpariert. Die einheitliche Steile wird dadurch in mehrere Treppenstufen aufgelöst. Auf den Wechsel von Engstellen im resistenten Gestein und Talweitungen im weniger resistenten sei hier nur nebenbei hingewiesen (Fig. 30).

Bei einer Aufwölbung werden im Gebiet der Gefällsvermehrung Resistenzsteilen sich neu bilden können oder werden neu belebt, im Gebiet der Gefällsverminderung wird neu akkumuliert, so daß Resistenzsteilen verdeckt werden können.

Bei der Tiefenerosion in einer ganzen Erosionsstrecke kann unter einheitlichem Gestein resistenteres Gestein neu zum Vorschein kommen und wird dann als Resistenzsteile herauspräpariert.

Bei einem Klimawechsel kann durch größere Wasserführung eine Akkumulationsstrecke wieder in eine Erosionsstrecke zurückverwandelt werden, wodurch verdeckte oder ausgeglichene Resistenzsteilen wieder abgedeckt oder neu belebt werden können.

Beim Ausgleich tieferliegender Steilen kann das sich in die Länge ziehende Gefälle an einer resistenten Stelle wieder gesammelt werden, es kann sich sogar, wenn die Oberkante dieser sich neu bildenden oder belebenden Steile besonders resistent ist, das Gefälle von mehreren sich ausgleichenden Steilen hier aufsammeln, es kann sich eine Sammelsteile bilden, wenn dieser Begriff der Systemliteratur* hier angewandt werden darf, ohne zu Verwechslungen zu führen, da er in diesem Zusammenhang rein beschreibend, und nicht chronologisch wertend gebraucht werden soll (Fig. 31).

Diese Hinweise auf Entstehungsmöglichkeiten sind, wie schon mehrmals in andern Zusammenhängen gezeigt wurde, immer auch ganz allgemein Hinweise auf die Mannigfaltigkeit der Vorgänge und Formen. Diese Mannigfaltigkeit der Vorgänge und Formen wird noch erhöht durch die verschiedenen Lagerungsmöglichkeiten der Gesteine, die sowohl die Entstehung wie auch den Ausgleich beeinflussen.

Den Einfluß der Gesteinslagerung skizzieren wir in der Reihenfolge unserer Resistenzsteilensystematik.

1. Typus: Das resistente Gestein ist horizontal.

Beim Nachbrechen der resistenten Schicht über einer weniger resistenten, die die erstere unterhöhlt, wandert eine solche Steile, wie Aurada bemerkt, maximal aufwärts. Hier ist offensichtlich der Niagarafall 19, 29 einzuordnen, der zwar nicht in den Alpen liegt, aber als Kronzeuge für das Wandern immer wieder zitiert wird (Fig. 32).

Beim Niagara war die ursprüngliche Steile eine Landstufe, das Niagara Escarpment, über die das Wasser des Eriesees zuerst abstürzte. Nach unsern frühern Darlegungen sollte der Fall ausgeflacht und erniedrigt werden. Nun liegen aber hier ganz besondere Verhältnisse vor. Da das Wasser aus einem See stammt, ist es geschiebearm, zudem ist das Gefälle verglichen mit alpinen Verhältnissen sehr gering, das Bett oberhalb des Falles außergewöhnlich breit, so daß die Erosion oberhalb des Falles nur sehr gering

* Anhaheim schreibt in der «Geomorphogenese der Südalpen»4 S. 108: «Harte Gesteinszonen oder Schuttmassen können die Steilenwanderung aufhalten, so daß sich mehrere Steilen zu Sammelsteilen akkumulieren können. Nach Überwindung des Hindernisses rückt die Sammelsteile geschlossen talauf; im obern Talabschnitt wird deshalb an Stelle mehrerer Systeme nur noch ein einziges System ausgebildet (Systcmverschluckung). Der umgekehrte Fall tritt ein, wenn eine Steile im angeschnittenen Untergrunde auf härteres Gestein stößt. Der obere Steilenteil marschiert dann weiter, wogegen der untere seine Rückwanderung nur mit Verzögerung fortsetzt. Durch Stcilcnumformung können sonach nicht nur Systeme ausgeglichen, sondern auch neue lokale Einschaltsysteme erzeugt werden.»

Wenn wir im ersten Satz an Stelle von «Steilenwanderung» «die Verlagerung von Gefälle» setzen, so können wir dem beistimmen. Das übrige Zitat schildert die Verhältnisse aber allzu schematisch und entspricht kaum der Wirklichkeit. Dies gilt besonders für die Vorstellung, da $\beta$ der «obere Steilenteil» weitermarschiere, der untere verzögert nachfolge. Diese Vorstellung beruht auf der Verwechslung von Gefällsverlagerung und Steilenwanderung (siehe Seiten 198 und 208 dieser Arbeit). 


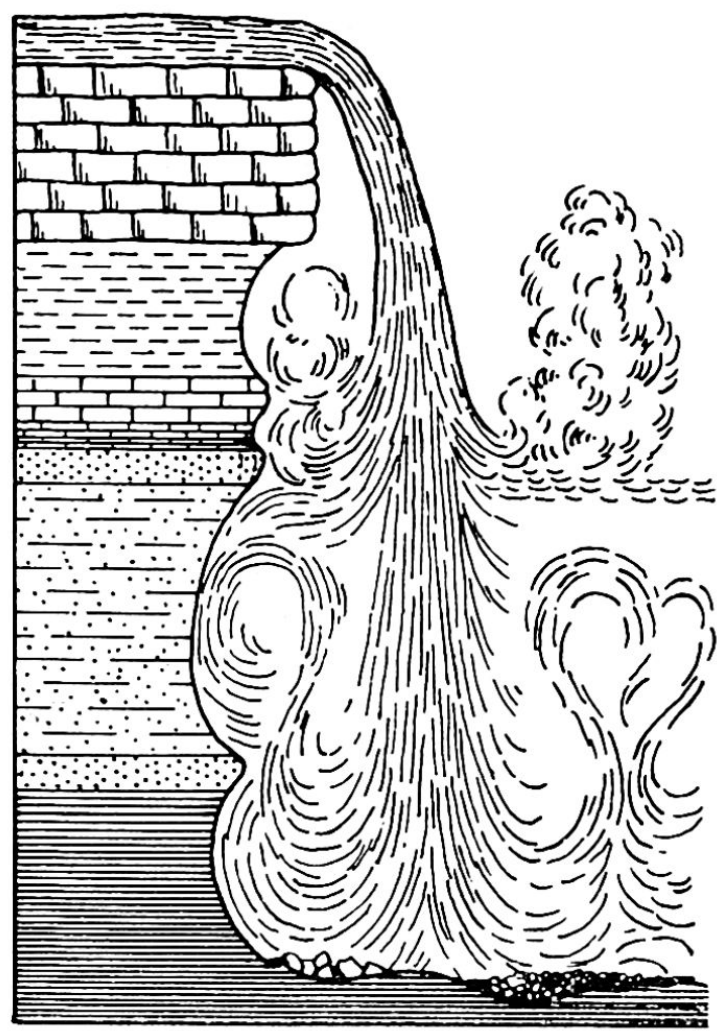

Fig. 32 Niagarafall nach Holmes ${ }^{29}$

sein kann*. Zudem rückt der Fall so rasch zurück, daß die Anschrägung des Fallscheitels fortlaufend nachbricht und sich nicht rückwärts auswirken kann. Das Nachbrechen wird durch die besondern Gesteinsverhältnisse begünstigt. In der Wand folgen sich von oben nach unten: 1. Widerstandsfähiger Dolomit, 2. Mergel, 3. Kalkbank mit Mergelbändern, 4. Harte Sandsteinbank, 5. Weicher Sandstein mit Mergeln, 6. Resistente Sandsteinbank, 7. Eine mächtige Mergelbank, die bis an die Basis reicht. Der freie Sturz des Wassers beträgt $49 \mathrm{~m}$, im $50 \mathrm{~m}$ tiefen Kolk sind zwei Walzen mit horizontaler Achse ausgebildet, von denen die eine die Unterspülung der Fallwand bewirkt. Der Kolk befindet sich im Bereich der Gesteine 5-7. Die Sandsteinbank 6 ist nur ein wenig mächtiges Band zwischen den beiden andern Schichten. Beim Zurückweichen wird der Kolk talabwärts fortlaufend wieder mit Material gefüllt. Am Fallscheitel bildet der Dolomit ein tragfähiges Dach, das bekanntlich so weit vorspringt, daß man hinter dem Wasserfall durchgehen kann. Dieser wasserreichste Fall der Erde rückt gegenwärtig jedes Jahr ungefähr $1,5 \mathrm{~m}$ zurück und hat vom Niagara Escarpment einen $11 \mathrm{~km}$ langen Weg zurückgelegt. Dabei hat er zwar am Scheitel nicht an Höhe verloren, wohl aber von unten her, ist er doch von etwa $100 \mathrm{~m}$ auf $49 \mathrm{~m}$ Fallhöhe zurückgegangen.

So demonstrativ und aufschlußreich dieser im menschlichen Leben meßbar zurückweichende Fall nun auch ist, so sicher ist es auch verfehlt, ihn als eindeutigen und allgemeingültigen Beweis für kilometerweites Wandern aufzufassen. Ein allzu einfacher Schematismus geht an der Vielgestaltigkeit der Erscheinungen vorbei und gibt nicht nur ein zu einfaches, sondern ein falsches Bild.

Damit ein Fall so regelmäßig zurückweichen kann, wie der Niagara, müssen eine Reihe von Bedingungen erfüllt sein, die in den Alpen wohl kaum verwirklicht werden könnten. Gehen wir einmal von der einfachen Annahme aus, auch in den Alpen beginne ein Fall als Wandstufe und auch hier seien die Gesteine im obern Teil sehr resistent, an der Basis aber leicht erodierbar. Damit das abstürzende Wasser am Fuß einen gutausgebildeten Kolk ausspült, muß es im Sturz nicht allzusehr zerflattern. Offensichtlich muß dazu die Wassermenge und die Fallhöhe in einem bestimmten Verhältnis stehen, auch die Geschwindigkeit und Richtung, mit denen das. Wasser über die Wand hinausschießt, sind von Wichtigkeit. Ferner muß die Blockgröße des nachbrechenden Gesteins so beschaffen sein, daß sie vom abstürzenden Wasser bewältigt, eventuell zerkleinert und wegtransportiert werden kann, da sonst aus dem freien

* Nach der Karte 1:100 ooo im schweizerischen Mitetlschulatlas (11. Aufl. 1955, S. 111) ist der Niagara River $3 \mathrm{~km}$ oberhalb des Falles über $2 \mathrm{~km}$ breit. Im Fallgebiet wird er durch die Goat Insel in zwei Arme aufgespalten, den Hufeisenfall von ca. $300 \mathrm{~m}$ Breite, geradlinig gemessen, der in der Verlängerung der $300 \mathrm{~m}$ breiten Schlucht liegt und den ca. $200 \mathrm{~m}$ breiten amerikanischen Fall, der scitlich in die Schlucht stürzt. Die Verengung beträgt also unmittelbar im Fall gut zwei Fünftel. Es ist auch zu beachten, daß gegenwärtig eine Richtungsänderung stattfindet. 
Fig. 33 Verwandlung einer Wandstufe in eine abgeflachte Steile (Kaskade) beim Höhersteigen der Akkumulation bei S.

Altes Längsprofil : $F_{1}, S F, S, S S, F_{2}$

Neues Längsprofil : $\mathrm{F}_{1}$ ', SF', S', $\mathrm{SS}^{\prime}, \mathrm{F}_{2}{ }^{\prime}$

KB Kolkboden (beim Zürückschreiten fortlaufend

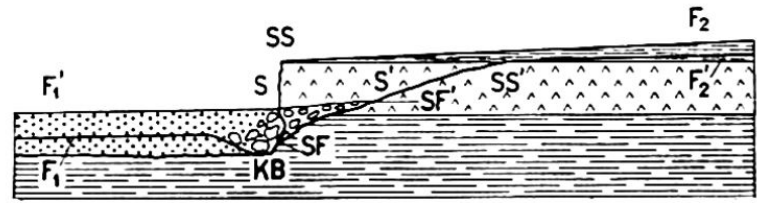
zugeschüttet).

Sturz eine Kaskade mit mehreren Absätzen entsteht. Weiter muß das Wasser oberhalb des Falles fast geschiebefrei sein, damit nicht der Fallscheitel angeschnitten wird.

Nehmen wir alle diese nicht so selbstverständlichen Bedingungen - auch die Konstanz der lithologischen Verhältnisse - als erfüllt an, so ist noch an das unter der zurückweichenden Stufe notwendige Gefälle zu denken. Hier sind nun wieder unterste Steilen und Steilen über Steilen zu unterscheiden.

Bei einer untersten Steile muß beim Rückwärtswandern der Steilenfuß notgedrungen höherrücken, damit das Wasser noch genügend Gefälle zum Abfließen hat. Dieser Vorgang hat auch beim Niagarafall stattgefunden. Dadurch wurde die freie Fallhöhe wie vorher schon angegeben wurde, von ca. $100 \mathrm{~m}$ auf $49 \mathrm{~m}$ reduziert. Es ist zu beachten, daß das Gefälle des Niagara unterhalb des Falles unter 3\%o beträgt, was etwa dem Gefälle des Rheins auf der Strecke Reichenau-Tamina entspricht. Ist das unterliegende Gefälle größer, als dieser Wert, so steigt auch der Steilenfuß entsprechend rascher in die Höhe. Wird aber gleichzeitig mit dem Rückschneiden in der untern Flachstrecke akkumuliert, so rückt der Fußpunkt der Steile noch rascher in die Höhe.

Beides, das natürliche Gefälle und die Akkumulation tragen also dazu bei, daß der Steilenfuß höher rückt, und die Steile dadurch von unten her an Höhe verliert. Beim Rückschreiten versinkt die Steile im eigenen ansteigenden Schutt.

Sobald beim Höherrücken des Fußes die weniger resistente Gesteinsbank verdeckt wird, fällt die Hauptbedingung für das Unterspülen der Wand und das senkrechte Nachbrechen der Stufe weg. Das Unterspülen wird auch verhindert, wenn Blöcke nachstürzen, die der Fluß nicht zu bewältigen vermag und dadurch der Fuß verdeckt wird. Wenn aber der Wandfuß nicht mehr unterschnitten wird, so hört das rasche Rückschreiten auf. Wenn nun noch in der obern Flachstrecke erodiert wird, so wird die Stufe auch vom Scheitel her erniedrigt, sie wird abgeschrägt und zunehmend verflacht (Fig. 33).

Günstiger scheinen die Bedingungen zum Zurückschreiten bei einer Steile über einer Steile, bei der die untere Flachstrecke durch Erosion fortlaufend tiefergelegt wird. Dies würde auch die mehrmals vermerkte Regel bestätigen, daß die Möglichkeiten zur Steilenbildung und Steilenerhaltung talaufwärts zunehmen.

Wir haben bei der Systematik als Sonderform die Treppensteile aufgeführt. Bei allen gut geschichteten Gesteinen mit Wechsellagerung von resistenten und weniger resistenten Gesteinen können beim Abschrägen der Steile vom Steilenscheitel her Wandstufen in Treppensteilen übergeführt werden. Bei massigen Gesteinen kann beim Ausgleich die Form der nach oben abgerundeten Steile entstehen.

Wir haben beim ersten Typus den wichtigen Unterschied zwischen unterster Steile und Steile über Steile hervorgehoben und auf die Bedeutung der Nähe des Übergangspunktes von Erosionsstrecke zu Akkumulationsstrecke hingewiesen. Dieser Hinweis gilt auch für die folgenden Typen.

Bei Typus 2, 1. Art, bei welcher das Gestein gleichsinnig, aber weniger steil als das Talgefälle einfällt, unterscheiden sich die Verhältnisse wenig von denjenigen von Typus 1. Die Art ist aber dadurch ausgezeichnet, daß die Unterkante der resistenten Schicht beim Rückwärtsschreiten höherrückt, so daß das Höhersteigen des Steilenfußes durch das Gefälle und eventuelle Akkumulation kompensiert werden kann, wodurch die unveränderte Wandermöglichkeit wenigstens theoretisch erhöht scheint. 
Typus 1 und Typus 21 . Art sind die einzigen, bei denen die Schnittfäche des resistenten Gesteins beim Zurückwandern gleich hoch bleibt oder sogar höher steigt. Bei allen andern nun noch zu besprechenden Typen und Arten sinkt die Schnittfläche des Gesteins. Das heißt, daß sie alle beim Zurückwandern zerschnitten oder ausgeglichen werden, wenn nicht gleichzeitig der Fuß tiefergelegt wird.

Unter Typus 2 2. Art haben wir als besondere Form die Plattenschußsteile eingereiht. Der Steilenscheitel wird durch Schichtköpfe gebildet. Plattenschußsteilen können rein geometrisch unbeschränkt an Höhe zunehmen, wenn die Erosion am Fuß größer ist, als die Erosion in den Schichtköpfen am Steilenscheitel. Der Ausgleich kann auf verschiedenem Weg stattfinden. Einmal kann sich das Gewässer parallel zu den Schichtflächen einschneiden, so, daß Schicht für Schicht weggeschält wird, bis das ganze Schichtpaket durchschnitten ist. Es kann aber auch die Plattenschußsteile in eine Steile mit treppenförmigem oder schiefem Schnitt übergeführt werden. Bei diesem Übergang geht die Plattenschußsteile in die Steile mit gleichsinnig einfallendem Gestein, das vom Talgefälle überschnitten wird, über (Typus 2, 2. Art, 2. Form.).

J ̈̈̈KLI ${ }^{31}$ schreibt von dieser Form, daß hier eine Steile beim fortschreitenden Erosionsvorgang abwärts wandern könne. Voraussetzung für dieses Abwärtswandern ist aber, da $\beta$ am Steilenfuß fortlaufend genügend erodiert wird.

Örtlich fixiert ist die Steile mit senkrecht einfallendem Gestein, Typus 3. Sie nimmt an Höhe zu, wenn am Fuß kräftig erodiert wird. Bleibt der Fuß auf gleicher Höhe, oder rückt er durch Akkumulation sogar in die Höhe, so wird diese Stufe oder Steile an Ort und Stelle zerschnitten. Wenn der Steilenscheitel sehr langsam eingeschnitten wird, so kann die obere Flachstrecke ständig auf diesen relativen Fixpunkt eingespielt bleiben, so daß auch nicht die Spur einer Steile über diese Schwelle wegwandern kann (was nicht zu verwechseln ist mit aufwärtswanderndem Gefälle).

Als Beispiel einer solchen an Ort und Stelle zerschnittenen Steile haben wir Stalvedro im Tessintale schon erwähnt.

Vom senkrecht einfallenden Gestein gelangen wir schließlich noch zum bergwärts einfallenden Gestein, zu Typus 4.

Fällt das Gestein sehr steil ein, so ist die Wandermöglichkeit sehr gering. Was wir vom senkrecht einfallenden Gestein sagten, gilt dann auch grosso modo hier. Fällt es sehr flach ein, dann nähern sich die Verhältnisse Typus 1 mit dem Unterschied, daß sich die Steilenhöhe nur halten kann, wenn der Fuß ständig tiefer gelegt wird, hier nun zusätzlich noch um den Betrag, um den das Gestein tiefer sinkt. Bleibt der Fuß in seiner Höhe erhalten, so wird die Steile beim Rückwärtswandern bald verschwinden.

\section{Bildung und Ausgleich von Akkumulationssteilen}

Akkumulationssteilen durch seitliche Einschüttung können an beliebiger Stelle des Längsprofils entstehen, sowohl in einer Akkumulations- wie in einer Erosionsstrecke, die dadurch unterbrochen wird. Durch die seitliche Einschüttung wird Gefälle talabwärts verlagert. Bei den Akkumulationssteilen ist Bildung und Ausgleich so mannigfaltig, daß hier nur einige schematische Hinweise gegeben werden können. Im Talbildungsprozeß sind sie nur episodenhafte Erscheinungen.

Wird in das Haupttal eine Akkumulationssteile eingebaut, so wird nicht nur im Bereich der seitlichen Einschüttung akkumuliert, sondern auch vom Talgewässer selbst oberhalb der Steile. Die Stauwirkung reicht umso weiter talaufwärts, je flacher die Gefällsstrecke ist, in die eingeschüttet wird. Kleinere seitliche Geschiebequellen wenig oberhalb einer großen Akkumulationssteile können sich ihrerseits in einer Flachstrecke nicht stauend auswirken, sondern beteiligen sich nur an der Hinterfüllung. In Steilstrecken des Tales vermögen sich dagegen auch kleine, engbenachbarte Einschüttungen geltend zu machen. Bei einer anhaltenden Einschüttung hält das Höherwachsen so lange an, bis sich die Haupttalerosion durch das erhöhte örtliche Gefälle und die Ein- 


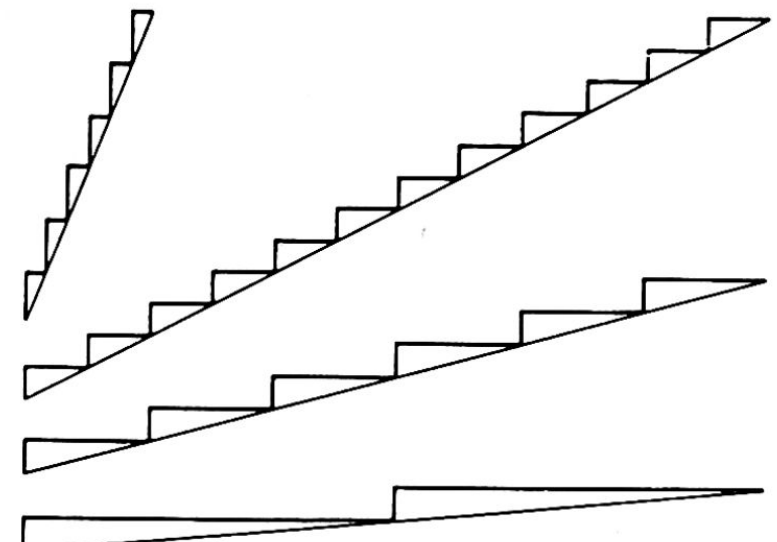

Fig. 34 Stufen gleicher Höhe bei verschiedenem Gefälle.

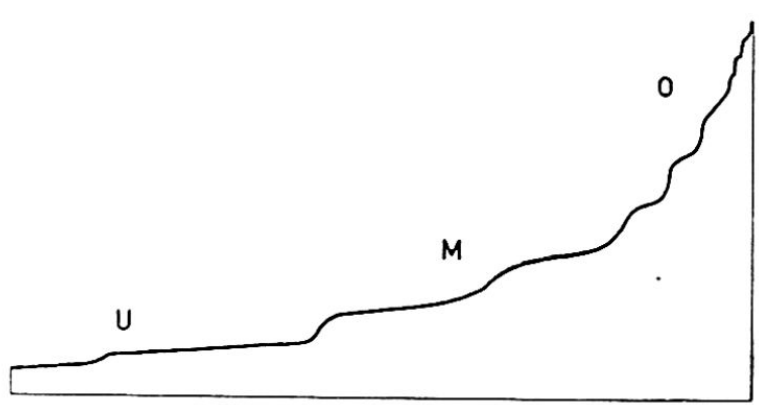

Fig. 35 Schema eines gestuften Längsprofiles. U Unterlauf, M Mittellauf, O Oberlauf. Die ausgeprägtesten Stufen befinden sich im Mittellauf (Vergl. Fig. 39 und 41).

schüttung die Waage halten. Hört die seitliche Einschüttung auf - beim Bergsturz z. B. sofort nach dem Ereignis, beim Wildbach, wenn er «zahm» wird und selbst ein ausgeglichenes Gefälle ausgebildet hat und seine Geschiebezufuhr nur noch sehr gering ist - so wird die Stufe je nach der Art des eingeschütteten Materials mehr oder weniger rasch ausgeglichen. Entspricht das Material in Korngröße dem Transportvermögen des Haupttalgewässers, so kann es als Geschiebe transportiert werden, während grobes Blockmaterial wie anstehendes Gestein erodiert werden muß. In einer Erosionsstrecke unterbricht die seitliche Einschüttung örtlich die Erosion. Bleibt die Akkumulation lange wirksam, so bedeutet dies einen Schutz des anstehenden Felsens an dieser Stelle, so daß unter der Aufschüttung eine Steile im anstehenden Fels entsteht. Für das verschiedene Verhalten von Bergsturzsteilen haben wir im systematischen Teil schon Beispiele gegeben.

\section{Optimale Bedingungen zur Ausbildung und Erhaltung von Steilen}

Wir haben mehrmals darauf aufmerksam gemacht, daß Steilen im Unterlauf seltener sind als im Oberlauf. Es soll hier an Hand von ganz schematischen Skizzen die Erscheinung nochmals im Zusammenhang behandelt werden.

Auch beim gestuften Längsprofil nimmt das Gefälle im Durchschnitt talaufwärts $z u$, so daß wir bei genügender Schematisierung eine parabolische Form erhalten. Wir können rein geometrisch drei Abschnitte unterscheiden, den verhältnismäßig flachen Unterlauf, ein Mittelstück von mittlerem Gefälle und einen obersten Abschnitt mit großem Gefälle.

In diesen drei Abschnitten sind offensichtlich die Bedingungen zur Ausbildung von Steilen verschieden groß. Es läßt sich das am besten an $\mathrm{Hand}$ von zwei schematischen Figuren zeigen. In Figur 34 sind 4 verschieden steile Gefällsstrecken gezeichnet, die wir mit Stufen gleicher Höhe so dicht als möglich besetzt haben. Offensichtlich ist die Stufungsmöglichkeit proportional dem Quotienten aus Höhe und Basislänge, also dem Tangens des Neigungswinkels. Von $0^{\circ}$ bis $20^{\circ}$ ist der Tangens mit genügender Genauigkeit proportional dem Neigungswinkel. Das heißt also, daß sich mit der Verdoppelung des Neigungswinkels die Möglichkeit zur Bildung von Stufen gleicher Höhe rein geometrisch ungefähr verdoppelt.

In Figur 35 haben wir eine schematische Zeichnung eines gestuften Längsprofils wiedergegeben, um die Stufungsmöglichkeiten in den 3 Talabschnitten im Zusammenhang zu zeigen. Vertiefen wir die rein geometrischen Überlegungen durch morphologische Einsichten.

Im Unterlauf ist die Wahrscheinlichkeit, daß Stufen vorhanden sind, aus zwei Gründen gering. In diesem Abschnitt ist einmal das Gefälle klein, zur Ausbildung von Steilen also einfach zu wenig Gefälle vorhanden. Hier wird zudem normalerweise akkumuliert, so daß vorhandene Steilen fortlaufend zugeschüttet werden. Aber auch 
für Akkumulationssteilen sind die Bedingungen nicht sehr günstig, da das Gewässer meist in einem breiten Talboden fließt. Nur ganz große Schwemmkegel oder Bergstürze vermögen den Haupttalfluß zu stauen.

Der Mittellauf bietet dagegen ideale Voraussetzungen für auffallende Steilen, die an Höhe nicht $\mathrm{zu}$ unbedeutend und doch auch wieder zwischen genügend großen Flachstrecken liegen. Im Mittellauf erodiert der Talfluß wenigstens noch stellenweise, so daß Resistenzsteilen herausgearbeitet werden und sich auch erhalten können. Im Mittellauf ist aber auch der Talfluß noch nicht so wasserreich, so da $\beta$ auch kleinere Seitentäler ihren Mündungseinfluß geltend machen können.

Im Oberlauf läßt das Gefälle rein geometrisch zwar noch mehr Steilen zu als im Mittellauf. Die einzelnen Steilen sind aber dann oft so eng benachbart, daß wir sie zu einer Steilenreihe, einer Großsteile zusammenfassen, und nicht mehr individualisieren. Im letzten Steilenanstieg werden die einzelnen Flachstrecken so schmal, daß wir besser von Absätzen oder sogar Gesimsen sprechen.

Diese kleine Übersicht soll uns auch zeigen, daß die Begriffe Steilen und Stufen, so klar sie scheinen, doch gewisse psychologische Unsicherheiten in sich tragen. Von den großen Steilen und Stufen im Mittellauf bis zu den kleinen Stufungen im bachartigen Oberlauf sind alle Übergänge vorhanden. Bei einer bestimmten Größenordnung machen wir aber instinktiv oder willkürlich halt und pflegen diese Kleinformen zu übersehen. Diese «Grenzgröße» ist aber individuell verschieden.

\section{TAFEL 1 GEW ÄSSER-LÄNGSPROFILE}

Die hier publizierten Profile wurden am Ende des 19. Jahrhunderts von der hydrometrischen Abt. des eidg. Oberbauinspektorates von $50 \mathrm{zu} 50 \mathrm{~m}$ auf den $\mathrm{cm}$ genau eingemessen. Die Kilometrierung des Rheines beginnt beim Vorder- und Hinterrhein bei deren Zusammenfluß bei Reichenau, beim Rhein von Reichenau bis Tamina bei der Mündung dieses Flusses, bei allen Zuflüssen an ihrer Mündung. Nicht genau vermessene Strecken in unzugänglichen Schluchten sind gestrichelt gezeichnet. Alle Längen sind im Maßstab 1:10000 dargestellt. Der Höhenmaßstab ist der Steilheit des betreffenden Profiles angepaßt.

1. Profil: Julia. Längen 1:10000, Höhen 1:2000. Linksseitiger Zufluß der Albula (Nr. 5) bei Tiefenkastel $(\mathrm{km} \mathrm{12,330)}$.

2. Profil Mönchalp-Bach, Längen 1:10000, Höhen 1:2500. Linksseitiger Zufluß der Landquart (Nr. 3) bei Klostersbrücke ( $\mathrm{km} \mathrm{31,889).}$

3. Profil : Landquart, Längen 1:10000, Höhen 1:1500. Rechtsseitiger Zufluß des Rheins bei Landquart ( $\mathrm{km} 5,570$ oberhalb der Taminamündung).

4. Profil : Err-Bach, Längen 1:10000, Höhen 1:5000. Rechtsseitiger Zufluß der Julia (Nr. 1) bei Tinzen ( $\mathrm{km} \mathrm{11,433).}$

5. Albula, Längen 1:10000, Höhen 1:2 500. Rechtsseitiger Zufluß des Hinterrheins bei Scharans

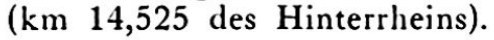

6. Profil: Valser-Glenner, Längen 1:10000, Höhen 1:1500. Rechtsseitiger Zufluß des Vorderrheins bei Ilanz $(\mathrm{km} 20,160)$.

7. Profil: Val Frisal, Längen 1:10000, Höhen 1:2000. Linksseitignr Zufluß des Vorderrheins bei Ruis (km 25,890).

8. Profil : Val Murtèr, Längen 1:10 000, Höhen 1:4000. Linksseitiger Zufluß des Val Frisal (Nr. 7) bei Andest (km 2,661).

9. Profil: Vorderrhein, Längen 1:10000, Höhen $1: 1500$.

10. Profil: Laaxer-Bach, Längen 1:10000, Höhen 1:4000. Linksseitiger Zufluß des Vorderrheins bei Sagens (km 14,280).

11. Profil: Flem, Längen 1:10000, Höhen 1:3000. Linksseitiger Zufluß des Vorderrheins bei $\mathrm{km} \mathrm{5,980.}$

12. Profil: Bach des Sether-Tobels, Längen 1:10000, Höhen 1:4000. Linksseitiger Zufluß des Vorderrheins bei $\mathrm{km} \mathrm{23,688.}$

13. Profil : Rabiusa, Längen 1:10000, Höhen 1:2 000. Rechtsseitiger Zufluß des Vorderrheins bei Versam ( $\mathrm{km} \mathrm{7,550).}$ 


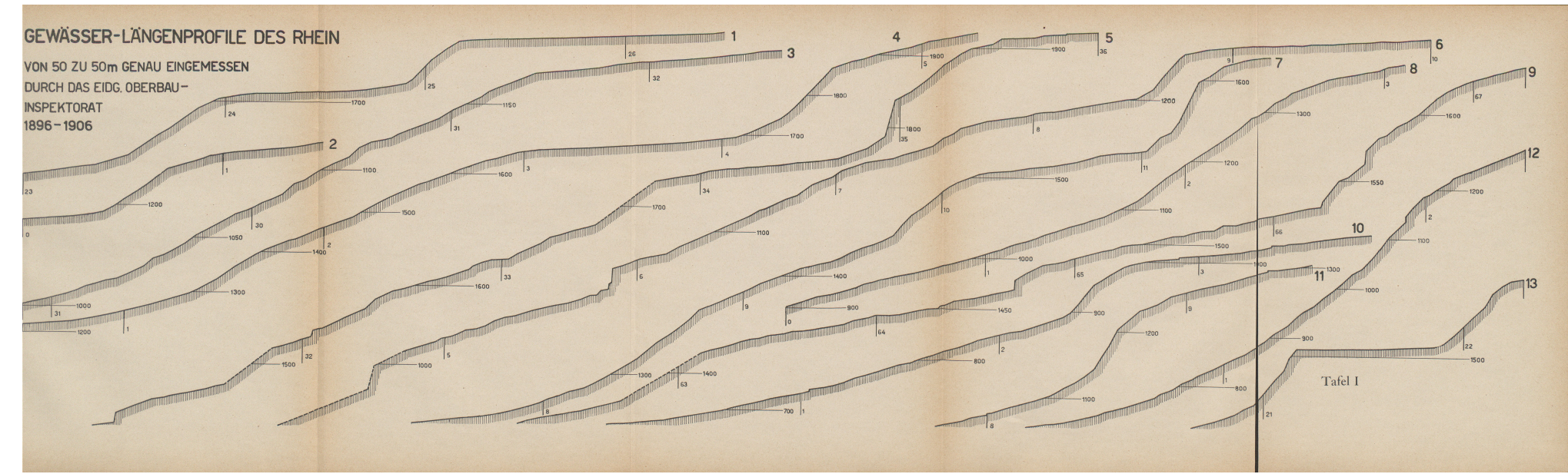


Wenn Annaheim ${ }^{4}$ mit seinem Rückschnittsquotienten bei 12 Tälern des Tessins auf Werte von 60-74\% kommt, wenn er die Kilometerzahl bis zur ersten großen Steile durch $1 \%$ der ganzen Tallänge teilt, so zeigt dies sehr schön, daß gut entwickelte Steilen im zweiten Drittel der Tallänge vorhanden sind, das heißt also im Mittellauf liegen. Ich glaube, dies sei die richtige Interpretation dieser auffallenden Übereinstimmung der Zahlenwerte.

\section{LÄNGSPROFILE}

Wir können das heutige Längsprofil alpiner Täler nur als Folgeform einer wechselvollen Entwicklung verstehen. Das heutige Längsprofil stammt aus einem fluviatil angelegten präglazialen Längsprofil, von dem zwar keine direkten Spuren mehr vorhanden sind. Die mächtigen Talgletscher der Glazialzeiten haben das fluviatile Längsprofil in mancher Beziehung stark verändert. Da die Glazialzeiten durch Interglazialzeiten mit fluviatilem Regime unterbrochen waren, wechselten mehrmals glaziale und fluviatile Umformungen. Vor uns haben wir heute ein ursprünglich fluviatiles, nachher aber in mehrfachem Wechsel stark umgeformtes Längsprofil, das immer noch glaziale Züge trägt, die weiterhin umgeformt werden.

Im Vordergrund stehen also klimabedingte Veränderungen des Längsprofiles. Diese beherrschen das Formbild. Denn auch, wenn wir die tektonische Priorität für alle Profiländerungen als selbstverständlich anerkennen, so ist deren Einfluß, so groß er auch einzuschätzen ist, durch fluviatile und glaziale Umänderungen und Ausgleichsvorgänge verwischt und verschleiert. Wir müssen uns also zum Verständnis der heutigen Formen mit den rein fluviatilen Längsprofilformen, dann mit den glazialen Profilumformungen und endlich mit dem fluviatilen Ausgleich glazialer Umformungen vertraut machen.

\section{Das rein fluviatile Längsprofil}

Das Talnetz der Alpen zeigt, trotzdem es sich durch Eintiefung sehr weit von seinen Uranlagen entfernt hat, auch heute noch mannigfache Zusammenhänge mit dem Bau und der Baugeschichte. Auf diese Zusammenhänge ist schon vielmals hingewiesen worden, vor allem auch von Geologen*. Einen großzügigen Überblick über den ganzen Fragenkomplex hat R. STAUB ${ }^{62}$ in seinem Buch: "Grundzüge und Probleme alpiner Morphologie» gegeben. Aber nicht nur die großen Anlagen des Talnetzes zeigen mannigfache Verkettungen, auch kleine Talbiegungen, die Anordnung von Seitentälern, Richtung und Ausbildung von Gehängerinnen, auffallende Geschiebequellen, sind an bestimmte Gesteine, an Verbiegungen, an Bruchsysteme und mylonitisierte Zonen gebunden ${ }^{32}$.

Eines der schönsten Beispiele einer an den Bau gebundenen Talanlage ist der Längstalzug Chamonix-Chur, der Massive trennt und Deckenstirnen folgt. Gerade dieses Beispiel zeigt aber auch, daß die Zusammenhänge zwischen Bau und Oberfläche sich nicht nur in der Grundrißanordnung der Täler äußern, sondern auch in deren Längsprofil. Der erste markante Anstieg von Brig hinauf ins Goms fällt mit dem Übergang vom Deckenrandfluß zum Fluß zwischen Aare- und Gotthardmassiv zusammen und der zweite Anstieg vom Goms hinauf in den Gletschboden ist zugleich eine rechtwinklige Richtungsänderung und ein Ausbiegen ins Aaremassiv.

* Hinweise auf geologisch bedingte Formeigentümlichkeiten sind im geologischen Schrifttum weitverbreitet. Dem Geologen muß ja die Morphologie oft genug zu Hilfe eilen, wenn Aufschlüsse fehlen. Selten stehen ihm aber die Zeit und Muße und die Mittel zur Verfügung, vielleicht auch das brennende Interesse, um die vielen Hinweise und Vermutungen als selbständiges Ganzes zur Darstellung zu bringen. Ihm ist der innere Bau und nicht die äußere Form das zentrale Anliegen. 
Die Steilen und Flachstrecken sind in einem Tal nicht beliebig verteilt, wie das beim freien Steilenwandern ja der Fall sein müßte, sie sind vielmehr meist an bezeichnende Stellen gebunden, an Talbiegungen, Talmündungen, Talvereinigungen. Wie weit die fluviatilen Längsprofile der Präglazialzeit ausgeglichen waren, soll hier nicht untersucht werden. Wir wollen hier nur festhalten, daß das Längsprofil, auch wenn es mehr oder weniger ausgeglichen war, offene und verdeckte, aktive und «latente» Steilen aufweisen mußte. Einmal mußten Steilen vorhanden sein in jeder Erosionsstrecke. Auch ein ausgeglichenes Tal besitzt, wenn es noch nicht bis zum Endprofil erniedrigt ist, wenigstens eine Erosionsstrecke, die des Oberlaufes und hier sind bei nicht ganz uniformem Gestein und bei nicht allzu geringem Gefälle reiche Möglichkeiten sowohl für Akkumulations- wie auch für Resistenzsteilen vorhanden. In Akkumulationsstrecken besteht hingegen der Ausgleichsvorgang nicht nur in einem Zerschneiden der Steile, sondern auch im Zuschütten, so daß sie im zugeschütteten Teil konserviert wird, latent vorhanden bleibt. Auf eine starke Zuschüttung durch Verwitterungsschutt in der Präglazialzeit hat schon 1905 Albert Heim ${ }^{24}$ hingewiesen, als er schrieb: «Die Hauptwirkung der Eiszeit im schweizerischen Alpengebiet besteht darin, daß sie den alt angehäuften Gebirgsschutt hinaustransportiert hat.» (Die Stelle wurde wegen der Erwähnung der Schuttanhäufung zitiert, denn ob die Hauptwirkung der Glazialerosion in deren Entfernung bestanden hat, darf füglich bezweifelt werden, wie noch auszuführen sein wird.) Aber auch wo eine Steile durch einen fluviatilen Ausgleichsvorgang bis zum Verschwinden in die Länge gezogen wurde, blieb in standfestem Gestein eine Talverengung, eine Schluchtstrecke vorhanden.

\section{Das glazial umgewandelte fluviatile Längsprofil}

Als die Eismassen in der Glazialzeit vordrangen, flossen sie nicht in fluviatile Normalprofiltäler, sondern in Täler mit gegliedertem Längsprofil, auch dort, wo diese Gliederung oberflächlich ausgeglichen war. Allein schon nur durch das Ausräumen des Schuttes mußte ein vielfach gestuftes Längsprofil zum Vorschein kommen. Bei der Glazialerosion spielen seitliche Einschüttungen eine ganz andere Rolle, als bei fluviatiler Erosion. Felssturz- und Bergsturzmaterial sperren den Gletscher nicht. sondern wird mitgetragen, Akkumulationsstufen im fluviatilen Sinn fallen weg. Der wesentliche Unterschied zwischen der fluviatilen und glazialen Erosion ist der ganz andere Bettanspruch. So spielen im Längsprofil des Glazialbettes die in der Steilensystematik aufgeführten Konfluenzsteilen eine ganz bedeutende Rolle. Jeder Zusammenfluß führt zu einer unsteten Eiszunahme und kann Anlaß zu einer Bettstufe sein.

Eine Möglichkeit, diese unstete Volumzunahme graphisch $\mathrm{zu}$ erfassen, ist die Arealsummenlinie. LEHMANN ${ }^{34}$ hat auf diese Linie, die ich für meine Arbeit über das Rhonetal ausgearbeitet hatte, in seiner Arbeit über Gefällsentwicklung hingewiesen. Sie sei hier als Beispiel wiedergegeben. Die Eismassen, die in den Glazialzeiten dem Rhonetal aus den Seitentälern zuflossen, kennen wir natürlich nicht. In grober Annäherung können aber die Flächen der Einzugsgebiete ein Vergleichsmaß für die relative Größe der Eismassen der verschiedenen Täler liefern. Für das Rhonegebiet wurden die Flächen der Einzugsgebiete sowohl der Rhone als auch sämtlicher Seitentäler von der Abteilung für Wasserwirtschaft ${ }^{66}$ planimetriert. Schon 1926 hat P. $\mathrm{BECK}^{8}$ auf Grund dieses wertvollen Zahlenmaterials seine Karte der letzten Vergletscherung der Schweizeralpen gezeichnet. Diese Flächenzahlen können nun auch für die Arealsummenlinie verwendet werden (Fig. $36 \mathrm{~B}$ ). Wir tragen in einem Koordinatensystem im gleichen Maßstab wie beim zu vergleichenden Längenprofil auf der $\mathrm{x}$-Achse die Länge des Haupttales ab und markieren darauf alle Seitentalmündungen. Nun tragen wir in einem geeigneten Maßstab von der $x$-Achse aus senkrecht nach unten die Flächeninhaltswerte des Einzugsgebietes der Rhone vom Quellgebiet her so $a b$, daß wir bei jedem Seitental den Flächenzuwachs zur schon vorhandenen Flä- 


\section{SUMMENKURVEN UND LANGSPROFILE}

DES RHONETALES

ZWISCHEN MARTIGNY UND DEM RHONEGLETSCHER

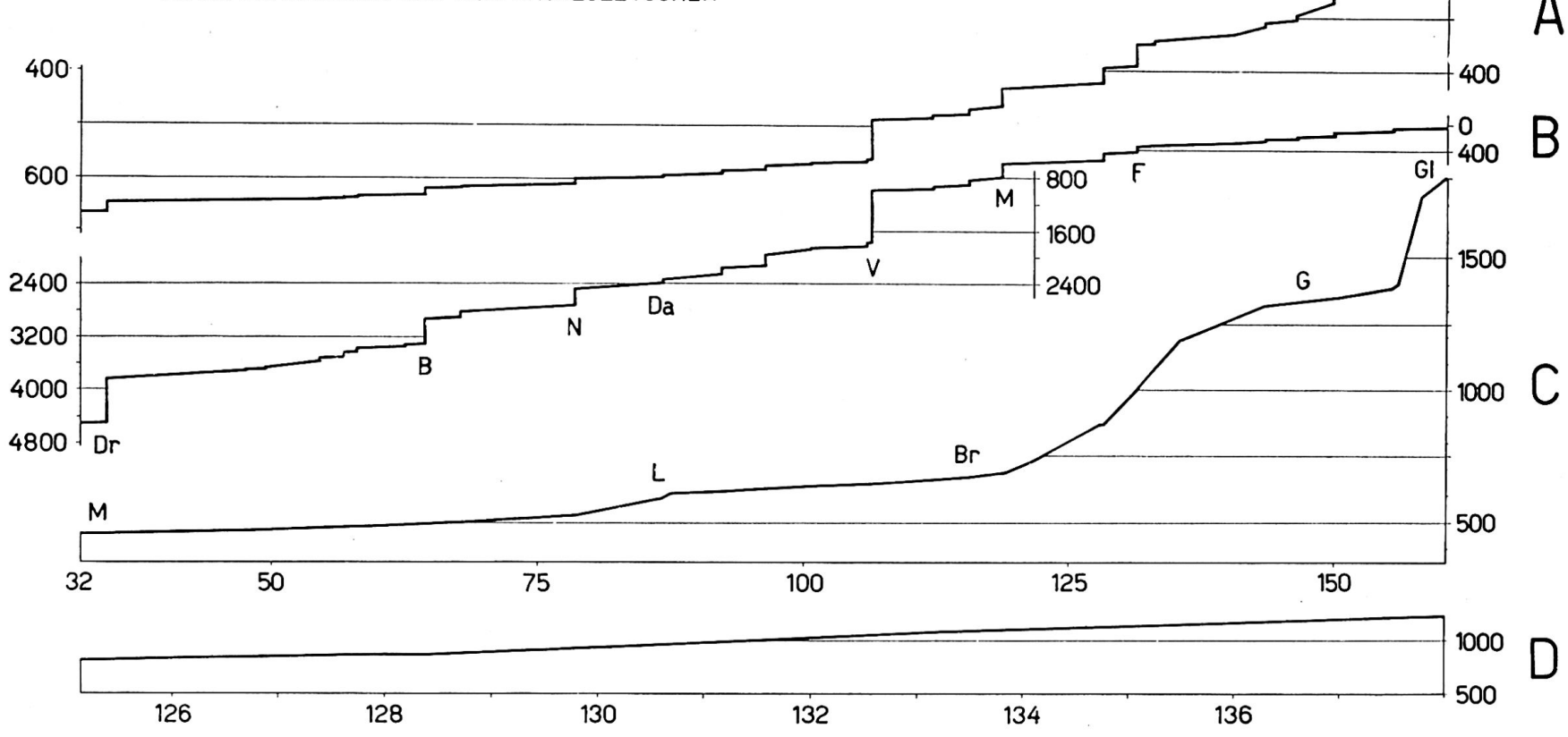

Fig. 36 Längenprofile und Summenkurven

A Prozcntsummenkurve. Längen wie bei $\mathrm{C}$. Höhen summierter prozentualer

C Lüngsprofil der Rhone von Martisny bis Gletsch. $25 \times$ überhöht. Längen

in $\mathrm{km}$ mit 0 -Punkt bei der Mündung in den Genfersee. M Martigny,

Zuwachs des Einzugsgebietes. G Gerenwasser.

in $\mathrm{km}$ mit 0 -Punkt bei der Mündung in den Genfersee. M Martigny,

Br Brig, G Goms, Gl Gletsch.

B Arcalsummcnkurve. Längen gleich wie bei C. Höhen summierte Quadrat-

D Nicht ïberliöhtes Längsprofilstïck aus Profil C (km 125-138).

$V$ Visp, $M$ Massa (Aletschgletscherabfluß), F Fiescherbach. 
chensumme addieren und auch den Zuwachs aus dem dazwischenliegenden Rhonetalgehänge und Talboden als stetigen Zuwachs einzeichnen. Der Streckenzug, der aus diesem Verfahren hervorgeht, ist stark getreppt.

An Stelle der absoluten Zuwachswerte können wir auch bei jeder Seitentalmündung das schon vorhandene Areal des Haupttales gleich 100 setzen und den prozentualen Zuwachs des Areals durch die Seitentalmündung errechnen (Fig. 36 A). Auch diese Werte können wir als Summenlinie graphisch darstellen. Wir gehen dabei von der Überlegung aus, daß nicht der absolute Zuwachs maßgebend sei, sondern das $\mathrm{Zu}$ wachsverhältnis zum schon Vorhandenen. Vergleichen wir die beiden Summenlinien mit dem Längsprofil der Rhone (Fig. 36C), so ist nicht zu verkennen, daß das gestufte Rhonetal seine Stufen dort aufweist, wo auch die beiden Summenlinien die größten Treppungen aufweisen, wobei die Arealsummenlinie im Oberlauf, die Prozentsummenlinie im Unterlauf besser übereinstimmt.

Es ist nicht zu übersehen, daß der Vergleich von Areal und Eismenge auf groben Vereinfachungen beruht. Der Zuwachs kann sich ja nicht nur in einer Bettvertiefung, sondern ebenso in einer Talverbreiterung, oder auch in einer Geschwindigkeitsveränderung der abfließenden Eismassen äußern. Zudem gibt das Längsprofil der Rhone sowohl im Goms als vor allem auch unterhalb Brig nicht das Felssohlenprofil, sondern das Profil hochaufgeschütteter Talstrecken wieder. Die auffallende Steile im heutigen Rhonetal bei Leuk ist eine Akkumulationssteile vom Bergsturz von Siders und dem Illschwemmkegel und verbirgt kaum eine glaziale Felssteile.

Nun ist aber das glaziale Längsprofil nicht nur gestuft, sondern auch mit Wannen und andersartigen Vertiefungen mit Gegengefälle sehr reich versehen. Gleich unter den Gratformen finden wir die Kare, zirkusförmige Wannen, von Felsabstürzen umgeben, talabwärts von einem Riegel abgeschlossen. In diesen Hohlformen liegen oft Karseen, allerdings nur dann, wenn die Zuschüttung langsam vor sich geht. Viele Kare sind durch Moränenmaterial, durch Gehängeschutt und Bergstürze, aber auch durch Schotter und Schlamm, wenn sie nicht zu hoch liegen, auch durch Verlandung, ausgefüllt worden. Diesen hochgelegenen Karen, die wir den Talschlußformen zuordnen, folgen talabwärts immer wieder Talbodenverbreiterungen, die von Talengen abgeschlossen sind. Oft sind diese Engen schluchtartig zerschnitten, es sind Talriegel.

Solche Riegel mit breiten Talböden dahinter sind an der Aare der Kirchet mit dem Becken von Innertkirchen, an der Rhone der Riegel von St-Maurice, an der Kander der Riegel am Ausgang des Gasterntales, an der Reuß das Urnerloch mit dem Becken von Andermatt, um nur einige wenige willkürlich herauszugreifen.

Die Böden hinter diesen Riegeln sind breit aufgeschüttet. Der Untergrund, die Form des Felsens ist uns verborgen. Es ist deshalb nicht verwunderlich, daß die Tunnelgeologen sowohl beim Gotthard- wie beim Lötschbergtunnel für diese Talsohlenschotterflächen ganz willkürliche Tiefen angaben. So schrieben die Experten des Lötschbergtunnels: «Die Auffüllung beträgt höchstens 60-70 m. Der Tunnel wird also sicher noch von mindestens $100 \mathrm{~m}$ Felsgestein überhöht sein » (HEIM ${ }^{25}$. Die weitern Angaben stammen alle aus dieser Schrift.)

Rollier, der auch noch um seine Meinung gefragt wurde, konnte sich allerdings dieser Expertise nicht vorbehaltlos anschließen: «Ich glaube, daß die Alluvialbildungen, Grundmoräne, Talausfüllungen und Aufschüttungen tiefer reichen, als das Expertenprofil es andeutet. Ob sie aber bis zur Tiefe von $200 \mathrm{~m}$ vorhanden sind, kann man nur dann annehmen, wenn man die Bildung des Gasternbodens der Gletschererosion zuschreibt. Darüber gehen bei den Fachleuten die Meinungen noch weit auseinander.»

Am 24. Juli 1908, morgens $2 \frac{1}{2}$ Uhr, fand dann nach einer Sprengung vor Ort der denkwürdige Einbruch vom Gasterntal in den Stollen statt und erfüllte diesen auf 
etwa $1800 \mathrm{~m}$ Länge mit Sand und Kies. Dieser unterirdische Murgang begrub 24 Arbeiter*.

Alb. Herm ließ sich von der wirklichen Übertiefung nicht überzeugen und glaubte im Riegel am Ausgang, der Klus, eine durch Bergsturz verschüttete Schlucht erkennen zu können. Mit beißendem Spott verteidigte er als überzeugter Antiglazialist seine Ansicht, der er bis an sein Lebensende treu blieb**.

«Der Gletscher soll die Talmulde bei Frutigen, bei Kandersteg, in Gastern ausgehobelt haben! Warum hat er nicht auch die Klus zum Becken erweitert, da er dort doch keine härteren Gesteine vorfand und noch länger und in größerer Mächtigkeit gearbeitet hat als am Thunersee und bei Frutigen und Kandersteg? Es ist dies eben eine jener unbegreiflichen Launen, wie sie die Vertreter der See- und Talaushoblung durch Gletscher auf Schritt und Tritt ihrem allmächtigen Liebling zumuten. Nicht einmal hat er den Gehängen der Klus Rundhöckertypus aufzuprägen vermocht, oder die viel schneller als der Gletscher arbeitende Talbildung durch Wassererosion und Abwitterung der Gehänge hat die Gletschererosionsformen längst wieder verwischt.»

Wenn nun auch das letzte Wort über die Gasterntalübertiefung noch nicht gesprochen ist und erst seismische Untersuchungen weitern Aufschluß zu geben haben werden, so muß die ganz gewaltige Übertiefung im Urserental, die sowohl seismisch wie durch Bohrung vom Gotthardtunnel aus eindeutig erwiesen ist, als Tatsache zur Kenntnis genommen werden, auch wenn wir über den Vorgang der Übertiefung noch nicht mehr wissen als Albert Heim. Beim Urserental beschränkt sich die Übertiefung aufs Andermatterbecken ${ }^{46}$ (Fig. 37), das an der Oberfläche ein ungefähr gleichschenkliges Dreieck ist mit $1 \frac{1}{2} \mathrm{~km}$ Schenkel- und $1 \mathrm{~km}$ Basislänge und $1430 \mathrm{~m}$ Meereshöhe. Da direkt nördlich vom Urnerloch auf Kote 1415 ein E-W-Stollen unter dem durchgehend anstehenden Fels der Reußschlucht durchführt, ist eindeutig eine Übertiefung des Andermatterbeckens von mindestens $250 \mathrm{~m}$ erwiesen. «An der tiefsten Stelle liegt demnach die Oberfläche des Felsuntergrundes nur $40 \mathrm{~m}$ über der Schwellenhöhe des Tunnels; die Erbauer des Gotthardtunnels haben demnach großes Glück gehabt» (E. NIGGLI). Endlich ist am Alpenausgang die Übertiefung der Alpenrandseen seit langem bekannt, wenn auch die Entstehung eine alte Streitfrage ist. So beträgt diese, als reine Wassertiefe gemessen, d. h. ohne Berücksichtigung der Auffüllung über der Felssohle für den Bodensee $241 \mathrm{~m}^{16}$, für den Genfersee $255 \mathrm{~m}$, für den Zürichsee $92 \mathrm{~m}$. Dabei hat eine Bohrung bei Tuggen ${ }^{43}$ oberhalb des Zürichsees den Fels erst in $236 \mathrm{~m}$ erreicht, wobei $15 \mathrm{~m}$ Alluvium und $221 \mathrm{~m}$ Diluvium durchbohrt wurden. Die Übertiefung der oberitalienischen Seen mit $-281 \mathrm{~m}$ beim Gardasee ist altbekannt.

In den Tälern, die für Stauseen vorgesehen sind, wird die Staumauer in Talengen, mit Vorliebe sogar auf zerschnittenen Riegeln angebracht, hinter denen sich das Tal wieder verbreitert. Zur Erforschung des Baugrundes wurden in verschiedenen Tälern ausgedehnte seismische Untersuchungen durchgeführt, die oft hinter den Talengen oder Riegeln unter Schottern rückläufiges Felsoberflächengefälle ergaben. Eine Veröffentlichung dieses dem Morphologen meist verborgenen Materials wäre äußerst wertvoll ****

* Im Exkursionsführer des 3. internationalen Kongresses für Erdbau 59 wird berichtet, daß 2 Bohrungen unmittelbar nach der Katastrophe in der Linie der Tunnelachse auch in $220 \mathrm{~m}$ noch keinen Fels trafen.

** Alb. Heim: Beim Blick von der Rigi auf die Seen 26. Es ist der Nachdruck einer Abhandlung aus dem Jahr 1922, die AlB. Heim dem Alpenklub zur Verfügung stellte. Er schrieb dazu von seinem Krankenlager wenige Tage vor seinem Tode: «Mich nimmt nur wunder, ob meine Glazialgegner stille bleiben ».

*** Auf die seismischen Untersuchungen und deren Ergebnisse hat mich Herr Aug. Süßtrunk aufmerksam gemacht, der in der Firma Dr. H. Knecht und A. Süßtrunk, geotechnische und geophysikalische Untersuchungen, als Physiker die seismischen Untersuchungen durchführt. Für viele wertvolle Hinweise sei ihm auch an dieser Stelle bestens gedankt. 


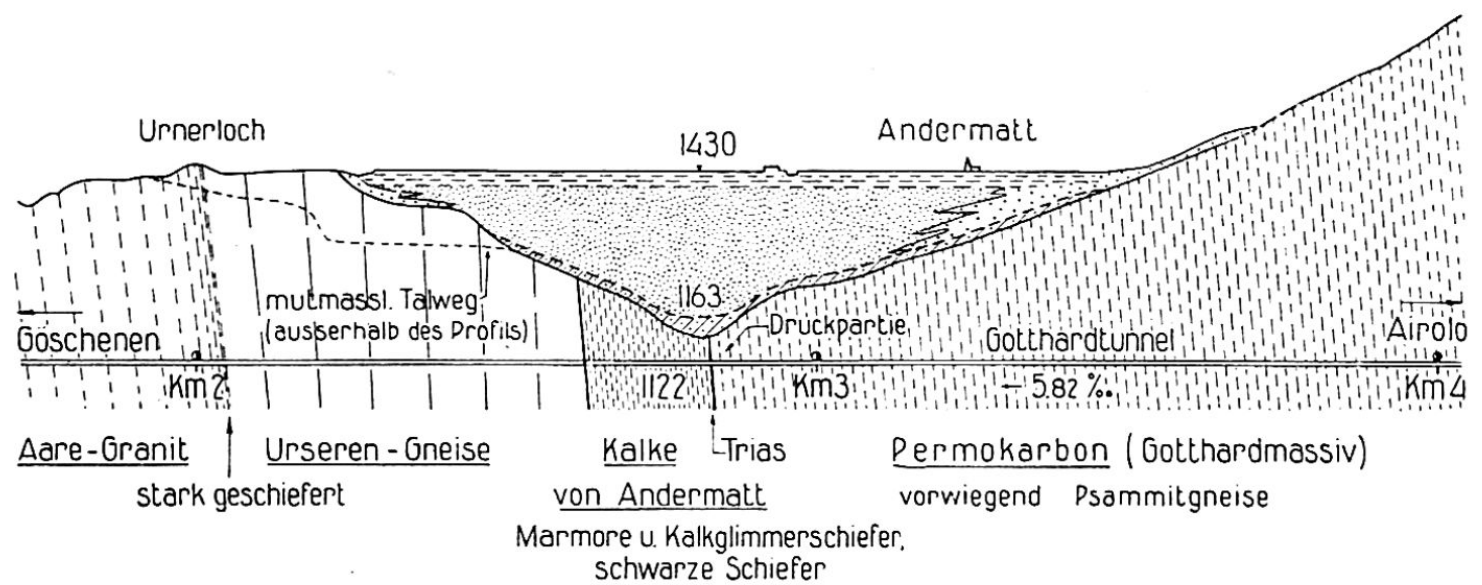

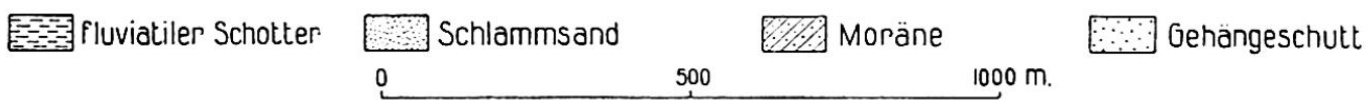

Fig. 37 Geologisches Profil 1:20000 durch das Andermatter Becken in der Achse des Gotthardtunnels (nach E. Meyer-Peter, Th. Frey, A. Kreis und R. U. Winterhalter, 1945).

Cliché aus E. NigGLI ${ }^{46}$, mit freundlicher Bewilligung der Red. der Eclogae Geol. Helv.

Kare, mehrfach stufenförmig übereinander angeordnete Erweiterungen hinter Talengen und Riegeln, die zweifellos oftmals hochaufgeschüttete Wannen darstellen, wenn auch bis heute nur wenige wirklich untersucht wurden, und übertiefte Zungenbecken beweisen zur Genüge, daß vom Talursprung bis zum Gletscherende ein außerordentlich unregelmäßiges glaziales Längsprofil geschaffen wurde.

Es wäre eine sehr aufschlußreiche Aufgabe einer wissenschaftlichen Untersuchung durch Seismik an ausgewählten Stellen den Felsuntergrund unserer großen Alpentäler zu ermitteln, einmal mitten im breitaufgeschütteten Tal, dann hinter Riegeln, wie denjenigen von St-Maurice und dem Kirchet. Die Erfüllung dieser Aufgabe, die einige Mittel beanspruchen würde, würde sich würdig an die Seite der Aufgabe der Gletscherkommission stellen.

Wie weit nun allerdings dieses von Wannen durchsetzte Längsprofil dem in der Systematik schon erwähnten glazialen Normalprofil entspricht, einem profil d'équilibre glaciaire, wie DE MARTONNE ${ }^{39}$ behauptet (Fig. 38), wie weit glazial herausgearbeitete Resistenzstellen, Konfluenzwannen usw. vorliegen, kann vorderhand nur spekulativ entschieden werden.

STREIFF-BECKER stellt sich den Vorgang der Wannenbildung so vor 63: «Ein Gletscher hat schon von seiner Geburtsstätte an die Tendenz, den Untergrund wellenförmig zu gestalten. Auf seinem Weg talwärts fährt er fort, vorgefundene Mulden zu vertiefen, Riegel dagegen zu schonen. Wo ein Hindernis seinen Lauf hemmt oder ein plötzlicher Gefällsknick vorkommt, schürft er sich oberhalb dieser Stellen eine Mulde aus, wo er sich dagegen flach ausbreitet, zwingt er den Gletscherbach, die hauptsächliche Bearbeitung seines Bettes zu leisten. Die Gletschererosion hängt stark vom Härtegrad des Untergrundes und der schürfenden Gesteine ab, in erster Linie jedoch vom Volumen der Geschiebeführung. Übersteigt dieses ein gewisses Maß, kann jede Schürfung unterbleiben.» STREIFF will durch sein Schema zeigen, daß im Bereich der Talstufe (der Steile) die Druckkräfte (die erodierend wirken) in Zugkräfte übergehen, die das Eis zerreissen und zu Spaltenbildung führen. Wie bei DE MARTONNE wird oberhalb und am Fuß der Steile am meisten erodiert. Doch ist nicht zu übersehen, daß die schematische Darstellung STREIFFs auf dem Beobachtungsmaterial an kleinen Gletschern mit Karbildung beruht, und die Extrapolation auf Eiszeitgletscher immer noch sehr unsicher ist. Die von ihm und DE MARTONNE behauptete «Tendenz, den Untergrund wellenförmig zu gestalten》 ist nach wie vor hypothetisch. Dies soll den vorläufigen Wert dieser Ansicht nicht herabmindern. F. Aurada 5 spricht von Schwerkraftfließen dort, wo das Gefälle groß genug ist und von Eisdruckfließen, wo der Untergrund Beckenform hat oder horizontal verläuft und endlich von untergeordneten Gleitbewegungen entlang von Scherflächen. Das Eisdruckfließen kann auch Gegengefälle überwinden. 


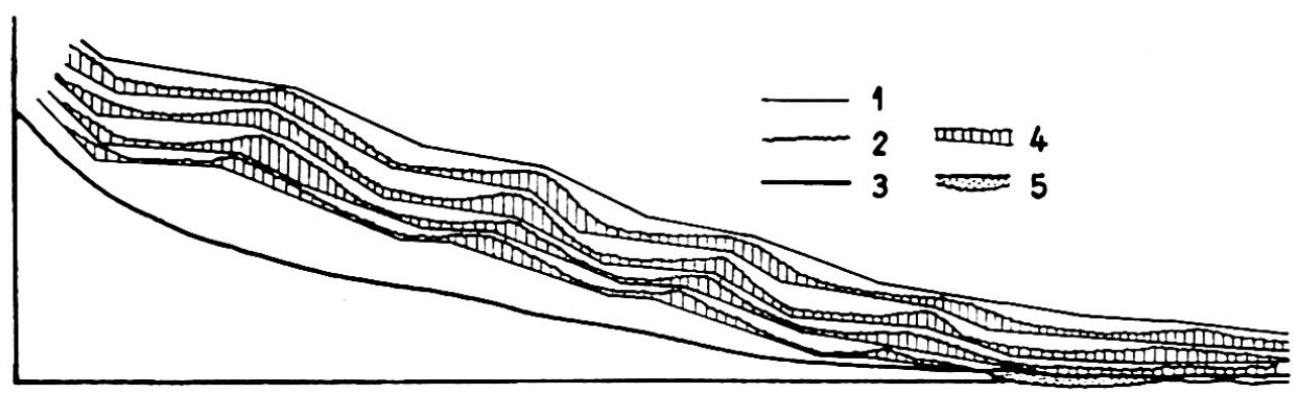

Fig. 38 Schema der Entwicklung des Längsprofiles eines großen Alpentales nach De MARTONNE ${ }^{39}$. 1. Fluviatile präglaziale und interglaziale Profile. 2. Glaziale Profile. 3. " Profil d'équilibre ». 4. Interglaziale Tiefenerosion. 5. Interglaziale Aufschüttung.

Wir wollen am Schluß noch einmal daran erinnern, daß der Gletscher das Tal ja nicht geschaffen hat, sondern ein fluviatiles Tal mit all seinen Unregelmäßigkeiten umgeformt hat, und daß der Wechsel von glazialer und fluviatiler Erosion mehrmals stattfand, endlich, daß auch tektonische Störungen in diesem langdauernden Ablauf anzunehmen sind. Aus dem jetzigen Längsprofil können wir so nur schlecht auf das Aussehen eines idealen glazialen Längsprofiles schließen.

\section{Das heutige Längsprofil, ein fluviatil umgestaltetes glaziales Längsprofil}

Das gegenwärtige Längsprofil ist die Folge eines ausgedehnten aber noch lange nicht abgeschlossenen Umwandlungs- und Ausgleichsprozesses, der das vorangegangene, sehr unregelmäßige und an vielen Stellen übertiefte glaziale Längsprofil wieder in ein fluviatiles zurückverwandelt.

Der eine Prozeß dieser Umgestaltung ist die Füllung der vielen Wannen, der andere die Durchschneidung der Riegel und aller nicht dem fluviatilen Längsprofil angepaßten Steilen und Stufen. Heute sind die meisten Wannen bis zur Schwellenhöhe gefüllt, nicht nur fluviatil, sondern in großem Maße auch durch seitliche Einschüttung, auch durch Material des sich zurückziehenden Gletschers.

Beim Andermatterbecken z. B. sind (Fig. 37) über einer Moränenschicht vor allem Schlammsand (als Seefüllung), dann beidseitig Gehängeschutt und nur $25 \mathrm{~m}$ fluviatiler Schotter bei einer Gesamttiefe von $270 \mathrm{~m}$ beteiligt (im Profil über dem Gotthardtunnel).

Seen finden wir nur noch in den höchsten Höhen, im Gebiet der Kare, ferner am Alpenrand. Bei den Karen ist die Geschiebeführung der meist noch kleinen Bäche gering, so daß die Zuschüttung langsam vor sich geht. Wo noch Karseen vorhanden sind, beteiligt sich an der Verschüttung in nicht unerheblichem Maß der Gehängeschutt der umgebenden Wände.

Am Alpenrand waren die Wannen zu groß, viel zu langgestreckt, wohl auch wurde zu viel Geschiebe zuerst zur Füllung höhergelegener Übertiefungen zurückgehalten, um ganz gefüllt zu werden. Immerhin sind unsere schönen Alpenrandseen doch nur noch Rudimente weit größerer Vorläufer. So reichte der Genfersee bis St-Maurice, der Vierwaldstättersee bis Amsteg usw. ${ }^{23}$. Gleichzeitig mit der Füllung der Wannen lief und läuft noch heute die Durchschneidung der Riegel. Einige sind bis zum Fuß zerschnitten, bilden wohl noch eine Engstelle, aber keine Steile mehr. Hierher gehören der Kirchet* des Aaretales und der Engpaß von St-Maurice an der Rhone.

* Die wechselvolle Geschichte des Kirchet mit verschiedenen moränenverstopften Rinnen, die eigenartige Übereinstimmung der Riegel vom Kirchet, St-Maurice, vom Gasterntal und der Sandalp, die alle aus Kalk bestehen, während die Wannen im Kontakt zum Kristallin liegen, wurde von M. Lugeon 36 eingehend erörtert. Ob es sich hinter dem Riegel um eine glaziale Übertiefung handelt oder eine fluviatile Ausräumung, wie LUGEON meint, kann kaum mit scharfsinnigen Überlegungen, wohl aber durch Untergrunderforschung klargestellt werden. 

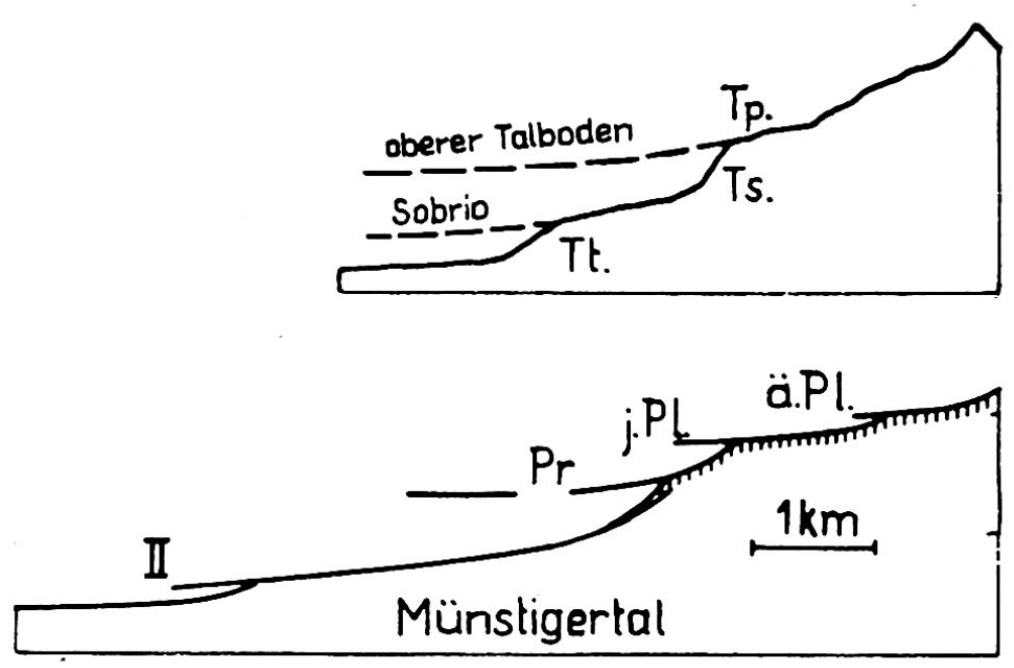

Fig. 39 Als Normalprofile ergänzte Talböden aus dem Valle Verzasca. (Aus GrGax ${ }^{20}$, S. 176.)

Fig. 40 Schematisierte Rekonstruktion aus dem Goms. (Aus BöGLI ${ }^{9}$, S. 24.)

Die Zerschneidung ist abgeschlossen, wenn die Aufschüttung am Ausgang des Riegels so hoch ist, daß im Riegel kein Erosionsgefälle mehr vorhanden ist.

Bei der Schöllenen, der Steile der Reuß unterhalb des Andermatterbeckens, ist dieser Zustand noch lange nicht erreicht. Beim Anschneiden des Andermatterbeckens, das sehr langsam erfolgt, wird das darüber hinaufwandernde Gefälle erst oberhalb der Aufschüttungen des Beckens sich ansammeln, und nicht als Steile durch das Becken wandern. Überall, wo oberhalb einer Steile eine durch Auffüllung ausgeglichene Flachstrecke folgt, wird das Gefälle in diesem sehr rasch in die Länge gezogen und sich erst wieder an der nächsten Resistenzsteile aufsammeln. Alle diese Steilen mit hinterfüllten Becken verhalten sich also wie Resistenzsteilen bei senkrechtem Einfallen des Gesteins. Kurz gesagt, es sind Resistenzsteilen, die nicht wandern können.

Ein weiterer Ausgleichsvorgang ist die Zerschneidung der vielen glazialen Konfluenzsteilen, sowohl der Bettsteilen im Haupttal beim Zufluß großer Seitentäler als auch der vielen glazialen Steilen an Seitentalmündungen. Diese Vorgänge sind ganz ungleich fortgeschritten, je nach der Erosionskraft des Gewässers, die durch die Wasserführung, das Geschiebe (Menge und Härte) und das Gefälle wesentlich bestimmt ist, aber auch je nach Resistenz der Steile selbst. Immerhin sind an Talmündungen viele Schluchten entstanden, die auf eine fortgeschrittene Zerschneidung hindeuten.

Um den Zustand der heutigen Längsprofile der Alpentäler zu erkennen, zeichnen wir aus Karten Profile heraus. $\mathrm{Zu}$ diesem Profilzeichnen haben wir uns noch zu äußern. Wenn wir vom heutigen Längsprofil unserer Alpentäler sprechen, so ist zu unterscheiden zwischen dem Längsprofil des Gewässers und dem Längsprofil der Talsohle, die wir mit mehr oder weniger Wahrscheinlichkeit zur Rekonstruktion früherer Zustände - z. B. des glazialen Talprofils - brauchen können. Das erste ist verhältnismäßig leicht zu definieren. Es ist die Gefällskurve des Wassers bei Nieder-, Mitteloder Hochwasser oder das Gefälle des Bettes im Stromstrich. Wenn wir von Ausgleichsvorgang sprechen - auch vom Rückwärtswandern von Steilen - dürfen wir nur dieses Gewässerlängsprofil zeichnen. Wird eine Steile in standfestem Gestein in enger Schlucht zerschnitten, fluviatil vielleicht sogar ganz ausgeglichen, so bleibt im Talbodenlängsprofil die ursprüngliche Steile erhalten, sie wandert nicht mit, auch dort, wo beim fluviatilen Ausgleich eine Stufe aufwärts wandert.

Neben diesen aus der Karte zu erschließenden Längsprofilen können natürlich auch noch theoretische (oder spekulative) Längsprofile gezeichnet werden. Von diesen sei zunächst die Rede und erst nachher von den eingemessenen. Wir entnehmen die Beispiele für theoretische Längsprofile der Wandersteilenliteratur 9, 20, 27,64. Aus diesen sollen die einzelnen Eintiefungsphasen erschlossen werden. Wie die beigegebenen Figuren zeigen (Fig. 39 bis 42), werden diese Profile so gezeichnet, daß jeweils eine Flachstrecke mit der nächst höhern Steile ungefähr ein Normalprofil bildet und mit 


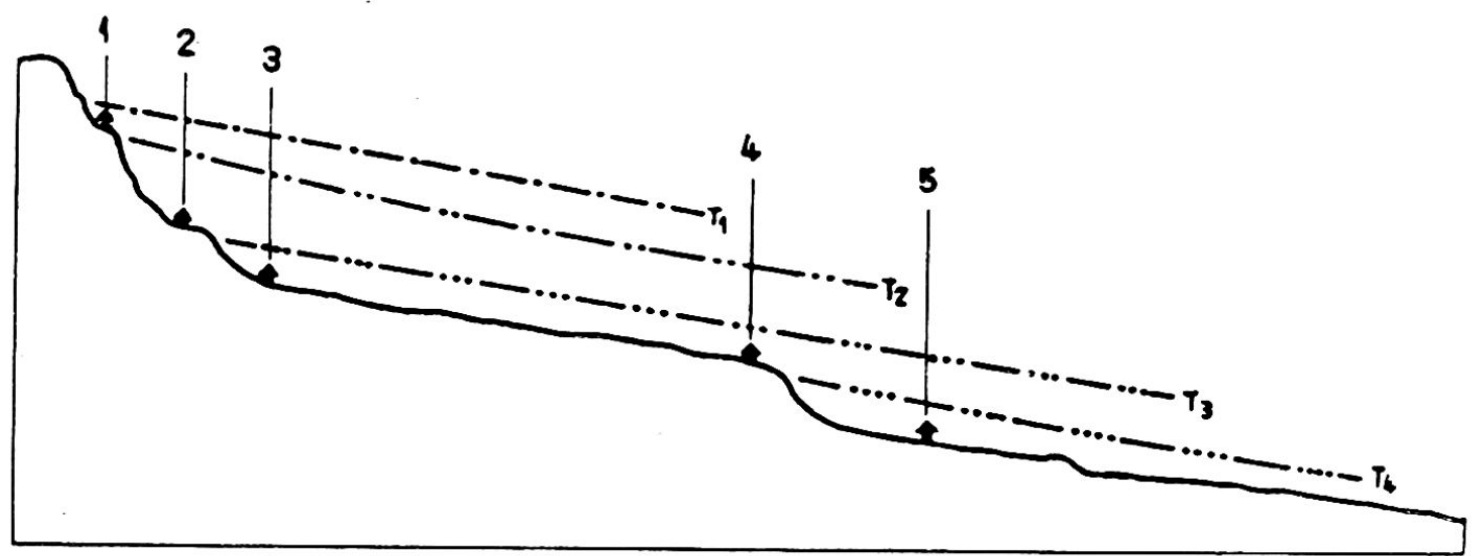

Fig. 41 Geradlinige Talbodenrekonstruktion aus dem Stillachtal. (Aus Uhuig ${ }^{64}$.)

einem scharfen Knick an die nächst höhere Flachstrecke anschließt. Jede Steile erhält dadurch eine gut bestimmbare Oberkante. Die obere Flachstrecke wird als noch nicht angegriffener Talboden einer ältern Einebnung aufgefaßt. In der Zeichnung des Profiles wird er über die Kante hinaus verlängert und mit Terrassenresten verbunden, die angeblich gleichen Alters sein sollen. Über die Fragwürdigkeit solcher Verknüpfungen soll hier nicht weiter diskutiert werden. Es ist auch durchaus nichts dagegen einzuwenden, wenn in rein theoretischen Profilen dieser Schematismus der scharfen Knicke angewendet wird. Dieser Schematismus sollte aber nicht in «wirkliche», mit Geländenamen versehene Profile übernommen werden, nur um die einzelnen Eintiefungsphasen deutlicher zu machen, da dies für jeden, der die Gegend nicht kennt, eine Irreführung über die tatsächlichen Formverhältnisse ist und zu ganz falschen Vorstellungen führt.

Nun ist es ja allerdings so, daß die meisten Profile morphologischer Arbeiten nicht direkt gemessen wurden, sondern aus Isohypsenkarten herauskonstruiert wurden. Solche Konstruktionen lassen gewisse Interpretationsfreiheiten $\mathrm{zu}$, da Isohypsenkarten nur zufällig auf die Äquidistanz abgestimmte Polygonzüge ergeben, die tatsächliche Lage von Knickpunkten, wenn solche überhaupt auftreten, nicht erkennen lassen. Subjektive, oder einer Theorie konforme Knicke lassen sich dann im Isohypsenpolygonzug an geeigneter Stelle eintragen. Dazu kommt noch die Schwierigkeit, daß in engen Talstrecken, ganz besonders aber in unzugänglichen Schluchten auch die sonst vorzüglichen, photogrammetrisch erstellten neuesten Karten versagen, weil die Wasserspiegelhöhe an diesen Stellen nur schlecht oder gar nicht eingesehen werden kann.

Die aus der Karte erstellten Profile sind dann ein Mittelding zwischen irgend einem Talbodenlängsprofil und einem reinen fluviatilen Längsprofil. Wir sollten aber zum Verständnis des fluviatilen Ausgleichsvorgangs ein wirklich rein fluviatiles Längsprofil betrachten können.

Eine weitere Schwierigkeit dieser Betrachtung gezeichneter Profile besteht in der Maßstabwahl und im Zwang zur Überhöhung. Viele Gefällsbrüche, die in der Natur am bewegten Lauf des Wassers sich ohne weiteres erkennen lassen, sind in einer Zeichnung so wenig markant, daß wir zum Kunstgriff der Überhöhung greifen müssen. Die Überhöhung ist nun wohl eine notwendige Darstellungsart, sie ist aber für unsere Vorstellung gefährlich, wenn wir uns der Überhöhung nicht immer bewußt bleiben und die überhöhten Profile uns als die wirklichen einprägen. Daß durch sehr starke Überhöhung auch Gefällsbrüche in einem Profil zum Verschwinden gebracht werden können, hat A. v. SPEYR 81 gezeigt.

Wie verhält es sich nun mit dem für die Steilenwanderungstheorie so wichtigen Knick im Längsprofil, mit der so scharf ausgeprägten Oberkante der Steile in Wirklichkeit? Darüber können aus den eben dargelegten Gründen die aus Isohypsenkarten herausgezeichneten Profile nur schlecht Auskunft erteilen. 


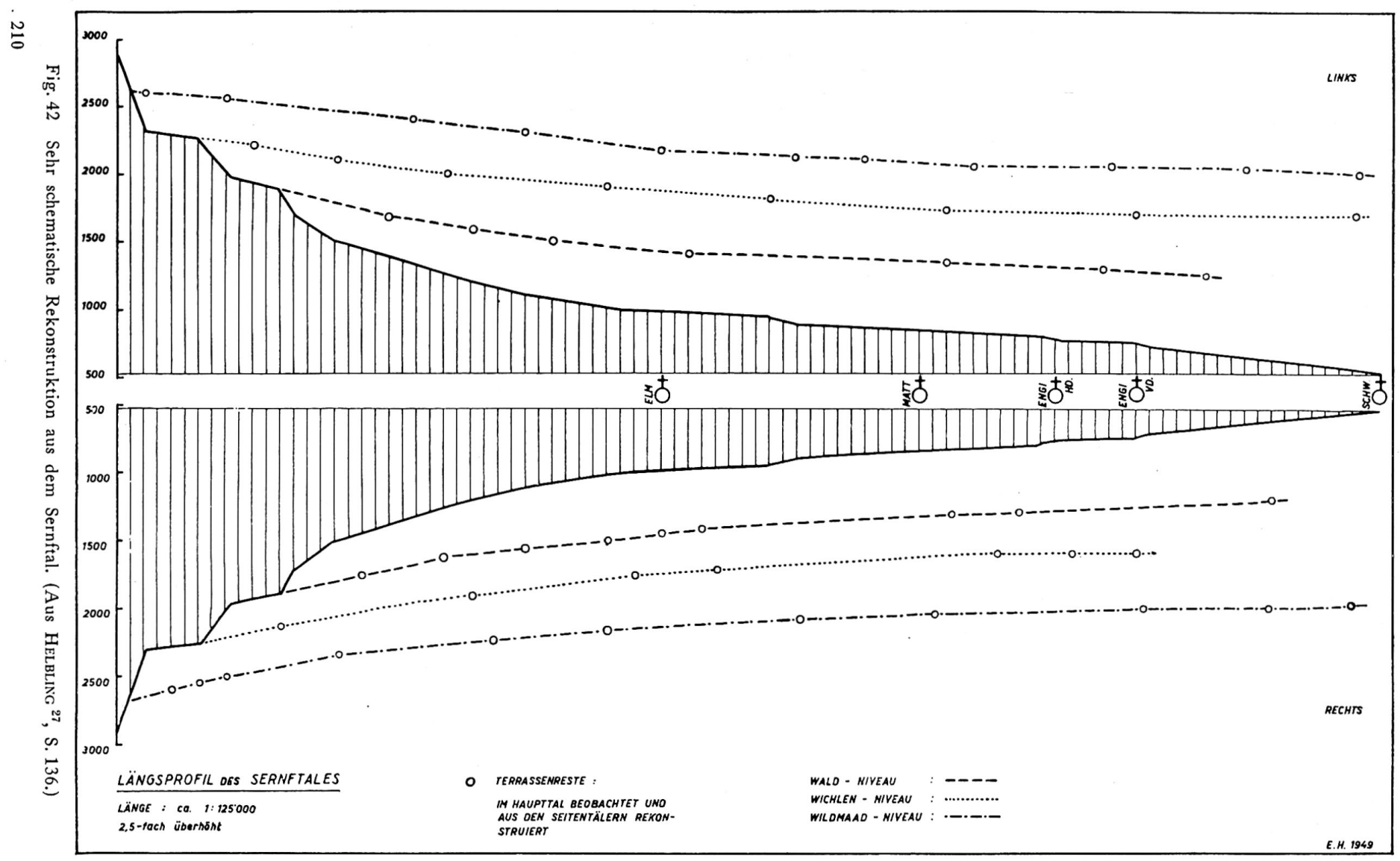


Nötig sind zur Beantwortung dieser Frage genaue und für die Längsprofilzeichnung besonders durchgeführte Vermessungen. Nun ist aber kaum ein Morphologe in der Lage, mit eigenen Mitteln solche Vermessungen durchzuführen. Es ist deshalb geradezu ein morphologischer Glücksfall, daß in den Neunzigerjahren des letzten Jahrhunderts von der hydrometrischen Abteilung des Eidgenössischen Oberbauinspektorates vom Rhein oberhalb der Tamina mit allen bedeutenden Zuflüssen (also fast ausschließlich vom Rhein im Kanton Graubünden) die Höhen des Wasserspiegels bei Niederwasser von $50 \mathrm{zu} 50 \mathrm{~m}$ auf den Zentimeter genau eingemessen wurden und daraus Längsprofile gezeichnet wurden. Einen Großteil dieser Vermessungen hat Ingenieur O. Lüтschg durchgeführt, der sich später durch seine Untersuchungen über Niederschlag und Abfluß im Hochgebirge einen Namen machte. Diese Profile sind in 4 Bänden ${ }^{65}$ im Maßstab 1:10000 für die Längen und 1:200 bis 1:5000 für die Höhen dargestellt worden, wobei jede vermessene Höhe noch in Zahlen beigefügt ist, so daß ein genaues Umzeichnen in einen andern Maßstab möglich ist. Dazu kommen noch viele typische Querprofile, die sich nicht nur auf das Flußbett beschränken, sondern in Felsschluchten ganze Schluchtprofile wiedergeben. Den Bedürfnissen der damaligen Zeit entsprechend reichen diese Längsprofile nur wenig über $2000 \mathrm{~m}$ hinauf, da an die heute noch höher gelegenen Speicherwerke damals noch nicht gedacht wurde. Im ganzen wurden $272 \mathrm{~km}$ mit einem Totalgefälle von $36953 \mathrm{~m}$ auf diese genaue Art vermessen und publiziert. Dazu kommen noch über 200 Querprofile, meist im Maßstab $1: 250$.

Dieses Material ist so groß, daß es uns einen Überblick über wirklich vermessene Längsprofile erlaubt, der weit über das rein Zufällige oder Einmalige hinausgeht und deshalb einen unschätzbaren Dokumentarwert besitzt, der leider bis heute nur viel zu wenig zu Rate gezogen wurde.

Ein erster Überblick zeigt, daß in all den vielen Tälern Wasserfälle als Träger einer ganzen Steile nicht vorkommen. Wasserfälle sind nur Teilstufungen innerhalb größerer Steilen, oft noch dazu in nur schwer zugänglichen Schluchten versteckt. Eine Statistik über 121 Steilen zeigt des fernern, daß das Durchschnittsgefälle von 55 Steilen oder $45 \%$ der Steilen, weniger als 100\%, von 97 Steilen oder $80 \%$ weniger als $150 \%$, und 109 Steilen oder $90 \%$ weniger als $200 \%$ Gefälle haben. Das größte Durchschnittsgefälle einer Steile, eine Stufenmündung (Tscharbach bei Tavanasa) beträgt $488 \%$. Keine einzige dieser Steilen erfüllt also als ganzes die Bedingung, die wir für ein Rückwandern des Fußes aufstellten, daß sie nämlich so steil sei, daß ein Kolk entstehen könne. Solche Durchschnittsgefällsberechnungen könnten nun wohl auch aus den normalerweise zur Verfügung stehenden Karten herausgelesen und berechnet werden, nicht aber die genaue Form, der wir uns nun zuwenden wollen. Wenn wir diese betrachten, so weichen die einzelnen Steilen wohl in Steilheit und Höhenausdehnung voneinander $a b$, nicht aber darin, daß sie fast ausnahmslos sowohl am $F u ß$ wie am Scheitel langhingezogene Übergänge und Abrundungen zeigen. Die von den theoretischen Profilen geforderten scharfen Knicke am Steilenscheitel sind nicht die Regel, sondern die Ausnahme. Wir betrachten die Publikation von so gut vermessenen Profilen als so wichtig, daß wir dieser Arbeit einige Ausschnitte in Originalgröße beigefügt haben (Tafel). Die eben geschilderte Form und die hier abgebildeten Profile sollen den Leser davon überzeugen, daß alle diese Steilen unserer Darstellung von Ausgleichsvorgängen entsprechen, die die Steilen nicht als ganzes wandern lassen, sondern sie mehr oder weniger an Ort in die Länge ziehen.

Was für das Rheingebiet gilt, das gilt sicher auch für jedes andere Flußgebiet der Alpen. Steilen und ihre obern Flachstrecken sind nicht unabhängige Formen, die einander nicht beeinflussen, sie gehen vielmehr fließend ineinander über, die Steile gleicht sich rückgreifend und sich verflachend in die darüberliegende Flachstrecke aus. Auch die vielen, selbst diesen gut ausgerüsteten Meßtrupp unzugänglichen Steilenstrecken in 
Schluchten sprechen eine beredte Sprache; diese Schluchtstrecken sind durch Ausgleichsvorgänge entstanden.

\section{ZUSAMMENFASSUNG}

Die Untersuchung geht aus:

1. Von der bekannten Erscheinung, daß die Alpentäler auch im Längsprofil gestuft sind.

Sie stellt fest,

2. daß die Stufung höchst differenziert ist, und zwar
a) statisch-morphologisch, was mit einer ausführlichen Steilensystematik belegt wird,
b) dynamisch-genetisch.

Um die Veränderungen des Längsprofiles beurteilen zu können, müssen gewisse Grundvorstellungen der Längsprofilbildung abgeklärt werden.

Es wird gezeigt, daß

3. das Normalprofil eine für die Beurteilung des rein fluviatilen Längsprofiles zwar sehr gute Grundvorstellung ist, daß sie aber auf folgenden idealen Voraussetzungen beruht:

a) homogenes Gestein,

b) gleichförmige seitliche Einschüttung auf der ganzen Profillänge,

c) konstantes Klima, ohne Vergletscherung an irgend einer Stelle,

d) tektonische Ruhe.

Daraus folgt:

4. daß ein Tal von alpinem Charakter immer Steilen aufweisen wird, denn

a) solange erodiert wird, werden aus dem inhomogenen Gestein immer wieder durch selektive Erosion neue Resistenzsteilen herauspräpariert,

b) aus dem Steilgehänge wird auch in Strecken mit homogenem Gestein zeitlich und örtlich ungleichförmig Material eingeschüttet, so daß immer wieder neue Akkumulationssteilen entstehen,

c) durch die mehrmaligen glazialen Erosionsperioden sind Bettunregelmäßigkeiten entstanden, die durch die jetzige fluviatile Erosion noch nicht ausgeglichen wurden. Besonders zu beachten sind glaziale Wannen im Längsprofil, die uns durch die fluviatile Zerschneidung verborgen sind und erst durch die modernen seismischen Erforschungen nach und nach erschlossen werden.

d) Tektonische Vorgänge auch kleinster Art, am Alpenrand und im Innern, verursachen neue Steilen und verändern die Erosions- und Akkumulationsbedingungen.

5. Der Ausgleich dieser sehr differenzierten und immer wieder neu entstehenden Steilen erfolgt nicht nach einem einzigen generell verwendbaren Ausgleichsgegesetz, sondern ist selbst wieder höchst differenziert. Vor allem ist die Steilenwanderungstheorie - das unveränderte Aufwärtswandern von Steilen durch ganze Täler - zu schematisch.

6. Es ergibt sich daraus die Forderung, das Interesse nicht einseitig den. «Wandersteilen» und der angeblich auf einfache Art damit verknüpften Hebungsphasen zuzuwenden, sondern in Zukunft wieder vermehrt den ganzen Reichtum an Formen und Vorgängen in seiner Gesamtheit zu studieren. 


\section{ZITIERTE ARBEITEN}

1 AhNert, F.: Zur Frage der rückschreitenden Denudation und des dynamischen Gleichgewichts bei morphologischen Vorgängen. Erdkunde, VIII 1954, 61-63.

1a Amprerer, O.: Über einige Beziehungen zwischen Tektonik und Morphologie. Z.f. Geomorphologie I, 1925/26, S. 83-104.

2 ÄNGEBY, O.: Evorsionen i recenta vattenfall. Lunds universitets ärsskrift. N. F. Avd 2 46, 1951, No 10 .

3 Annaheim, H.: Die Landschaftsformen des Luganerseegebietes. Pencks geogr. Abh. Stuttgart 1936.

4 Annaheim, H.: Studien zur Geomorphogenese der Südalpen zwischen St. Gotthard und Alpenrand. Geographica Helvetica I, 1946, S. 65-149.

5 Aurada, F.: Steinernes Wunderland. Die Formen der Alpen. Stuttgart 1951.

6 BALTZER, A.: Geologische Exkursion im Berner Oberland und Gotthardmassiv. Livret-guide géologique, Lausanne 1894, 159-170.

7 BECK, P.: Gletscherablagerungen der Kanderschlucht und des Gütschtales. Geol. Führer d. Schweiz Fasc. VIII, 1934, 578-583.

8 BECK, P.: Eine Karte der letzten Vergletscherung der Schweizeralpen. Mitt. Natf. Ges. Thun. Bern 1926.

9 BögLI, A.: Morphologische Untersuchungen im Goms. Diss. Freiburg i. Ü. 1941.

10 Brunhes, J.: Le travail des eaux courantes. La tactique des tourbillons. Mém. Soc. Fribourgeoise des Sc. Nat. II. Fasc. 4, Géologie et Géographie. Fribourg 1902.

11 Buxtorf, A., WiLhelm, O.: Über Sackungserscheinungen im Safiental (Graubünden). Ecl. Geol. Helv. XVI, $1920-22,520-527$.

12 Collet, L. W.: Le charriage des alluvions dans certains cours d'eau de la Suisse. Abt. für Wasserwirtschaft der Schweiz. Annalen Nr. 2, 1916.

13 Davis,W. M.: Die erklärende Beschreibung der Landformen. Deutsch bearb. v. A. RüHL. Berlin 1924.

14 Eggenberger, W.: Kolkbildung bei Überfall und Unterströmen. Mitt. a. d. Versuchsanstalt für Wasserbau an der Eidg. Techn. Hochschule 5, Zürich 1943.

15 Escher, B. G.: Über den Wert geologischer Experimente. Festgabe der GEP zur Hundertjahrfeier an der Eidg. Techn. Hochschule. Zürich 1955, S. 143-152.

16 FrÜH, J.: Geographie der Schweiz. St. Gallen 1930.

17 Gerber, E.: Morphologische Untersuchungen im Rhonetal zwischen Oberwald und Martigny. Arbeiten a. d. Geogr. Inst. d. Eidg. Techn. Hochschule Nr. 1, Zürich 1944.

18 Gerber, E.: Zum Problem der alpinen Talterrassen. Viertelj. Schr. Natf. Ges. Zürich, XCVI, I951, S. 131-135.

19 GILBERT, G. K.: Rate of recession of Niagara Falls. U. S. Geol. Survey, 1907.

20 Gygax, F.: Beitrag zur Morphologie des Verzascatales. Schweizer Geograph, 11, 1934, 116$142,168-187 ; 12,1935,11-45$.

21 HeGi, G.: Flora von Mitteleuropa. Bd. II. München 1939.

22 Helm, Alb.: Bergsturz und Menschenleben. Zürich 1932.

23 Heim, Alb.: Geologie der Schweiz. Leipzig, 1919, 1921, 1922.

24 Heim, Alb.: Das Säntisgebirge. I. Textbd. Beitr. z. Geol. Karte d. Schweiz. Bern 1905.

25 Heim, Alb.: Beweist der Einbruch im Lötschbergtunnel glaziale Übertiefung des Gasterntales? Geol. Nachlese Nr. 20. Viertelj. Schr. Natf. Ges. Zürich 1908, 471-480.

26 Heim, Alb.: Beim Blick von der Rigi auf die Seen. Die Alpen XIII, 1937, 361-369.

27 Helbling, E.: Morphologie des Sernftales. Geographica Helvetica VII. 1952, 89-141.

28 Hess, O.: Normalkurve und Erosionsterminante. Viertelj. Schr. Natf. Ges. Zürich LXXVI 1931, S. $420-434$.

29 Holmes, A.: Principles of physical geology. London 1945.

30 JäCKLI, H.: Die Bodenbewegungen im Hinterrheintal und ihre bautechnischen Auswirkungen. Schweiz. Bauzeitung 66, 1.948, 503-505.

31 JäCKLI, H.: Geologische Voraussetzungen für das Wandern von Gefällsstufen. Geographica Helvetica VII, 1952, 367-370.

32 Kündig, E.: Morphologie, Tektonik und Petrographie. Schweizer Geograph XIII, 1936, 92-99.

33 Lehmann, O.: Die Bodenformen der Adamellogruppe. Abh. Geogr. Ges. Wien, 1920, 1-87.

34 Lehmann, O.: Gefällsentwicklung und Talstufen im Hochgebirge. Z. f. Geomorphologie, X, 1937, 5-45.

35 LoBeCK, A. K.: Geomorphology. New York 1939.

36 Lugeon, M.: Sur la fréquence dans les Alpes de gorges épigénétiques et sur l'existence de barres calcaires de quelques vallées suisses. Bull. Labor. de géol., géograph., physiques etc. No 2, Lausanne 1901.

37 Machatschek, F. und Staub, W.: Morphologische Untersuchungen im Wallis. Ecl. Geol. Helv., XX, 1927, 335-379.

38 Machatschek, F.: Die Arbeit des fließenden Wassers. Supan, A.: Grundzüge der physischen Erdkunde. 7. Aufl. Bd. II Teil 1, Berlin und Leipzig 1930

39 Martonne, E. DE: Traité de géographie physique. Tomme second, Paris 1926.

40 Maull, O.: Geomorphologie. Enzyklopädie der Erdkunde. Leipzig und Wien 1938. 
41 Meyer-Peter, E., Favre, H., Mũller, R.: Beitrag zur Berechnung der Geschiebeführung. Schweiz. Bauzeitung, 105, 1935, 3-12.

42 Mortensen, H.: Sechzig Jahre moderne geographische Morphologie. Jahrb. d. Akad. d. Wissenschaften. Göttingen 1943/44, 33-77.

43 Mólberg, M.: Temperaturmessungen in der Bohrung Tuggen in der Linthebene und einige andere Befunde in der Schweiz. Ecl. Geol. Helv., 36, 1943, 17-34.

44 Müller, R.: Über einige Grundlagen der Fluß- und Wildbachverbauung. Schweiz. Zeitschr. f. Forstivesen, 1944, 1-15.

45 Múler, R.: Theoretische Grundlagen der Fluß- und Wildbachverbauungen. Mitt. Versuchsanstalt f. Wasserbau a. d. Eidg. Techn. Hochsch. Zürich, 4, 1943, 193 S.

46 Nigglı, E.: Bericht über die Exkursion .... in die Urserenmulde. Ecl. Geol. Helv., 47, 1954, $384-401$.

47 Nussbaum, F.: Die Täler der Schweizeralpen. Wissensch. Mitt. des Schweiz. Alpinen Museum, Bern 1910.

48 Nussbaum, F.: Zur Frage der präglazialen Talböden im Berner Oberland. Schweizer Geograph, 22, 1945, S. 24.

49 Oberholzer, J.: Geologie der Glarneralpen. Beitr. z. geol. Karte d. Schweiz. N. F. 28, Bern 1933, III. Teil : Quartärbildungen.

50 Ogilvie, A. G.: The earthsculpture laboratory. The geogr. Journal, LXXXVII, 1936, $145-149$.

51 Penck, A.: Morphologie der Erdoberfläche. Stuttgart 1894.

52 Penck, W.: Die morphologische Analyse. Stuttgart 1924.

53 Philippson, A.: Grundzüge der allgemeinen Geographie. II. Bd. 2. Halbbd., 2. Aufl. Leipzig 1931.

54 PIwowar, A.: Über Maximalböschungen trockener Schuttkegel und Schutthalden. Diss. Univ. Zürich 1903, $29 \mathrm{~S}$.

55 Richthofen, F. v.: Führer für Forschungsreisende. Berlin 1886.

56 Rütimeyer, L.: Über Thal- und See-Bildung. Basel 1869. Zweite Ausgabe 1874.

57 SAPPER, K.: Das Experiment in der physikalischen Geographie. Pet. Mitt., 59, 1913, II. Halbbd.1-2.

58 SchardT, H.: L’éboulement préhistorique de Chironico. Bull. soc. ticinese Sc. Nat., Lugano 1910.

59 Société internationale de mécanique des sols et des travaux de fondations. Troisième congrès. Bull.3, Suisse 1953.

60 Sölch, J.: Fluß- und Eiswerk in den Alpen zwischen Ötztal und St. Gotthard. Pet. Mitt., Ergänzungsheft $219 / 220,139 \mathrm{ff}$.

60a SöLch, J.: Landoberfläche in Kende. Handb. d. geogr. Wissenschaft, I, 1914, S. 174.

61 SPEYR, A. v.: Die morphologisch günstigsten Überhöhungen für die Längsprofile von Gewässern. Z. f. Geomorphologie, XI, 1940, 85-92.

62 Staub, R.: Grundzüge und Probleme alpiner Morphologie. Denkschr. Schweiz. Natf. Ges., LXIX, 1934.

63 Streiff-Becker, R.: Über die Entstehung glazialer Felsformen. Viertelj. Schr. Natf. Ges. Zürich, 1941.

64 Uhlig, H.: Die Altformen des Wettersteingebirges mit Vergleichen in den Allgäuer- und Lechtaler Alpen. Forsch. z. deutsch. Landeskunde, 79, Remagen 1954.

\section{Wasserverhältnisse der Schweiz:}

65 I. Rheingebiet von den Quellen bis zur Taminamïndung. Dritter Teil : Die Längsprofile : A. Vorderrhein (1901); B. Hinterrhein (1904) (2 Bde); C. Rhein (Reichenau-Ragaz) (1906).

66 V. Rhonegebiet von den Quellen bis zum Genfersee. Erster Teil : Die Flächeninhalte (1898). Hydrometrische Abteilung des eidg. Oberbauinspektorat.

67 Weber, J.: Geologische Wanderungen durch die Schweiz. Clubführer d. Schweiz. Alpen-Club, Bd. 1 o. J. (1911) S. 118.

68 Wilhelm, O.: Geologische Karte der Landschaft Schams.

69 Wissmann, H. v.: Über seitliche Erosion. Colloquium Geographicum, 1, Bonn 1951.

70 Wurm, A.: Morphologische Analysen und Experimente. Z. f. Geomorphologie, LX, 1935, $1-24$.

\section{LE PROFIL LONGITUDINAL DES VALLÉES DES ALPES}

Cette étude se base sur le fait que les vallées des Alpes comportent aussi des gradins dans le sens longitudinal. Elle détermine que cet étagement est très différencié morphologiquement d'une part, ce qui est consigné dans une systématique approfondie des gradins, et génétiquement d'autre part. Pour pouvoir juger des variations du profil longitudinal, il faut tout d'abord en connaitre les principes de base. Le profil normal est un très bon point de départ pour l'estimation du profil longitudinal purement fluviatil, mais il doit satisfaire aux conditions idéales suivantes : roche homogène, éboulis réguliers de chaque côté de la vallée, climat constant sans glaciation nulle part, période de calme tectonique.

Il s'ensuit qu'une vallée de caractère alpin présentera toujours des gradins car,

a) durant une période érosive, l’érosion sélective fera toujours ressortir dans la roche hétérogène de nouveaux gradins de résistance. 
b) sur la pente du gradin, il se dépose de temps en temps et çà et là des matériaux irréguliers, même dans les régions à roche homogène, de telle sorte qu'il se forme de nouveaux gradins d'accumulation.

c) les différentes périodes d'érosion glaciaire ont provoqué des irrégularités dans le lit des rivières, lesquelles n'ont pas encore été effacées par l'érosion fluviatile actuelle. Il faut tenir compte surtout dans le profil longitudinal des surcreusements glaciaires qui nous sont cachés par l'accumulation fluviatile et qui n'ont été découverts que récemment par les recherches sismiques modernes.

d) des phénomènes tectoniques, même de faible envergure, provoquent au bord et à l'intérieur des Alpes de nouveaux gradins et transforment les conditions d'érosion et d'accumulation.

La nivellation de ces gradins très différenciés et se reformant constamment ne se fait pas d’après une loi de nivellation générale, mais elle est elle-même très variée. Ainsi, la théorie de la migration des gradins - leur déplacement rétrograde sans changement de forme le long de vallées entières - est trop schématique.

Cette étude invite à ne pas s'intéresser uniquement aux migrations des gradins et aux phases de soulèvement qui leur sont tout simplement liées, mais aussi à se tourner vers la grande richesse de formes et de phénomènes en sa totalité qu’offrent les vallées des Alpes.

\section{EINE ALTE KARTE VON NEU ENGLAND}

\section{Hans BoEsch}

Dank dem Entgegenkommen der Firma Kümmerly \& Frey, Bern, konnte aus dem «Theatrum Orbis Terrarum sive Atlas Novus», in erster Auflage 1635 in den Offizinen des WILLEM Janszoon BlaEU in Amsterdam erschienen, ein Teil des Kartenblattes «Nova Belgica et Anglia Nova» hier reproduziert werden. Die Originalkarte stammt aus der Auflage 1660 und wurde von Dr. D. BrunnschweIler, Zürich, freundlicherweise zur Verfügung gestellt. Die Reproduktion konnte aus dem 1956 erschienen Werke des Verfassers «USA — Die Erschließung eines Kontinentes» (bei Kümmerly \& Frey, Bern) übernommen werden.

Um 1600 verschob sich das Zentrum der kartographischen Produktion von Antwerpen (Abraham Ortel oder Ortelius, Gerard Kraemer oder Mercator) nach Amsterdam. Die Holländische Ost- und Westindische Kompanie als Auftraggeber für genaue Seekarten und die im Kolonialhandel reich gewordenen Kaufleute als Käufer von kostbaren Atlanten und vollendet gestalteten Wandkarten waren hier die Voraussetzung für eine blühende Entwicklung einer vielseitig orientierten Kartographie und Kartendruckerei.

R. A. Skelton (in: Decorative Printed Maps of the 15th to 18th Centuries, London 1952, p. 58 ff.) berichtet uns über den Autor der vorliegenden Karte Folgendes: «Ungefähr 1596 begann Willem Janszoon BlaEU sich als Hersteller von Instrumenten und Globen, etwas später als Kupferstecher und Drucker zu betätigen.... Seine frühesten Publikationen waren Tabellen der Deklination, Plattkarten und Segelanweisungen für die Lotsen; seine Verdienste um die Seefahrt wurden durch finanzielle Unterstützung von Seiten der Generalstaaten und durch seine Ernennung (1633) zum Kartographen der Republik anerkannt. Nicht geringere technische Begabung zeigte BlaEU bei der Einrichtung seiner Druckerei. In den Annalen der Typographie ist BlaEU bekannt als der Erfinder einer Druckerpresse, welche die Produktion um einen Viertel zu vermehren gestattete. Eine bekannte Beschreibung seiner Druckerei, welche er in den Jahren 1616-1637 - ein Jahr vor seinem Tode - errichtet hatte, hebt die auf das höchste entwickelte Betriebsorganisation des Unternehmens von BLAEU und seinen Söhnen hervor. FILIP vON ZESEN, welcher Amsterdam anno 1663 besuchte, schrieb darüber: < An der Blumengracht . . . findet man die weitbekannte Druckerei von Johan Blaeu. Sie ist mit neun Typenpressen, welche nach den neun Musen benannt sind, sechs Pressen für Kupferplatten-Druck sowie einer Typengießerei ausgerüstet> , 》

Neben der Firma von BLAEU und seinen Söhnen war um diese Zeit in Amsterdam die Kartendruckerei des flämischen Kupferstechers Jodocus Hondius bekannt, welche später von seinem Schwiegersohn JAN JANSSON übernommen wurde. In beiden Fällen handelt es sich, wie aus der obigen Beschreibung hervorgeht, um bedeu- 